University of Tennessee Health Science Center UTHSC Digital Commons

\title{
Assessing the Role of Faith-Based Organizations in Health Promotion
}

Troylyn Braud Francis

University of Tennessee Health Science Center

Follow this and additional works at: https://dc.uthsc.edu/dissertations

Part of the Community Health and Preventive Medicine Commons, Health and Medical Administration Commons, Health Services Administration Commons, and the Public Health Education and Promotion Commons

\section{Recommended Citation}

Francis, Troylyn Braud (http://orcid.org/0000-0003-2829-6379), "Assessing the Role of Faith-Based Organizations in Health Promotion" (2016). Theses and Dissertations (ETD). Paper 374. http://dx.doi.org/ 10.21007/etd.cghs.2016.0395.

This Dissertation is brought to you for free and open access by the College of Graduate Health Sciences at UTHSC Digital Commons. It has been accepted for inclusion in Theses and Dissertations (ETD) by an authorized administrator of UTHSC Digital Commons. For more information, please contact jwelch30@uthsc.edu. 


\title{
Assessing the Role of Faith-Based Organizations in Health Promotion
}

\author{
Abstract \\ Objective: The objective of this analysis was to evaluate the relationship between organizational \\ readiness (OR) and weight loss and physical activity outcomes among faith-based organizations (FBOs).
}

Methods: Data for this study were collected in two phases. Phase I data were based on a feasibility study and targeted African-American individuals $(\mathrm{N}=55)$ who participated in an obesity prevention program. The intervention was accomplished in two stages, which included a 10-week core period followed by a 6-month maintenance period. Phase II data were based on key informant interviews that were conducted with community health leaders ( $\mathrm{CHLs})(\mathrm{N}=6)$ from participating FBOs. These interviews addressed six dimensions of readiness, with each dimension receiving an independent score that ranged from 1 to 9 (no awareness to a high level of community ownership). Dimension scores were averaged and each FBO was assigned a numerical OR score. OR scores were computed from the interview data, utilizing anchored rating scales outlined in the Community Readiness Model (CRM). These scores were subsequently combined with the Phase I data and used to statistically estimate the associations of OR. Linear mixed models, using SAS/STAT ${ }^{\circledR}$ software, were used to evaluate the relationship between OR scores and weight loss and physical activity while adjusting for covariates. A qualitative analysis of the Phase II data was also performed.

Results: Approximately $12.5 \%$ of the sample had an OR score of $4,69.6 \%$ had an OR score of 5 , while $17.9 \%$ were assigned an OR score of 7 . An OR score of four indicated a pre-planning stage of readiness. Those with an OR score of 5 were in the preparation stage of readiness, while those with a score of seven were in the stabilization stage.

An OR score of 5 was associated with a significant increase in weight $(2.532, p=0.048)$ when compared with an OR score of 7. Post hoc analysis revealed significant mean differences in weight when comparing congregation 1 with congregations 4 (difference $=3.452, p=0.016$ ) and $5($ difference $=4.646, p=0.0005$ ).

Congregation 2 had a significant mean difference in weight compared to both congregations 4 (difference $=5.264, p<0.0006)$ and 5 (difference $=6.457, p<0.0001)$.

During the maintenance period, Group(s) with an OR score of 5 gained weight compared to those with an OR score of 7 (6.093, $p=0.0018)$. Post hoc analyses revealed significant mean differences between congregation 1 and congregations 4 (difference $=7.896, p=0.001$ ) and 5 (difference $=10.708, p=0.003$ ).

The mean activity level of group(s) with an OR score of 4 and 5 were 166.02 minutes $(p<0.0001)$ and 177.33 minutes $(p<0.001)$ lower, respectively, than the group with an OR score of 7 . Post hoc analysis revealed significant mean differences in physical activity minutes for congregation 1 compared with congregations 2 (difference $=-91.698, p=0.011)$, and 4 (difference $=-203.90, p<0.0001)$. There were also significant mean differences between congregations 2 versus $4(-112.20, p=0.010)$ and 4 versus 5 $(155.18, p<.0006)$. There were also statistically significant differences in physical activity by OR category. Physical activity minutes among group(s) with an OR score of $4(-1284.21, p<0.0001)$ and $5(-933.21$, $p<0.0001)$ were lower than those with a score of 7 . The post hoc analysis revealed significant mean differences between congregations $2(-2191.82, p<0.0001)$, and $4(-1631.77, p<0.0001)$ when compared with congregation 1 . There were also significant mean differences in physical activity between congregations 2 versus 3 (difference $=2557.60, p=0.0009$ ) and 5 (difference $=1602.11, p<0.001$ ), 3 versus 4 (difference $=-1997.55, p=0.007$ ) and 4 versus 5 (difference $=1042.06, p<0.001$ ).

Despite the enthusiasm of participating FBO, the qualitative evaluation revealed that health behavior change can be difficult to adopt and maintain. Moving into an organization that is well structured is seemingly a great formula for success; however, the strength of the organization alone is not sufficient to 
promote and support health behavior change. Irrespective of an organization's position on the readiness continuum, several barriers may exist. Primary obstacles included: age of the congregation, competing activities, time frame of the initiative, recognizing the issue and appropriate problem solving, motivation and cost of healthy food options.

Conclusion: Although physical activity and weight outcomes were associated with OR scores, the posthoc analysis revealed variations in outcomes by congregation. Congregational differences may be attributable to intra-group distinctions rather than organizational readiness levels. Therefore, health promotion coordinators must work closely with FBO to pinpoint effective recruitment, implementation, and maintenance strategies that reach the community at various sectors.

\section{Document Type}

Dissertation

\section{Degree Name}

Doctor of Philosophy (PhD)

\section{Program}

Health Outcomes and Policy Research

\section{Research Advisor}

Shelley I. White-Means, Ph.D.

\section{Keywords}

Organizational readiness, Faith-based organization(s), Community health leader(s), Community readiness model

\section{Subject Categories}

Community Health and Preventive Medicine | Health and Medical Administration | Health Services Administration | Medicine and Health Sciences | Public Health | Public Health Education and Promotion 


\author{
A Dissertation \\ Presented for \\ The Graduate Studies Council \\ The University of Tennessee \\ Health Science Center \\ In Partial Fulfillment \\ Of the Requirements for the Degree \\ Doctor of Philosophy \\ From The University of Tennessee
}

By

Troylyn Braud Francis

May 2016 
Copyright (C) 2016 by Troylyn Braud Francis.

All rights reserved. 


\section{DEDICATION}

I would like to dedicate this dissertation to my best friend, my dear husband Adrian, who has been supportive in so many ways. Thank you for your unconditional love, patience, and encouragement throughout this process. Words cannot express my honor and appreciation for you. I love you now and always.

Additionally, I dedicate this dissertation to my much-loved Zachary and Betty. I thank you so much for everything. I am honored to say that God has truly blessed me with the best parents. Over the years you have given me unconditional love, unparalleled support, and encouragement in everything I attempted to do. Thank you for your guidance and constant prayers. I know that none of this would be possible without you! 


\section{ACKNOWLEDGEMENTS}

To my Lord and Savior, I thank you for your agape love. My faith rests in you alone. I am confident that I can do all things through Christ who strengthens me. You have been a consistent lamp unto my feet, lighting your chosen path for me. I give all honor and glory to you.

I acknowledge all of my family for their support and confidence in me. To all of my family in Louisiana, I cherish you and thank you for all of your prayers.

I would like to especially thank my only living grandparent, Natalie Braud. You are the sunshine on a gloomy day. Thanks for your unconditional love and compassion. To my sister (Tiona) and my babies (Laila and Liam), I love you with everything in me. Thanks for your genuine love. Your company provided joy and laughter in the midst of the storm. I thank my aunt Cora Ross for always treating me as a daughter. You have always been one of my biggest cheerleaders. To my aunt and uncle, Drs. Rosemary and Logan Miller, I thank you so much for facilitating the adjustment process as I transitioned from Louisiana. I will forever be grateful for your benevolence, prayers, and medical expertise provided throughout the years. To my sisters/cousins/friends (Jazmin Miller, Latesha Braud-Thomas, and Rashonda Ross), I love you dearly. Thanks for the: prayers, encouragement, advice, kindness, laughter, fun, and all of the countless moments we've shared. You are truly irreplaceable.

I would also like to thank my good friend Miki Rushton. You are one of the sweetest people that God has ever created. I truly admire your kind and meek spirit. Thanks for your unwavering support and assistance with the qualitative evaluation. To my friend Lawrence Brown, thanks for your advice and encouragement. You told me what I should expect prior to entering the program and encouraged me to pursue my goals.

To my academic committee members, Shelley White-Means, George Relyea, Nancy Mele, Latrice Pichon, and Wendy Likes, thank you for all of your time and dedication. I truly appreciate you for offering guidance and meaningful feedback, despite your numerous obligations. Also, I thank you for remaining pleasant and encouraging throughout this journey.

I would also like to acknowledge Elizabeth Webb for her contributions, even before this process began. You possess a wealth of knowledge. I will eternally be thankful for your counsel, reassurance, and kindheartedness. 


\begin{abstract}
Objective: The objective of this analysis was to evaluate the relationship between organizational readiness (OR) and weight loss and physical activity outcomes among faith-based organizations (FBOs).

Methods: Data for this study were collected in two phases. Phase I data were based on a feasibility study and targeted African-American individuals $(\mathrm{N}=55)$ who participated in an obesity prevention program. The intervention was accomplished in two stages, which included a 10-week core period followed by a 6-month maintenance period. Phase II data were based on key informant interviews that were conducted with community health leaders (CHLs) $(\mathrm{N}=6)$ from participating FBOs. These interviews addressed six dimensions of readiness, with each dimension receiving an independent score that ranged from 1 to 9 (no awareness to a high level of community ownership). Dimension scores were averaged and each FBO was assigned a numerical OR score. OR scores were computed from the interview data, utilizing anchored rating scales outlined in the Community Readiness Model (CRM). These scores were subsequently combined with the Phase I data and used to statistically estimate the associations of OR. Linear mixed models, using SAS/STAT ${ }^{\circledR}$ software, were used to evaluate the relationship between OR scores and weight loss and physical activity while adjusting for covariates. A qualitative analysis of the Phase II data was also performed.
\end{abstract}

Results: Approximately $12.5 \%$ of the sample had an OR score of 4, 69.6\% had an OR score of 5, while $17.9 \%$ were assigned an OR score of 7 . An OR score of four indicated a pre-planning stage of readiness. Those with an OR score of 5 were in the preparation stage of readiness, while those with a score of seven were in the stabilization stage.

An OR score of 5 was associated with a significant increase in weight $(2.532, p=0.048)$ when compared with an OR score of 7 . Post hoc analysis revealed significant mean differences in weight when comparing congregation 1 with congregations 4 (difference $=3.452, p=0.016)$ and $5($ difference $=4.646, p=0.0005)$. Congregation 2 had a significant mean difference in weight compared to both congregations 4 (difference $=$ $5.264, \mathrm{p}<0.0006)$ and $5($ difference $=6.457, \mathrm{p}<0.0001)$.

During the maintenance period, Group(s) with an OR score of 5 gained weight compared to those with an OR score of 7 (6.093, $\mathrm{p}=0.0018)$. Post hoc analyses revealed significant mean differences between congregation 1 and congregations 4 (difference $=7.896$, $\mathrm{p}=0.001)$ and $5($ difference $=10.708, \mathrm{p}=0.003)$.

The mean activity level of group(s) with an OR score of 4 and 5 were 166.02 minutes $(p<0.0001)$ and 177.33 minutes $(p<0.001)$ lower, respectively, than the group with an OR score of 7 . Post hoc analysis revealed significant mean differences in physical activity minutes for congregation 1 compared with congregations 2 (difference $=-91.698$, $\mathrm{p}=0.011)$, and $4($ difference $=-203.90, \mathrm{p}<0.0001)$. There were also significant mean differences between congregations 2 versus $4(-112.20, p=0.010)$ and 4 versus $5(155.18$, 
$\mathrm{p}<.0006)$. There were also statistically significant differences in physical activity by OR category. Physical activity minutes among group(s) with an OR score of 4 (-1284.21, $\mathrm{p}<0.0001)$ and $5(-933.21, \mathrm{p}<0.0001)$ were lower than those with a score of 7 . The post hoc analysis revealed significant mean differences between congregations $2(-2191.82$, $\mathrm{p}<0.0001)$, and $4(-1631.77, \mathrm{p}<0.0001)$ when compared with congregation 1 . There were also significant mean differences in physical activity between congregations 2 versus 3 (difference $=2557.60, p=0.0009)$ and $5($ difference $=1602.11, p<0.001), 3$ versus 4 (difference $=-1997.55, \mathrm{p}=0.007)$ and 4 versus $5($ difference $=1042.06, \mathrm{p}<0.001)$.

Despite the enthusiasm of participating FBO, the qualitative evaluation revealed that health behavior change can be difficult to adopt and maintain. Moving into an organization that is well structured is seemingly a great formula for success; however, the strength of the organization alone is not sufficient to promote and support health behavior change. Irrespective of an organization's position on the readiness continuum, several barriers may exist. Primary obstacles included: age of the congregation, competing activities, time frame of the initiative, recognizing the issue and appropriate problem solving, motivation and cost of healthy food options.

Conclusion: Although physical activity and weight outcomes were associated with OR scores, the post-hoc analysis revealed variations in outcomes by congregation.

Congregational differences may be attributable to intra-group distinctions rather than organizational readiness levels. Therefore, health promotion coordinators must work closely with FBO to pinpoint effective recruitment, implementation, and maintenance strategies that reach the community at various sectors. 


\section{TABLE OF CONTENTS}

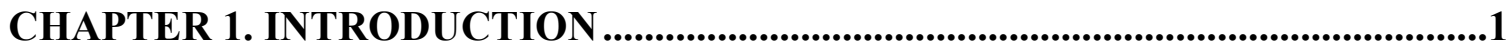

Statement of the Problem.................................................................................... 1

Purpose of the Study ............................................................................................ 1

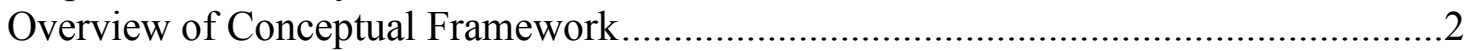

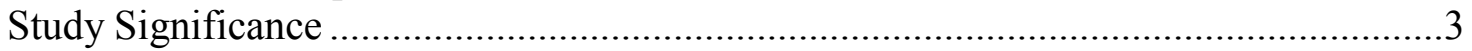

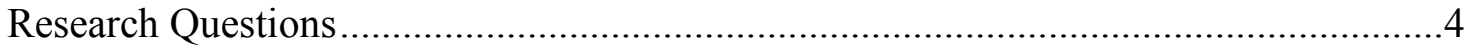

Specific Aims ................................................................................................. 4

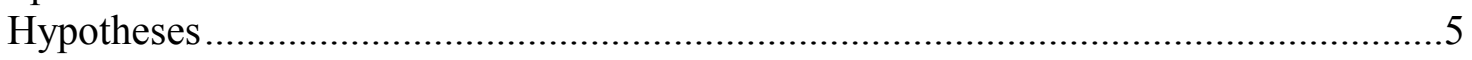

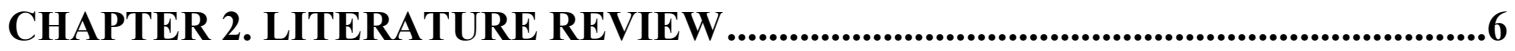

Type 2 Diabetes and Related Complications and Costs ..............................................6

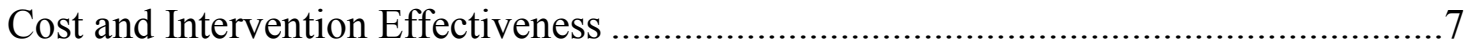

DPP: A Cost-Effective Prevention Technique......................................................... 7

Program Effectiveness in Faith-Based Settings ......................................................... 8

Health Promotion Strategies .................................................................................. 10

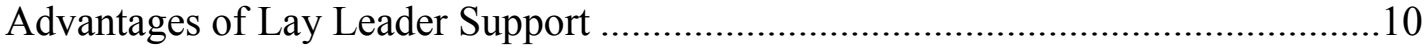

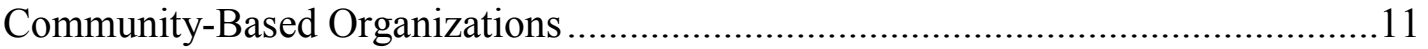

Faith-Based Interventions and the African-American Community ............................11

Readiness for Behavior Change....................................................................... 13

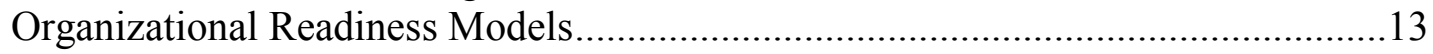

Qualitative Research Design .............................................................................. 16

CHAPTER 3. METHODOLOGY ......................................................................18

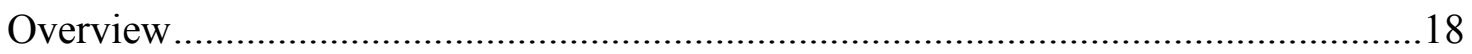

Phase I Data ........................................................................................................ 19

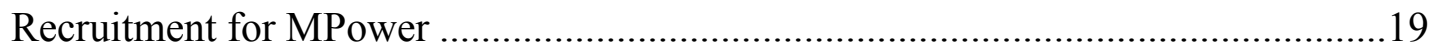

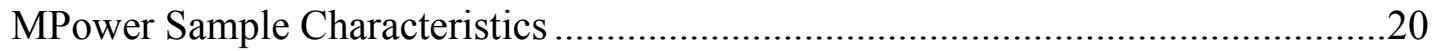

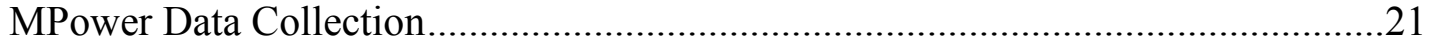

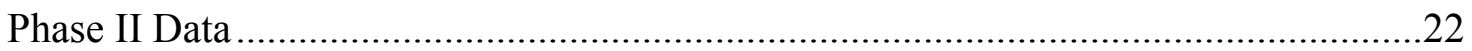

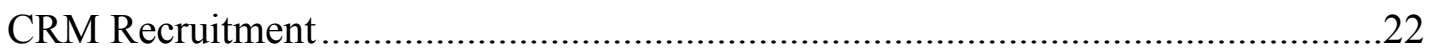

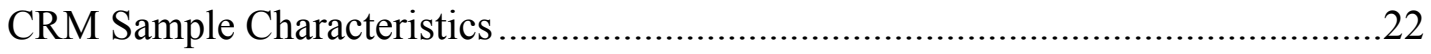

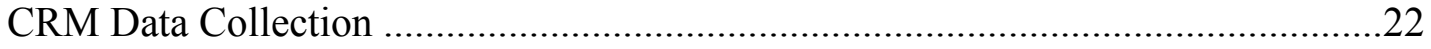

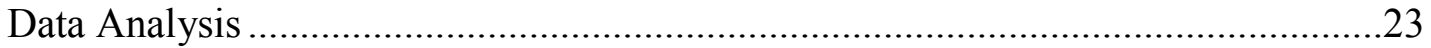

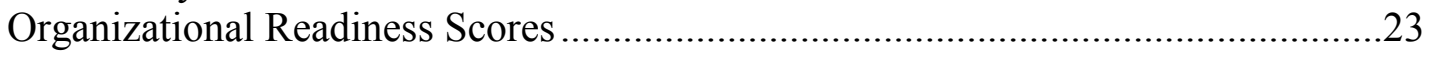

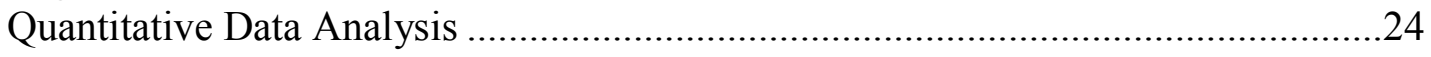

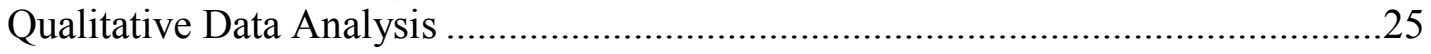

CHAPTER 4. RESULTS ...................................................................................................26

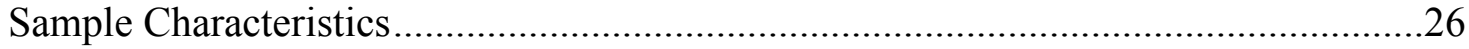

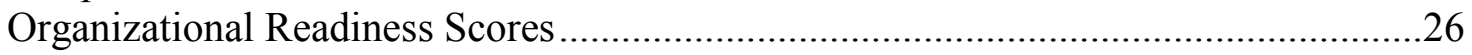

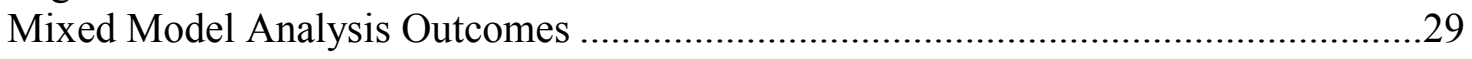

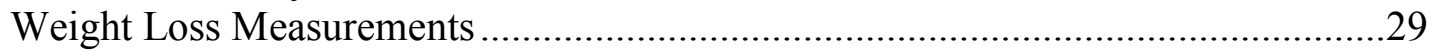




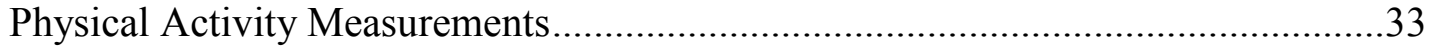

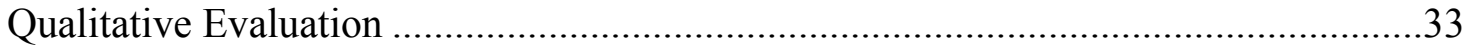

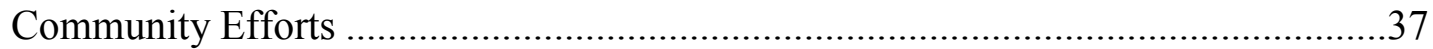

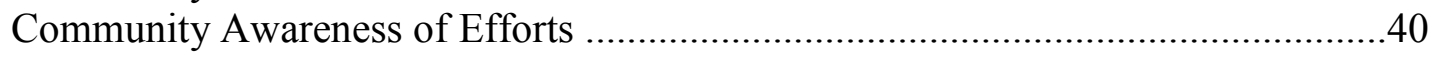

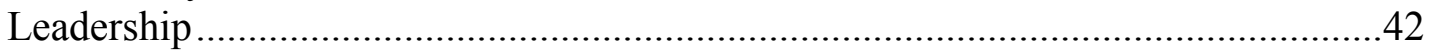

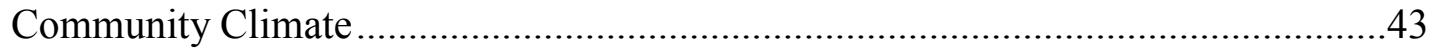

Community Knowledge about the Issue ......................................................44

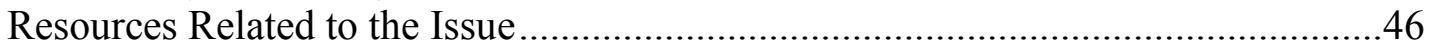

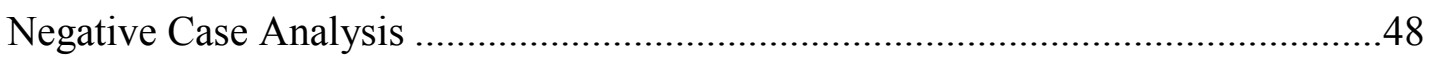

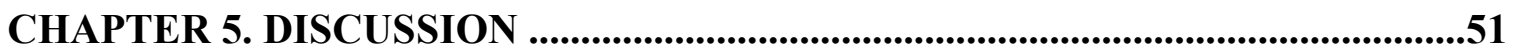

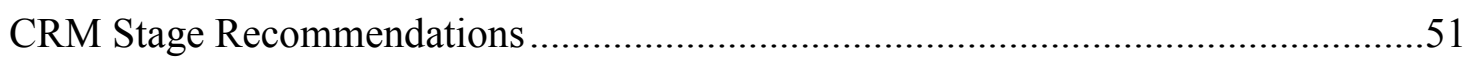

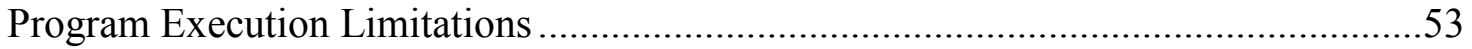

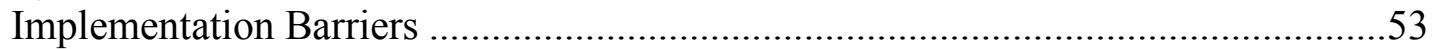

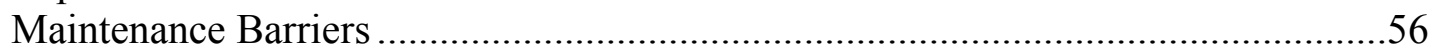

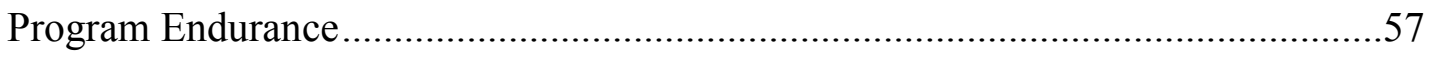

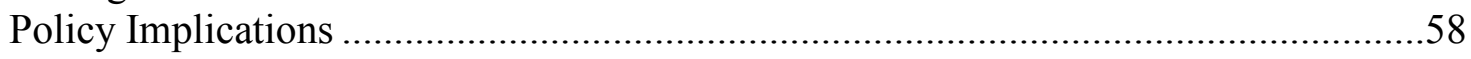

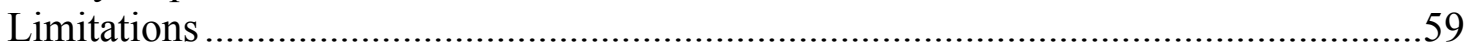

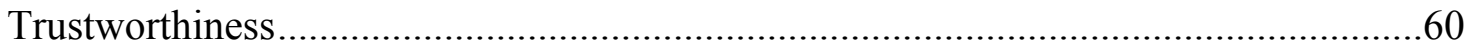

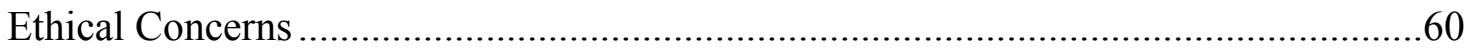

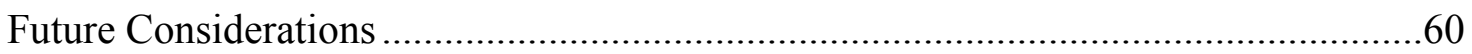

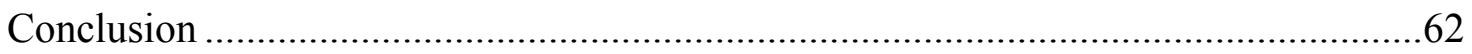

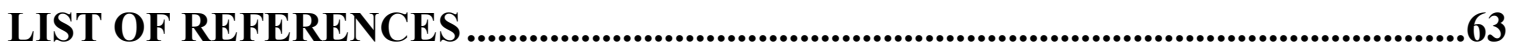

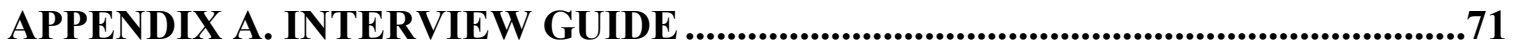

APPENDIX B. ANCHORED RATING SCALES (DIMENSIONS A-F) ...................74

APPENDIX C. STAGES OF READINESS OUTLINE .......................................80

VITA 


\section{LIST OF TABLES}

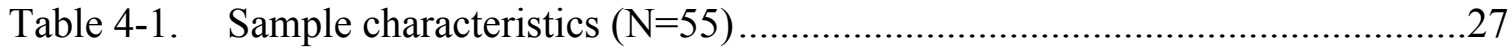

Table 4-2. Comparison of weight and physical activity measures ...............................28

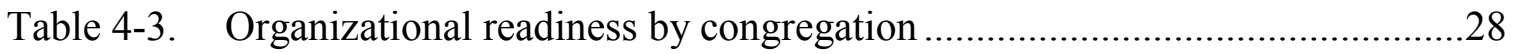

Table 4-4. $\quad$ Mixed model estimates for core weight measurements $(\mathrm{N}=42)$...................30

Table 4-5. Comparison of core weight between congregations ...................................

Table 4-6. Mixed model estimates for maintenance weight measurements $(\mathrm{N}=40) \ldots . .31$

Table 4-7. Comparison of maintenance weight between congregations .......................32

Table 4-8. Mixed model estimates for core physical activity measurements $(\mathrm{N}=47) \ldots .34$

Table 4-9. Comparison of core physical activity between congregations.....................35

Table 4-10. Mixed model estimates for maintenance physical activity $(\mathrm{N}=44) \ldots \ldots \ldots \ldots . . .35$

Table 4-11. Comparison of maintenance physical activity between congregations ........36

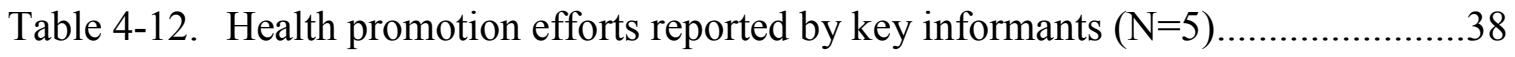




\section{CHAPTER 1. INTRODUCTION}

\section{Statement of the Problem}

Trends in U.S. death rates warrant strategic outreach efforts to change the trajectory of health outcomes. Diabetes, particularly, has increasingly impacted communities over the past 10 years. According to the Centers for Disease Control and Prevention (CDC) (2011), diabetes affects approximately 26 million Americans and is cited as the "7th leading cause of death." It is associated with various complications, including cardiovascular disease, cerebrovascular events, renal failure, hypertensive disorder, and vision loss (American Diabetic Association (ADA), 2013, CDC, 2011). Additionally, disparities between subgroups persist, as minorities are more likely to be diagnosed with the disease and/or experience disease related complications (CDC, 2011). The disproportionate incidence of diabetes and disease specific complications may be accredited to: socio-economic status, environment, culture/health beliefs, lack of resources and/or social support, all of which may contribute to the unfavorable health outcomes witnessed in minority subgroups (Sawyer \& Deines, 2013). In order to efficaciously address health disparities, it is essential to pinpoint strategic methods that account for potential barriers.

\section{Purpose of the Study}

Diabetes prevention programs around the country, modeled after the National Diabetes Program, have aligned with community partners to diminish health barriers, especially among underserved populations (CDC, 2012). Various studies have demonstrated the effectiveness of engaging in community-based health promotion (Rafferty, Jimmieson, \& Armenakis, 2013). Though there are various approaches to reaching individuals at the community level, some key concepts are central to affecting and measuring change: confidence-building, aptitude, problem area, community involvement, and applicability (Glanz, Rimer, \& Lewis, 2002). While some have attempted to find this balance in the traditional setting, others have sought to identify novel health promotion methods. Recognizing the potential within ecclesiastical organizations, faith-based health promotion projects have increased in recent years. Logically, this is a good starting point, especially in disadvantaged populations, in which health disparities are rampant. The benefit of addressing health concerns via faith-based entities lies in the fact that they are viewed as honorable organizations that can possibly impact minority outcomes. Faith-based organizations are in an opportune position to impact health outcomes; not only do they possess a consistent platform, as they house church health ministries and typically command an audience 2-3 times a week, but may be effective despite having very limited resources (Baruth and Wilcox, 2013). Additionally, these organizations are run by clerics who have the power to implement policies that promote wholesome practices (Baruth \& Wilcox, 2013). Still, researchers are challenged with determining the most suitable methods for integrating health projects into the faith-based arena, especially given the dynamics of the organization. 
All things considered, strategists have borrowed from divergent frameworks to understand organizational readiness to change within faith-based settings. However, there are limited data on the organizational readiness of FBOs to successfully deliver health interventions. Organizational "readiness is the degree to which a community is prepared to take action on an issue" (Plested, Edwards, Jumper-Thurman, 2006, p. 3). Faith-based entities can conceivably be efficacious partners in collaborative research efforts or even initiate and implement in-house health promotion programs. However, it is necessary to distinguish key attributes that may have an impact on program success and determine how these should be developed to sustain systematic efforts. Hence, the goal of this project is to understand the organizational readiness (OR) of FBOs enrolled in the MPower Program. These findings will provide deeper insight regarding the organizational aptitude of faith-based establishments and highlight the influence of organizational readiness on group-based health behavior change. This, in turn, will inform future research designed to improve health outcomes within a faith-based setting.

\section{Overview of Conceptual Framework}

The Community Readiness Model (CRM) was used to estimate organizational readiness levels amongst FBOs. Developed by Plested, Edwards, and Jumper-Thurman (2006), the CRM provides a straight-forward means for determining an organization's readiness to engage in health promotion. Specifically, the CRM is a prototype that: “integrates a community's culture, resources, and level of readiness to more effectively address an issue, can be used to address a wide range of issues in any community (geographic, issue-based, organizational, etc.), allows communities to define issues and strategies in their own contexts, and builds cooperation among systems and individuals" (Plested, Edwards, \& Jumper-Thurman, 2006, p.3).

Additionally, the model provides tools that permit a multi-faceted estimation of readiness, considering that readiness can diverge at different sectors of a population (Plested et al., 2006, p.3). The CRM addresses six dimensions of readiness, which include:

1) community efforts (To what extent are there efforts, programs, and policies that address the issue?), 2) community knowledge of efforts (To what extent do community members know about local efforts and their effectiveness, and are the efforts accessible to all segments of the community?), 3) leadership (To what extent are appointed leaders and influential community members supportive of the issue?), 4) community climate (What is the prevailing attitude of the community toward the issue?) 5) community knowledge about the issue (To what extent do community members know about the causes of the problem, consequences, and how it impacts your community?), 6) resources related to the issue (To what extent are local resources - people, time, money, space, etc. - available to support efforts?) (Plested, Edwards, Jumper-Thurman, 2006, p.7). 
Furthermore, the model provides realistic and economical means for accumulating preliminary data (Plested, Edwards, Jumper-Thurman, 2006). It highlights seven elements for readiness estimation, which includes: 1) documentation of the problem, 2) distinguishing the population of interest, 3 ) assessing readiness via interviews with community leaders, which includes any individual within a community that is connected to the issues (i.e., medical professionals, social workers, clergy or spiritual community, youth, law enforcement), 4) classification and analysis of findings, 5) development of programs that are congruent with organizational strength, 6) program review, and 7) monitoring progress and incorporating additional communal concerns (Plested, Edwards, Jumper-Thurman, 2006).

The CRM was chosen to inform the dissertation process due to its distinctive tools, which permit the quantification of qualitative data. Despite its various elements, only components one through four were used to inform the dissertation process. The aforementioned elements 5 through 7 were not incorporated because they were beyond the scope of this study.

\section{Study Significance}

Public health officials have recognized the necessity for targeted health strategies, hence prompting the need for community partnerships. With the assistance of financial backing institutions, numerous programs have been introduced in various settings to initiate, sustain, and/or improve health gains. Some of the nation's top health objectives have been successfully addressed through public programming and targeted outreach. The literature substantially demonstrates the breadth of programs in the market; however, it is important to consider the notion that programs have varying degrees of intensity and applicability. This is an especially important consideration in underserved populations, where individuals tend to forego necessary healthcare or adopt emergency care as the standard (Weiner, 2001). As a mechanism for reaching the ordinarily untapped population, researchers have investigated the value of applying techniques in faith-based affiliations. While the faith-based community appears to be a ready target for such initiatives, barriers to progress may persist. Therefore, it may be necessary to assess organizational attributes when health promotion programs are intentionally integrated into the faith-based system. Despite the aforementioned advantages of faith-based interventions, understanding the organization's level of readiness to engage in health promotion may illuminate performance barriers. Additionally, it may help describe why certain organizations are more successful in impacting health behaviors.

This study, specifically, focused on the organizational readiness of FBOs, explicitly their in-house strategies to execute effective health promotion amongst congregants. In an effort to assess health behavior change across organizations, OR scores were compared with quantitative measures obtained from an obesity prevention study. This dissertation is timely because it links health behavior change, among hard to reach populations, with organizational patterns. Therefore, this assessment may validate the impact of readiness on program success. Additionally, it will also highlight the 
appropriateness of using organizational readiness measurements to predict progress. This is essential considering research funding cutbacks and the competitiveness associated with obtaining such funding. If organizational readiness is associated with progress, it could guide funders in the appropriation of scarce resources. It will also highlight barriers and add to the body of literature regarding faith-based health promotion. Furthermore, it will inform researchers in the development of future training programs that equip FBOs to act as change agents for health.

Based on the following review of the literature, this represents the first retrospective evaluation of readiness to change, amongst FBOs in Memphis, TN, which will be compared with real time outcomes. Several studies have evaluated readiness to change using the CRM; however, they primarily focused on the following: hypothetical interventions (DeMarco et al., 2011), preliminary assessments to guide research before implementation (Sliwa et al., 2011), readiness within the school system (Ehlers, Huberty, Beseler, 2013), or community readiness as it pertains to childhood/adolescent obesity (Kesten et al., 2013; Millar et al., 2013; Findholt, 2007).

\section{Research Questions}

This study addressed the following research questions:

1. What was the level of organizational readiness amongst MPower's participating FBOs?

2. How were FBOs similar and/or dissimilar regarding dimensions of readiness?

3. Was organizational readiness indicative of weight loss amongst participants of the MPower obesity prevention program?

4. Was organizational readiness indicative of increased physical activity levels amongst participants of the MPower obesity prevention program?

\section{Specific Aims}

The goal of this project was to understand the organizational capacity of FBOs enrolled in the M-Power Program and to assess the role of organizational readiness in health behavior change. In an effort to achieve the aforementioned goal, this project was designed to:

1. Observe the attributes of MPower's participating FBOs and their in-house efforts to support health behavior modification amongst congregants.

2. Assess the relationship between organizational readiness to change and weight loss among MPower participants. 
3. Assess the relationship between organizational readiness to change and physical activity among MPower participants.

\section{Hypotheses}

This study was based on the following postulations:

1. Organizational readiness is associated with health intervention outcomes and will be linked to group-based differences among faith-based organizations.

2. Faith-based organizations will have divergent weight patterns over time depending on their organizational readiness level.

3. Faith-based organizations will have divergent physical activity levels over time depending on their organizational readiness level. 


\section{CHAPTER 2. LITERATURE REVIEW}

Many programs have attempted to impact the burden of diabetes through targeted outreach. Although the literature highlights various methods for reaching individuals, the strength of community-based initiatives is well documented. Considering this, the literature review will address key concepts that are central to impacting diabetes outcomes at the community level. The literature review is divvied into four primary components. The initial component highlights the effect of diabetes and the associated complications; and, it contrasts subgroup differences, which underscore the need for targeted outreach among African-Americans. The second outlines cost-effective diabetes prevention techniques and intervention effectiveness in a community-based setting. The third component emphasizes specific health promotion strategies that can contribute to intervention success amongst minorities. This includes the influence of faith-based organizations and their authority within the African-American community. In addition to favorable health promotion strategies, an intervention's success is linked to appropriate behavior change, which may be manipulated by many factors. Therefore, the final component is centered on organizational readiness models that explain key phases of behavior change. Additionally, it highlights the importance of qualitative research and its contributions to change readiness.

\section{Type 2 Diabetes and Related Complications and Costs}

Diabetes, as defined by the CDC (2011), "is a group of diseases marked by high levels of blood glucose resulting from defects in insulin production, insulin action, or both." Consequently, diabetes is associated with various health complications that may result in extreme lifestyle changes or even death. Type 2 diabetes specifically, impacts the population at an alarming rate, accounting for more than $94 \%$ of identified cases (CDC, 2011). Furthermore, African-Americans are disproportionately impacted by the disease. Nearly 5 million African Americans over the age of 19 have diabetes (ADA, 2013). Furthermore, African-Americans are approximately 2 times more likely to develop diabetes compared with their White counterparts (ADA, 2013). Additionally, due to diabetes induced impediments, "African Americans are almost 50 percent as likely to develop diabetic retinopathy, 2.6 to 5.6 times as likely to suffer from kidney disease, and 2.7 times as likely to suffer from lower-limb amputations" (ADA, 2013). Early diagnosis of diabetes is uncommon, which increases the risk for disease related complications (Ahmad \& Crandall, 2010). Additionally, the pecuniary burden associated with diabetes and related complications, totaling " $\$ 174$ billion in 2007(CDC, 2011)," is extensive (Ali, Echouffo-Tcheugui, \& Williamson, 2012; Ahmad \& Crandall, 2010; Zhang et al., 2009; ADA, 2007). Population health statistics along with interrelated costs suggest that type 2 diabetes prevention strategies are essential. Specifically, targeted strategies that motivate communities to proactively address health concerns may be necessary. Therefore, researchers have recognized the value of community-based partnerships. However, community-based partnerships alone may not be sufficient, as organizational attributes may influence outcomes. Thus, understanding an organization's level of readiness to 
engage in health promotion may be necessary. Organizational readiness estimation not only provides a means for evaluating communal strengths and weaknesses but may also highlight cost-efficient methods for resource distribution.

\section{Cost and Intervention Effectiveness}

\section{DPP: A Cost-Effective Prevention Technique}

Pre-diabetes, which affects approximately 80 million individuals over the age of 19 , is a condition in which blood glucose or A1c levels are above average, but are not sufficient for a diabetes diagnosis (CDC, 2011). Individuals with elevated glucose levels are predisposed to developing chronic disease, including type 2 diabetes (ADA, 2013; Tabák, Herder, Rathmann, Brunner, \& Kivimäki, 2012; CDC, 2011; Mokdad, Bowman, Ford, Vinicor, Marks, \& Koplan, 2001; Harris et al., 1998). As reported by Tabák et al. (2012), ADA approximations suggest that the majority of Americans with pre-diabetes will likely develop type 2 diabetes. However, preventive techniques can postpone disease progression (Nathan, 2002; Chapman-Novakofski \& Karduck, 2005; Ahmad \& Crandall, 2010; CDC, 2011; Albright \& Gregg, 2013). In addition, the potential to reduce the incidence of type 2 diabetes has been recognized in both U.S. and foreign experiments (Lindstrom et al., 2006; Li et al., 2008; Diabetes Prevention Program Research Group, 2009; Gong et al., 2011).

The NIH sponsored Diabetes Prevention Program (DPP) represents a national effort to change the trajectory of type 2 diabetes among at- risk populations in the U.S. (CDC, 2012; Clark et al., 2001; DPP, 1999). It incorporates substantiated lifestyle modifications, including dietary amendments and a structured exercise regimen, which can reduce the probability of emergent disease by approximately $60 \%$ (CDC, 2012). Additionally, "the National DPP puts in place the necessary components of workforce training, quality assurance through program recognition, an effective program delivery and payment model, and health marketing to increase program uptake necessary for reducing the incidence of type 2 diabetes" (Albright \& Gregg, 2013, p.8). Such interventions have proven to be both feasible and cost-effective means for impacting the incidence of type 2 diabetes (Venditti \& Kramer, 2013; Vojta, Koehler, Longjohn, Lever, \& Caputo, 2013; DPP, 2012; Ahmad \& Crandall, 2010; Kramer et al., 2009; Ackermann, Finch, Brizendine, Honghong, \& Marrero, 2008; Li et al., 2008; Gillies et al., 2007; Lindström, 2006).

Considering the scarcity of resources, cost-effectiveness is a vital measure. Therefore, researchers are typically equipped with the task of determining if their program is financially feasible with respect to other options. Cost-effectiveness considers the expenditures needed to achieve pre-determined goals (Deniston, Rosenstock, \& Getting, 1968). It is outlined as a proportion between an "output (net attainment of program objectives) and an input (program resources expended), or AO: AR" (Deniston OL, Rosenstock IM, Welch, 1968, p. 604). An appropriate assessment should highlight 
the degree to which goals were accomplished in comparison to the associated expenses (Deniston, Rosenstock, \& Getting, 1968). There should be some equilibrium between contributions and productivities (Abramson, 1979). The average interventionist should seek a reasonable stratum of achievement and marginal expenses (Deniston 0L, Rosenstock IM, Welch, 1968).

A joint effort, between the UnitedHealth Group (UHG) and the YMCA, demonstrated feasibility in maintaining the consistency of the DPP prototype while producing comparable results at reduced costs (Vojta et al., 2013). Among the 1,723 individuals who completed the program at an average service-delivery cost of about $\$ 400$ each, the average weight loss was about 5\% (Vojta et al., 2013). Kramer et al. (2009) used a dual stage forthcoming strategy to assess the practicality and efficacy of implementing the DPP model in a community-based setting. With annual expenditures of roughly " $\$ 300 "$ per person, statistically meaningful outcomes were documented in each stage of the study $(\mathrm{N}=93)$ (Kramer et al., 2009). Although neither of the aforementioned studies conducted a cost-effectiveness analysis, they documented the cost of implementation per person, which was less than the annual per person costs $(\$ 1400)$ reported in the original DPP (Albright \& Gregg, 2013). The aforementioned studies demonstrated that the DPP model is not only valid in real world settings, but also provides a means for maximizing health benefits at a reasonable cost.

\section{Program Effectiveness in Faith-Based Settings}

In addition to cost-effectiveness, an assessment of intervention effectiveness requires that particular markers for achievement are established and information regarding progress is methodically amassed (Deniston, Rosenstock, \& Getting, 1968). This includes careful documentation of both program and cost efficacy (Deniston, Rosenstock, \& Getting, 1968). A study concerned with nutrition, evaluated the practicality of modifying plant and produce intake among participants (Allicock, Campbelll, Valle, et al, 2012). The researchers noted that nutrition was associated with specific advantages; however, it was necessary to determine the impact of their program (Allicock, Campbell, Valle, et al, 2012). Following robust assessments, via "randomized controlled" experiments, researchers evaluated the impact of introducing this paradigm in a faith-based setting and concluded that it was a viable and realistic approach (Allicock, Campbell, Valle, et al, 2012). The program focused on areas such as: ministerial enthusiasm, education, setting, and support (Allicock, Campbell, Valle, et al, 2012). The overarching objective of this study was to substantiate the distribution and application of a program with minimal provision (Allicock, Campbell, Valle, et al, 2012). They hoped to replicate previous efficiency experiments and assess program implementation through detailed process evaluation (Allicock, Campbell, Valle, et al, 2012).

The "RE-AIM" paradigm was used to facilitate the assessment, which contained measures for: 1) reach- enrollment and completion of successive questionnaires; 2) efficiency- the extent to which goals were achieved; 3) adoption - percentage of organizations that actually launched the intervention; 4) implementation- the magnitude 
and merit of program distribution 5) Maintenance- the degree to which program components were sustained (Allicock, Campbell, Valle, et al, 2012). The findings indicated that the distribution of the "Fit Body \& Soul Program" was ineffective as is (Allicock, Campbell, Valle, et al, 2012). There were no advancements in intake comparable to former efficiency assessments (Allicock, Campbell, Valle, et al, 2012). Researchers concluded that the following areas required improvements: reliability, upkeep, obstacles, and intervention environment (Allicock, Campbell, Valle, et al, 2012). Similarly, the "Faith, Activity, and Nutrition" program evaluated a faith-based intervention based on nutrition and exercise (Saunders, Wilcox, Baruth, \& Dowda, 2014). The key objective was to complete a thorough evaluation of: program execution, censoring strategies, and techniques used to gauge program execution at the administrative stage (Saunders, Wilcox, Baruth, \& Dowda, 2014). Their evaluation revealed that there was no observed surge in isometrics following program execution, nor was there any impact on diet (Saunders, Wilcox, Baruth, \& Dowda, 2014). A subsequent evaluation illuminated the concept that program execution was related to perceptions about aptitude and patronage, which was linked with exercise (Saunders, Wilcox, Baruth, $\&$ Dowda, 2014). In their discussion, the authors noted that "organizational level" adjustments can be quite cumbersome to attain and more work may be necessary to successfully integrate similar programs into the faith-based community (Saunders, Wilcox, Baruth, \& Dowda, 2014).

Though the aforementioned studies reported marginal success in program implementation, the literature boasts some successful accounts of faith-based health initiatives. For example, a faith-centered "mammography" awareness experiment evaluated the impact of mobile support among 30 FBOs (Duan, Fox, Derose, \& Carson). Phone surveys provided the necessary information to evaluate the impact of the program on "mammography adherence" (Duan, Fox, Derose, \& Carson). The 12-month postintervention measurement revealed that individuals maintained momentum and the percentage of "non-adherence" declined by 7\% (Duan, Fox, Derose, \& Carson). Decision-makers determined that ecclesiastical organizations were valuable intermediaries for health advancement (Duan, Fox, Derose, \& Carson). Moreover, a faith-based "cholesterol education program, using a Reflotron, and other coronary heart disease risk factor screenings," was introduced to 6 organizations, for which the objective was to determine the impact on "serum cholesterol" (Wiist \& Flack, 1990, p. 381). The authors documented substantial declines in average "cholesterol level 6-months" following the preliminary testing (Wiist \& Flack, 1990, p. 384). The results had significant implications in the medical realm; therefore, researchers concluded that the use of their program model was effective for African-American groups vulnerable to cardiovascular illness (Wiist \& Flack, 1990).

In addition to the previous examples, a literature review of church centered interventions, in more than thirty regions, evaluated the impact of various programs and their intended goals (DeHaven, Hunter, Wilder et al., 2004). They identified interventions for various disease categories such as, preclusion (50.9\%), overall well-being $(25.5 \%)$, heart conditions (20.7\%), or melanomas (18.9\%) (DeHaven, Hunter, Wilder et al., 2004). Explicitly, interventions in the following areas indicated a substantial impact on 
cardiovascular illness (36.4\%), size/diet (18.2\%), "breast cancer (18.2\%), prostate cancer (18.2\%), and smoking cessation (9.0\%)" (DeHaven, Hunter, Wilder et al., 2004, p. 1032). They noted that more robust evaluations of program efficiency are necessary. Out of " 386 " articles, only a small percentage "(27.5\%)," fit with the program objective and an even smaller proportion " $(13.7 \%)$ " detailed a particular intervention (DeHaven, Hunter, Wilder et al., 2004, p. 1032). Additionally, there was only one study that went beyond efficiency and evaluated expenditures (DeHaven, Hunter, Wilder et al., 2004). While there is some documentation of cost-effectiveness of community-based programs in the literature, the research specific to faith-based programs is somewhat limited. However, the aforementioned research demonstrates the replicability of the DPP model in various settings and it highlights the implications for cost-savings under the umbrella of community-based establishments. The idea that faith-based programs are achieving "costeffectiveness" can be inferred based on reported successes and recommendations for future utilization (Kramer, Kriska, Venditti, et al., 2009).

\section{Health Promotion Strategies}

\section{Advantages of Lay Leader Support}

One health promotion strategy that is both cost-saving and cost-effective includes the use of non-professionals for intervention delivery, which can potentially reduce administrative overhead. This is because successful implementation of the DPP is not contingent on the educational background of the instructor (Albright \& Gregg, 2013; Vojta et al., 2013; Ali et al., 2012; Katula et al., 2011; Ahmad \& Crandall, 2010; Kramer et al., 2009). A review of more than 27 studies, modeled after the DPP, revealed that mean weight loss was comparable irrespective of the interventionist's educational background (Ali, Echouffo-Tcheugui, \& Williamson, 2012). For example, Boltri et al. (2011), with a total of 37 participants, used trained professionals to implement the DPP in African-American churches. Congregations were assigned to either a 6-week or 16-week curriculum, yielding similar results one year after the intervention (Boltri et al., 2011). In general, there was a significant reduction in both "fasting glucose, 108.1 to $101.7 \mathrm{mg} / \mathrm{dL}$ post intervention ( $\mathrm{p}=.037)$, and BMI, 33.2 to $32.9 \mathrm{~kg} / \mathrm{m} 2(\mathrm{p}<.05)$ " (Boltri et al., 2011, $\mathrm{p}$. 194).

Alternatively, the HELP PD project, "a randomized controlled trial with 301 overweight and obese volunteers (BMI 25-40 kg/m2)," used nonprofessional educators to implement the DPP in a community-based setting (Katula et al., 2011, p. 1451). At 12months follow-up, they reported significant reductions on the following measures: "blood glucose $(-4.3$ vs. $-0.4 \mathrm{mg} / \mathrm{dL} ; \mathrm{P}<0.001)$, insulin $(-6.5$ vs. $-2.7 \mu \mathrm{U} / \mathrm{mL} ; \mathrm{P}<0.001)$, homeostasis model assessment of insulin resistance $(-1.9$ vs. $-0.8 ; \mathrm{P}<0.001)$, weight $(-7.1$ vs. $-1.4 \mathrm{~kg} ; \mathrm{P}<0.001)$, BMI ( -2.1 vs. $-0.3 \mathrm{~kg} / \mathrm{m} 2 ; \mathrm{P}<0.001)$, and waist circumference ( -5.9 vs. $-0.8 \mathrm{~cm} ; \mathrm{P}<0.001)$ " (Katula et al., 2011, p. 1451). Ali et al. (2012) concluded that the use of nonprofessional educators was just as efficient and more cost-effective than using clinically trained professionals. Furthermore, they suggested 
that successful versus unsuccessful rollout of the DPP is more closely tied to perceived threat and the impact of performance strategies, including "readiness-to-change" evaluations, peer support, and compensation (Ali et al., 2012).

Nonprofessional instructors are not only cost-efficient, but may be the best choice for targeted interventions. They are likely to reside in the communities they serve, thus representing the necessary linkage between high-risk populations and operative health interventions (Ali et al., 2012; Calman, 2005; Gary et al., 2003; Lorig and González, 2000). This is especially important as all of the aforementioned studies indicated one or more barriers to implementation and/or program success. Considering that barriers can be a huge threat to program delivery and maintenance, it is necessary to authentically connect with the target community. Lay leaders can potentially provide researchers with vital insight about the target community and help establish recruitment protocol. Alternatively, they may also be able to squelch any trust issues that may deter participation, specifically in the African-American community, as they have an unfavorable history with researchers due to former investigative techniques. Likewise, lay leaders can also offer information regarding cultural relevance.

According to Ali et al. (2012), "effective detection and recruitment of people with pre-diabetes requires channels that people can culturally relate to, through which highrisk individuals can be identified and can gain access to programs" (p. 72). It is probable that the reduction of obstacles would prompt millions of at-risk individuals to contemplate enrollment in diabetes prevention initiatives (Ali et al., 2012). Additionally, they are well positioned ambassadors for program execution, as their connection to prevailing communal networks can potentially minimize location and access barriers (Ali et al., 2012; Norris et al., 2006). Lay leaders may be able to link researchers with community-based organizations that are willing to house health promotion programs.

\section{Community-Based Organizations}

Another strategy for health promotion includes the use of community-based organizations, which are prime conduits for intervention dissemination (Baruth \& Wilcox, 2013; Calman, 2005; Winett et al., 1999; Lasater, Becker, Hill \& Gans, 1997). They represent an essential and dependable channel for public health initiatives. Therefore, they can possibly have a grave impact in underserved neighborhoods by offering a means for socially acceptable interventions, and diminishing health inequities (Calman, 2005). FBOs, especially, present a favorable environment for program delivery among minorities (Baruth and Wilcox, 2013). Historically, ecclesiastical organizations have had tremendous influence in the African-American population (Baruth et al., 2011).

\section{Faith-Based Interventions and the African-American Community}

Dating back to the pre-civil rights period, the church has functioned as a haven for African-Americans, as it provided a source of dignity to those seeking parity and justice 
under a skewed system. Today, the church is just as vital to the African-American community, as systemic injustices, health disparities, and economic vulnerabilities are at work. They continue to be a beacon of hope for the communities they serve. According to Brody et al. (1994), FBOs even surpass the spiritual call of duty as they often provide essentials, including groceries, lodging and apparel. Consequently, they are in a unique position to exceptionally impact "social norms" (Baruth et al., 2011).

A frequently cited catalyst for success in faith-based health promotion is the importance of ministerial endorsement (Harmon, Blake, Armstead, Hébert, 2013; Hippolyte et al, 2013; Williams et al., 2013; Newlin et al., 2012; De Marco et al., 2011; Austin \& Claiborne, 2011; Williams, Glanz, Kegler \& Davis, 2009; Ammerman et al., 2003; Markens et al., 2002; Taylor et al., 2000). For example, Hippolyte et al.(2013), focused on structural components that are integral to program implementation and maintenance within faith-based organizations; this includes but is not limited to the support of a lay leader, appropriate timing of intervention activities, and availability of meeting space. They found that ministerial approval, coupled with demonstrated patronage of efforts, contributed to program maintenance (Hippolyte et al., 2013). Some pastors are more proactive in their in-house health promotion efforts, which may be indicative of their willingness to reconcile faith and practice.

Also noted is that African-American FBOs typically incorporate health strategies into their global objectives, by offering "services" via appointed boards and localized health "ministries" (Resnicow et al., 2002). Thus, introducing health behavior interventions in such settings may be more practicable, yielding various advantages which include: simplified enrollment and follow-up, and contact with economically secure minorities, a frequently untapped population in public health interventions (Rescinow et al., 2002). Also, FBOs provide an avenue for reaching poverty-stricken minorities, who may potentially be at risk for disease onset and progression. This is because they may lack pertinent resources for health maintenance. Consequently, they may over-utilize emergency services and may even forego or delay necessary medical care as a function of costs. These issues were underscored by the recent healthcare reform law, as it highlighted the need for medical stability in underprivileged populations. While faith-based health promotion cannot replace the benefits of consistent primary care, the potential to impact the well-being of the vulnerable is noteworthy.

Various studies have documented some success in reaching high-risk groups via faith-based recruitment (Baruth \& Wilcox, 2013; Hippolyte et al., 2013; Williams et al., 2013; Wilcox et al., 2013; Newlin, Dyess, Allard, Chase, Melkus, 2012; Asomugha, Derose, \& Lurie, 2011; Austin \& Claiborne, 2011; DeHaven, Hunter, Wilder, Walton, \& Berry, 2004; Resnicow et al., 2002; McNabb, Quinn, Kerver, Cook, \& Karrison, 1997). For example, Resnicow et al. (2002) evaluated the efficiency of a customized nutrition and fitness program. Participants were "randomized" to one of three groups in which they received: 1) general educational materials, 2) socially relevant materials only, or 3) a combination of socially relevant materials and 4 mobile support sessions (Resnicow et al., 2002). Individuals who were in groups two or three were more likely to increase fitness and "fruit and vegetable" consumption, with the greater increase occurring in 
group three (Resnicow et al., 2002). They concluded that a culturally structured intervention coupled with motivational interviewing yielded significant results and that the issuance of health materials alone was not sufficient to significantly impact the main outcome (Resnicow et al., 2002).

Subsequently, Wilcox et al., (2013) used a community-based participatory research approach (CBPR) to evaluate fitness and nutrition practices amongst predominately Black churches. Although participating FBOs did not identify the issue of interest, each formed a five person committee that assisted with program development, implementation, and evaluation. Furthermore, the organization's members assisted with the development of strategies to address both physical activity and healthy eating. A significant increase in "self-reported moderate- to vigorous-intensity physical activity," amongst the intervention group, was reported (Wilcox et al., 2013, p. 1). Alternatively, Baruth and Wilcox (2013) reported marginal success in their evaluation of the "Faith, Activity, and Nutrition" study, a 1.5 year evaluation of "health behavior" change amongst congregants of more than 30 southern churches. Although some individuals improved in one or more of the intended categories, "nearly 1 in 5 participants made no changes in any targeted behaviors," which suggests that "faith-based interventions" centered on "environmental and organizational change" can impact "multiple behaviors;" yet more work is necessary (Baruth \& Wilcox, 2013, p. 6). The results of the aforesaid studies clearly demonstrate that health promotion initiatives can be integrated into the faith-based community. However, outcomes may not always reflect the intended objectives. Despite a desire to promote healthy lifestyles among congregants, some FBOs may be illprepared to successfully incorporate a health-based intervention "into the overall mission of their ministry" (Austin \& Claiborne, 2011, p. 8).

\section{Readiness for Behavior Change}

\section{Organizational Readiness Models}

Essentially, the success of a faith-based intervention may be best understood by evaluating the organization's "readiness to change" (De Marco et al., 2011). According to DeMarco et al. (2011), "Organizational readiness for change is a 2-dimensional construct that reflects organization members' collective commitment (willingness) and collective efficacy (ability) to implement an innovation to change" (p. 2). A keen understanding of preliminary readiness to change may impact overall outcomes (Rafferty, Jimmieson, \& Armenakis, 2013; Gagnon et al., 2011; Holt, Helfrich, Hall, \& Weiner, 2009; Weiner, 2009; Weiner \& Lee, 2008; Holt, Armenakis, Field, Harris, 2007; Donnermeyer, Plested, Edwards, Oetting, \& Littlethunder, 1997). "When organizational readiness for change is high, organizational members are more likely to initiate change, exert greater effort, exhibit greater persistence, and display more cooperative behavior; resulting in more effective implementation" (Weiner, 2009, p. 1). 
There are various models that measure an organization's willingness to transform, such as the CRM, the Readiness for Community Change (RCC), and the Community Self-Organizational Model (CSM). The CRM is "a model for community change that integrates a community's culture, resources, and level of readiness to more effectively address an issue" Plested, Edwards, \& Jumper-Thurman, 2006, p. 3 ). Application of the CRM permits a tactical approach for research development and implementation by linking investigative procedures to organizational receptivity. The RCC utilizes the Transtheoretical Model (TM) as an operational guide for readiness assessment (Bowen, Kinne, \& Urban, 1997). Each component of the TM, which includes pre-contemplation, contemplation, action, and maintenance stages, is assessed through interviews with chief members of the target community (Bowen, Kinne, \& Urban, 1997). This model utilizes a "structured" format to assess former, current, and prearranged activities (Bowen, Kinne, \& Urban, 1997) Like the CRM, the RCC model allows for a more efficient use of resources by methodically categorizing communities based on qualitative data. However, the RCC utilizes a more structured data collection approach. Basically, the investigator team identifies the questions, the sectors, and the information they needed in order to standardize the assessment across communities (Bowen, Kinne, \& Urban, 1997). Despite the benefits of standardization, the RCC may be limited in its ability to fully capture the community's voice, which is possible with the unstructured CRM assessment.

Additionally, the RCC may be advantageous when competing interests are an issue because it can be administered via phone. However, this eliminates the opportunity for "direct observation," which is essential to the qualitative process (Bowen, Kinne, \& Urban, 1997). The RCC provides fewer stages of readiness than CRM so groups may be more easily categorized. However, since the RCC incorporates a person level behavioral model to evaluate community level behaviors, it may not sufficiently capture the overall community readiness in a detailed fashion. Similar to the CRM, this model relies on the perspective of a few community members to represent the whole; thus, it may not fully represent the needs or views of the community at large and may be subject to selection bias.

The CSM, which combines concepts from the field of psychology and the readiness literature, is an all-inclusive model that can be applied to "community-based prevention activities" (Chilenski, Greenberg, \& Feinberg, 2007, p. 4). This model is centered on antecedent "psychosocial" qualities and is comprised of four components, including: "Community Attachment, Initiative, Efficacy, and Leadership" (Chilenski, Greenberg, \& Feinberg, 2007, p. 3). By addressing the aforementioned components, this model, unlike the CRM and RCC goes beyond intentions to more thoroughly understand community buy-in and its degree of involvement. CSM utilizes ordinal "subscales" to measure beliefs and opinions for each of the aforementioned model domains; therefore, it is easily "quantifiable" and requires less time from administration (Chilenski, Greenberg, $\&$ Feinberg, 2007). However, the data may not be as rich. Also, this model provides an economical means for data collection that can be applied in person, via mail, or internet. In line with Likert Scales, the CSM data collection method may not truly measure attitudes because respondents may be influenced by previous questions. However, this model can be more useful than the aforementioned models when employing "large-scale 
change" that requires input from many community collaborators (Chilenski, Greenberg, \& Feinberg, 2007).

The CRM was the preferred framework for this analysis, as it provides a simple measurement instrument that is far-reaching, and cost-efficient. Furthermore, it can be used to "assess the overall effectiveness of efforts, and give insight into key outcomes (such as shifts in community norms, support of local leadership) in ways that traditional evaluation methods may not bring to light" (Plested, Edwards, \& Jumper-Thurman, 2006, p. 56). The CRM can be an asset to researchers because it provides valuable preliminary insight for upcoming projects, illuminates a community's potential success with an intervention, and provides general capacity building strategies for various stages of readiness.

The CRM, principally geared towards substance abuse, has been employed to assess "health and nutritional (such as STD, heart disease, and diet), environmental (such as water and air quality, litter, and recycling) and other social issues (such as poverty, homelessness, and violence)" (Thurman, Vernon, \& Plested, 2007, p. 50).Various studies have cited the CRM as an effective resource for evaluating community readiness amongst diverse audiences (Ehlers, Huberty, Beseler, 2013; Millar et al., 2013; DeMarco et al., 2011; Sliwa et al., 2011; Findholt, 2007; Lawsin et al., 2006; Slater et al., 2005; Scherer et al., 2001; Plested et al., 1999; Oetting et al., 1995). Explicitly, Silwa et al. (2011) used the CRM to synchronize health promotion techniques with public demand in an adolescent weight management study. Through interviews with key patrons across 10 comparable U.S. communities, researchers were able to identify groups that recognized "childhood obesity" as an indigenous issue, as well as pinpoint those who might successfully complete intervention components (Silwa et al., 2011). The authors concluded that evaluating readiness is instrumental in: deciphering a population's ability to implement health initiatives, and pinpointing the necessary level of intervention (Silwa et al., 2011). Otherwise, "programs risk over- or underestimating what communities are capable of implementing, making for an inefficient use of resources" (Silwa et al., 2011, p. 6).

Likewise, Plested et al. (2007) used the CRM to evaluate "prevention and social marketing related to HIV/AIDS" among American Indians (p. 49). They identified key areas of development for stakeholders, such as: location barriers for infected individuals, lack of education regarding the disease and reduced social support (Plested et al., 2007). Additionally, Lawsin et al. (2006) used the CRM to gauge challenges to participation in "breast cancer prevention trials" among "Latina women in Colorad" (p. 1). Upon scoring the CRM interviews, they determined that the community was ambiguous, which meant there was basic acknowledgement of the problem within the Latina community, but frontrunners were not necessarily initiating progress (Lawsin et al., 2006). In accordance with recommendations from the CRM, the authors concluded that it was primarily necessary to increase public recognition of existing "breast cancer prevention" endeavors (Lawsin et al., 2006, p. 9). 
The CRM has also served as a marker for policymakers who were interested in community-level change. In a "cross-sectional" analysis of "two United States-Mexico border communities, semi-structured surveys, based on the CRM," were used to isolate common concerns among the target population, ascertain willingness to transform, and establish progression strategies (Scherer et al., 2001, p.22). Data assessments indicated that societal concerns, such as brutality, were mutually problematic for each population; but, they were in the "denial stage of readiness" (Scherer et al., 2001, p. 26). Contrarily, the communities exhibited divergent phases of "readiness" regarding substructure (Scherer et al., 2001). While one was in the "vague awareness to the preplanning stage," the other was in the "denial stage," meaning there was some acknowledgement of a problem, but hardly any acknowledgement of a plausible solution (Scherer et al., 2001, p. 26). Therefore, it would be prudent to heighten awareness by utilizing appropriate avenues to educate one community, while providing the other with tangible strategies to address structural concerns (Jumper-Thurman et al., 2003; Scherer et al., 2001).

Aside from evaluating phases of action across communities, the CRM has been used to assess differences between racial groups. In their evaluation of "drug use prevention in rural communities," Plested et al., (1999) sourced "1990 Census data, from which 102 communities were randomly selected from all communities in the contiguous U.S.” (Plested et al., 1999, p. 525). They found that, in comparison to their White counterparts, "minority (Mexican American and Indian American) communities were especially at a low stage of readiness, with only $2 \%$ having drug use prevention programs in place" (Plested et al., 1999, p.528). DeMarco et al. (2011) specifically evaluated the CRM as a tool for faith-based outreach and suggested that the CRM was an operational device that "informed research projects, strengthened church-academic partnerships and improved capacity to address health disparities" (p. 1). As indicated by the aforementioned examples, the CRM provides a logical approach to social research.

\section{Qualitative Research Design}

Qualitative research encompasses various mechanisms for data collection, some of which include: "case study, personal experience, introspection, life story, interview, artifacts, cultural texts and productions, along with observational, historical, interactional, and visual texts" (Denzin \& Lincoln, 2011, p. 3-4). Qualitative research tactics are labeled as "subjective" - because each participant is viewed as "a subject in his or her own right; he or she is present in the same world as those studied, and actively participates in the formulation of what comes to be regarded as data" (Holstein, \& Gubrium, 2002). Although it permits an in-depth evaluation of experiences, for which data are collected to the point of saturation, qualitative findings are typically not generalizable to the broader population (Holstein, \& Gubrium, 2002).

Conversely, quantitative research studies are more decisive in their approach. They are usually geared toward a larger sample of unsystematically sampled individuals in an attempt to draw meaningful conclusions about the general population (World Health Organization, 2008). Qualitative methodologies are more heuristic and are centered on 
all-inclusive (Newman, \& Benz, 1998) principles such as the following: 1) there are multiple existences 2) experience is subjective and varies across people and time. 3) information has value only in a specific "situation or context" (Joubish, Khurram, \& Ahmed, 2011).

The CRM primarily utilizes qualitative data collection techniques and allows for meaningful comparisons across communities. The CRM not only permits the quantification of measurements, but like traditional qualitative designs, it highlights cultural undertones that are associated with a specific group, illuminating how information is received, processed, and applied (Denzin \& Lincoln, 2011). Although such qualitative designs were regarded as less robust in the past, it's current use in educational arenas is invaluable (Denzin \& Lincoln, 2011). This is because it helps researchers understand the richness and complexity of social experience by attending closely to the actions, interactions, and social contexts of everyday life (Holstein, \& Gubrium, 2002).

The application of qualitative designs, such as the CRM, permits the evaluation of occurrences with respect to one's environment (Denzin \& Lincoln, 2011). In turn, researchers can derive value from the "dynamics and texture" of daily occurrences, which may be challenging to categorize (Holstein, \& Gubrium, 2002). 


\section{CHAPTER 3. METHODOLOGY}

\section{Overview}

This was a mixed-methods study designed to evaluate organizational readiness among FBOs. This study was evaluated in two phases and designed to: 1) compare the outcomes of MPower's faith-based organizations, 2) use qualitative interviews to assess the ability of FBOs to support members in achieving desired behavioral goals.

The MPower Program was a health disparities initiative led by the University of Tennessee's Center for Health Systems Improvement. MPower intended to demonstrate a cost-effective approach to positive lifestyle change including: goals of at least $5 \%$ weight loss and a graduated physical activity goal of 150 minutes per week. The goal of MPower was to address the disproportionately high rates of obesity within the Memphis urban core, specifically targeting individuals at risk for diabetes, hypertension, and/or heart disease. MPower utilized an evidence-based approach to weight loss through healthy eating and physical activity outlined in the Group Lifestyle Balance TM (GLB) curriculum, which was adapted from the NIH-sponsored Diabetes Prevention Program. MPower data were collected in two stages, core and maintenance. The core component included weekly data collection over a 10 week period. Data for the maintenance stage were collected monthly for a period of 6 months. Both stages were delivered by community health leaders(CHLs) who were the health ministry leaders in their respective organizations.

Phase I data was sampled from the MPower Program, which was a 1 year longitudinal study (April 2013-April 2014). MPower recruited five CHLs who were responsible for delivering the intervention to organizational members. The sample was comprised of 56 African-Americans who attended a FBO in one of the following zip codes: $38106,38107,38108,38112$, and 38114 . Eligible members, identified by the ADA diabetes risk screening, were invited to participate in 16 prevention sessions. The program was comprised of weekly group sessions that occurred over a period of 10 weeks and monthly sessions over a period of 6-months. All group sessions, approximately 1 hour long, were coordinated by the group's CHL and housed in the group's faith-based facility.

Phase II Data Collection was a case study used to evaluate the attributes of MPower's FBOs. A purposive sample, which included six of MPower's trained CHLs, was used. All CHLs were African-American women between the ages of 48 to 56 and were the health ministry leaders/coordinators for their respective FBO. Data was collected via one-on-one interviews. Sixty to ninety minutes interviews, guided by the CRM, were conducted over a 6 months period at the University of Tennessee Health Science Center. The final interview guide consisted of a sequence of open-ended questions that were based on six dimensions of readiness. Field notes were collected as written documentation of the participants' responses, feelings, and expressions. Every interview was recorded with digital audio technology and was subsequently uploaded to a 
process server. Bracketing and an audit trail were used to minimize inherent bias. All data were de-identified and stored electronically.

The interviews were scored according to CRM guidelines in order to determine organizational readiness. A score, ranging from 1 to 9 , was assigned to each interview. Each score represented a unique category of readiness, ranging from no awareness to a highly functional state. These scores were plugged into a statistical model to compare the associations between organizational readiness scores and MPower's intervention outcomes. Although six interviews were conducted, the score for interview 6 was not included in the statistical model because there were no data to analyze.

General linear mixed modeling (using PROC MIXED from SAS/STAT software) was used to evaluate statistical significance. Primary outcome measures included weight loss and physical activity. In this study, congregations were nested within organizational readiness categories. Therefore, post hoc analyses were used to evaluate mean differences among groups within the same OR category.

The qualitative data were analyzed to determine similarities and differences in interview responses. To prepare for data analysis, all transcripts were reviewed for accuracy following the transcription process. Interview transcripts were re-examined, along with field notes, to identify data patterns. Emerging themes were identified and organized into categories that were based on CRM dimensions of readiness.

\section{Phase I Data}

\section{Recruitment for MPower}

The MPower Program was implemented in FBOs that were recruited through a community partnership with Memphis Healthy Churches (MHC). Memphis Healthy Churches was an outreach program of Christ Community Health Services (CCHS), which provided disease education in the African-American community. Through MHC, MPower was able to access a network of African-American FBOs. The MPower protocol required Community Health Leaders (CHLs) to introduce and implement the intervention. In an effort to recruit CHLs, researchers initially gauged interest by attending a MHC quarterly meeting, which was attended by individuals who were health ministry representatives for their respective FBO. Interested representatives completed a sign-up form and were subsequently contacted via phone and/or email to attend an introductory meeting. The meeting attendees were provided with a general overview of the MPower intervention and goals.

Meeting attendees were also provided with a brochure and tasked with obtaining pastoral approval. The brochure contained a summary of the information provided during the meeting. Participating FBOs submitted a memorandum of understanding, signed by the pastor and the appointed organizational leader, which indicated their approval to 
introduce MPower to their congregation. Following consent, the approved CHLs attended an one-day training in May 2013. The CHLs were trained on the GLB curriculum, downloaded from the CDC's website. The GLB curriculum was adapted from the NIH sponsored Diabetes Prevention Program (DPP), which demonstrated that physical activity and diet modification could change the trajectory of type 2 diabetes among at- risk populations in the U.S. (DPP, 2002). The curriculum provided an evidence-based approach to weight loss and was devised to assist individuals with lifestyle changes that could prevent and/or delay the onset of diabetes. The GLB prevention materials targeted improvements in diet, physical fitness, goal setting, and anxiety management. This curriculum has been used in various adaptations of the DPP (Venditti \& Kramer, 2013; Vojta, Koehler, Longjohn, Lever, \& Caputo, 2013; Ahmad \& Crandall, 2010; Kramer et al., 2009; Ackermann, Finch, Brizendine, Honghong, \& Marrero, 2008; Li et al., 2008; Gillies et al., 2007; Lindström, 2006).

Following the training, MPower's CHLs were required to recruit participants within their respective FBO and establish the protocol to administer the GLB curriculum to congregants. Participants were recruited based on their risk for developing diabetes using the ADA's Type 2 Diabetes Risk Test. If individuals scored five or more, they were at an increased risk for developing type 2 diabetes and were invited to join MPower. According to the ADA (2015), the probability of developing diabetes is augmented for all overweight individuals; therefore, individuals who scored lower than five, but were overweight, were also allowed to join MPower.

Eligible members were invited to participate in a 16 session prevention program. As stated previously, MPower was accomplished in two stages: 1) core weekly sessions that occurred over a period of 10 weeks and 2) monthly post-core sessions over a period of 6-months. Participants attended both weekly and monthly group sessions, which were housed in their respective faith-based facility. All group sessions, approximately 1 hour long, were coordinated by the group's CHL. Each CHL was given: copies of the GLB curriculum, pedometers for all enrollees, a supply of low-calorie snacks for their group sessions, data reporting documents, and a scale for group weigh-ins. Throughout the program, participants were encouraged to: develop and retain equilibrium between diet and physical activity, self-monitor their weight, diet, and physical activity, track their progress, problem-solve when faced with challenges, and develop motivational strategies to compliment lifestyle changes.

\section{MPower Sample Characteristics}

MPower was a longitudinal (prospective cohort) study that targeted ecclesiastical establishments specifically. Seven FBOs agreed to participate in MPower. Each FBO was represented by one CHL. Five CHLs were successful in their attempt to implement the intervention in their respective organizations. Despite pastoral approval, two CHLs were unsuccessful in their recruitment efforts. Although participation varied with each congregation, 56 individuals were enrolled in MPower. The age of the population ranged 
from 32 to 79 . Exclusion criteria included individuals with clinically diagnosed diabetes, and/or persons less than 18 years of age.

\section{MPower Data Collection}

The CHLs were responsible for scheduling and leading the GLB curriculum sessions. Although CHLs coordinated sessions for mass delivery of the MPower intervention, alternate intervention delivery methods were permitted to accommodate participants who missed one or more sessions. If a participant missed a scheduled session, CHLs either administered the intervention one-on-one or dispensed the intervention materials to participants. All attendance and outcome data were collected by CHLs. During the group sessions, CHLs administered the curriculum and documented individual weight measurements using MPower provided digital scales. They also collected self-reported data, which included physical activity minutes, pedometer steps, and/or dietary recalls. The dietary recalls were submitted in paper form and information was subsequently entered into the ASA24 software provided by the National Cancer Institute. The ASA24 is a web-based instrument that enables users to enter 24-hr food recalls. It also permits the analysis of submitted recall data. Due to the sparsity of food recalls, the data were not included in the analysis.

The CHLs met with MPower investigators and staff on a monthly basis to report progress. MPower investigators provided CHLs with a formula for assigning a unique identifier to each participant. De-identified data were submitted, in paper/electronic form, to assigned MPower staff, which verified and entered it into a central database. Data were reported every week over a period of 10 weeks during the core sessions and once a month for a period of 6-months during the post-core sessions. The MPower database contains the following measures, obtained from the ADA's diabetes risk test: age category, gender, hypertension status, history of gestational diabetes, parental history of diabetes, active lifestyle, and diabetes risk score. Additionally, it contains weekly (core) and/or monthly (post-core) outcomes including: educational session type, intervention session attendance, weights, physical activity minutes and/or pedometer steps, and selfmonitoring. The self-monitoring variable included diet, weight, and physical activity surveillance. Participants were provided with booklets to track diet choices, weight change, and physical activity minutes. The booklets were reviewed by the CHLs who determined if participants actually self-monitored. The intervention session attendance variable measured educational session turnout. It was measured as yes or no and was documented during the core and maintenance periods. The active lifestyle variable was a baseline measure obtained from the ADA Risk Test. Individuals were asked to specify if they were physically active. This variable was measured as yes or no. Although the initial sample included 56 participants, the number of individual observations may vary due to attrition at various stages of the program. 


\section{Phase II Data}

\section{CRM Recruitment}

The second phase of this project was a case study that evaluated the organizational readiness of MPower's participating FBOs. Following completion of MPower, all of the CHLs were invited to participate in an one-on-one interview to provide specific information about their ecclesiastical organizations. The CHLs were contacted via phone and/or email. Following consent, a mutually agreeable interview time was arranged. A period of six months was allotted for recruitment and interview completion. All interviews were completed between September and October of 2014. Since CHLs were accustomed to monthly MPower meetings at the University of Tennessee Health Science Center, all interviews were conducted at the university in the Pharmaceutical Sciences building. Each interview was approximately 60 to 90 minutes in length.

\section{CRM Sample Characteristics}

All CHLs, who completed the GLB curriculum training administered by MPower $(\mathrm{N}=7)$, were included in the study population. Following the training, only five CHLs were able to implement the intervention in their respective FBO. However, all CHLs were targeted to gain insight regarding congregational differences and potential barriers to progress. Six CHLs completed the interview. One CHL could not be reached via phone or email. All recruited CHLs were African-American women between the ages of 48 to 56. All of the women were the health ministry leaders/coordinators for their respective FBO.

\section{CRM Data Collection}

In an effort to evaluate organizational readiness "key informant" semi-structured interviews were conducted in accordance with the CRM (Plested, Edwards, JumperThurman, 2006). According to the CRM guidelines, "key respondents are individuals who are knowledgeable about the community, but not necessarily a leader or decisionmaker; however, they are involved in community affairs and know what is going on" (Plested, Edwards, Jumper-Thurman, 2006, p. 31). Data collection was guided by the CRM and applicable tools provided within the model. The model contained a sample interview guide, which illustrated how the interview questions should be formatted. The interviewer was permitted to slightly tailor questions to address the health issue of interest. Additionally, questions could be added or deleted as needed; however, all CRM bolded questions were required for scoring purposes. The final interview guide consisted of a sequence of open-ended questions that were based on six dimensions of readiness; and, all questions addressed diabetes/obesity prevention and other health promotion efforts (Appendix A). The organization's ranking for each dimension was the key to 
determining community readiness. Field notes were collected as written documentation of the participants' responses, feelings, and expressions. Every interview was recorded with digital audio technology and was subsequently uploaded to a process server. Bracketing and an audit trail were used to minimize inherent bias. All data were deidentified and stored electronically.

\section{Data Analysis}

\section{Organizational Readiness Scores}

CRM data analysis began with data collection and continued throughout the 6 month data collection period. Each interview was converted to a text file via a professional transcriptionist. All transcripts were subsequently verified by the interviewer prior to the scoring process. Following the transcription of the data, the interviews were independently scored by both the researcher and an additional observer for credibility (Plested, Edwards, Jumper-Thurman, 2006). This procedure was in line with CRM guidelines that required scorers to review the data and assign numerical values independently before reconvening to determine a combined score. Upon completion of the independent scoring process, scorers met to compare results and collectively assigned a combined score for each of the six "dimensions" (Plested, Edwards, Jumper-Thurman, 2006). Scores ranging from one to nine were based on the CRM provided anchored rating scales (Appendix B) (Plested, Edwards, Jumper-Thurman, 2006). Stages of community readiness were as follows: $1=$ no awareness, $2=$ denial/resistance, $3=$ vague awareness, $4=$ pre-planning, $5=$ preparation, $6=$ initiation, $7=$ stabilization, $8=$ confirmation/expansion, 9= high level of community ownership (Plested, Edwards, Jumper-Thurman, 2006) (Appendix C).

Each interview received one of the aforementioned scores for each of the six dimensions. To determine readiness for each congregation, the combined scores were summed for each interviewee and divided by the total number of dimensions (i.e. Interview 1 score= "Dimension A + Dimension B + Dimension $\mathrm{C}+$ Dimension D+ Dimension E + Dimension F" / the total number of dimensions (6) (Plested, Edwards, Jumper-Thurman, 2006, p. 16). This process was repeated for five of the participating FBOs. These scores were used to categorize organizational readiness and were subsequently plugged into the statistical model as outlined in phase I of the analysis. The independent readiness scores were evaluated with MPower's primary outcome data to determine if organizational readiness was associated with the intervention's outcomes. Although six interviews were conducted, the score for interview 6 was not included in the statistical model because there were no data to analyze. Therefore, interview 6 was used for comparison purposes only and was discussed in the results section. 


\section{Quantitative Data Analysis}

Longitudinal evaluations monitor an experimental group for a specified period, while documenting recurring measurement differences as time progresses (Twisk \& de Vente, 2002). This process allows researchers to associate measurements with emerging patterns; furthermore, it highlights the course and breadth of contributory associations (Twisk \& de Vente, 2002). However, such data necessitates sophisticated statistical methods that appropriately account for intra-subject correlation, which could impact statistical soundness (Skup, 2010).

General linear modeling (GLM) refers to a category of contemporary techniques that can be used to evaluate different types of data. A traditional method for evaluating longitudinal data, specifically, includes analysis of variance (ANOVA) (Nakai \& Ke, 2009). The general mixed model extends traditional ANOVA analyses by including fixed and random factors. A fixed effects design accounts for individual factors that may be present within an experimental group (Charnessa, Gneezyb, \& Kuhn, 2012). Differences at the individual level are controlled through comparison of records of an entity in one state to the records of the identical entity in other states; hence, each entity functions as their own control (Lane, 2012). The model assumes that anything impacting the unobserved variable will have the same impact at each point in time (Lane, 2012). However, the fixed effects procedure will not take into account the variability between groups (Charness, Gneezyb, \& Kuhn, 2012). A random effects model assumes that observations represent a random sample and that the variance between them provides information regarding the larger population (Charness, Gneezyb, \& Kuhn, 2012).

The mixed effects model fits a variety of circumstances and permits the benefits of both fixed and random effects, thus accommodating cluster and personal variations (Krueger \& Tian, 2004). Additionally, a mixed approach permits: 1) the handling of missing data-instead of deleting a participant completely, only the missing observation is omitted, 2) post hoc analysis- provides clarity regarding mean differences 3) treatment flexibility-time can be measured as a continuous or categorical variable (Krueger \& Tian, 2004). Also, experimental units may be assessed proportionately over time or unsystematically and have various response patterns (Moser, 2004). A fundamental strength is that the model is not weakened by low participation (Moser, 2004). In the past, this was a problem; however, analysis techniques have evolved significantly with time, allowing for the use of all collected data despite omitted measurements (Deeg, 2002; Twisk \& De Vente, 2002). Additionally, this design can be applied to longstanding or short-range experiments (Deeg, 2002).

When employing the mixed effects models, both the fixed and the random effects contribute linearly to the response function (Equation 3-1):

$$
\mathrm{y}=\mathrm{X} \beta+\mathrm{Z} \gamma+\varepsilon \quad \text { (Eq. 3-1) }
$$

$\mathrm{y}$ is the $\mathrm{n} \times 1$ vector of observations, $\beta$ is a $\mathrm{p} \times 1$ vector of fixed effects, $\gamma$ is a $\mathrm{q} \times 1$ vector of random effects, $\varepsilon$ is a $n \times 1$ vector of random error terms, $X$ is the $n \times p$ design matrix 
for the fixed effects relating observations $\mathrm{y}$ to $\beta, \mathrm{Z}$ is the $\mathrm{n} \mathrm{x}$ q design matrix for the random effects relating observations y to $\gamma$ (Isik, 2011).

This analysis employed general linear mixed modeling (using PROC MIXED from SAS/STAT software) to evaluate associations while controlling for covariates. The principal analysis evaluated the relationship between organizational readiness scores and MPower's primary outcomes. Primary outcome measures included weight loss and physical activity. The organizational readiness scores were obtained from the qualitative analysis and were discussed in further detail in phase II of the study methods. Pedometer steps were converted to physical activity minutes using an estimation provided in the GLB curriculum. The curriculum specifies that 2,000 steps are equivalent to one mile; and a mile is equivalent to 15 to 20 minutes. This conversion ( 1 mile $=20$ minutes) was only used when participants reported pedometer steps instead of physical activity minutes. The model covariates included: age category, history of gestational diabetes, hypertension status, family history of diabetes, gender, active lifestyle, baseline weight, ADA risk score, intervention session attendance, and self-monitoring. Post hoc analysis was computed by including the LSMEANS statement in SAS. This analysis is typically conducted after the statistical analysis and reveals any subgroup patterns that may have been undetectable. In this study, congregations were nested within organizational readiness categories. The post hoc analysis was used to evaluate mean differences among groups within the same OR category. Additionally, the statistical model typically compares each group against the model selected reference group. The post hoc analysis allows for every possible pairwise comparison. All data were evaluated using SAS/STAT software, version 9.2 (SAS Institute Inc., 2002-2008). SAS and all other SAS Institute Inc. product or service names are registered trademarks of SAS Institute Inc., Cary, NC, USA.

\section{Qualitative Data Analysis}

The qualitative data were analyzed to determine similarities and differences in interview responses. To prepare for data analysis, all transcripts were reviewed for accuracy following the transcription process. Interview transcripts were re-examined, along with field notes, to identify initial patterns within the data. After documenting initial patterns, transcripts were compared to highlight similarities and differences in responses. The data were revaluated to develop emerging themes. Additionally, data were examined to find any additional information relating to each theme and to determine if any themes were missed initially. The themes were then sorted into categories, which were based on the CRM's six dimensions of readiness. All information was examined to determine the final write-up for each theme. Themes were reported by dimension. 


\section{CHAPTER 4. RESULTS}

\section{Sample Characteristics}

Fifty-six individuals were initially enrolled in MPower. One individual was excluded due to missing baseline data. Since the MPower Project targeted AfricanAmerican FBOs specifically, the study population only included Blacks $(\mathrm{N}=55)$. Approximately $91 \%$ of the sample was comprised of women. Most participants were over 49 years of age $(60 \%)$. Sixty-nine percent reported a family history of diabetes, while $7 \%$ experienced gestational diabetes. Roughly $53 \%$ of individuals had high blood pressure. Forty-seven percent reported that they were physically active. Eighty-four percent of individuals scored 5 or more points on the ADA risk test, which determined if they were at risk for developing diabetes. The mean baseline weight for the sample was 204.8 pounds. Average physical activity minutes were 105 minutes at baseline (Table 4 -1).

At the end of the 10 week core period, $11.6 \%$ of the sample achieved $2-4 \%$ weight loss. Approximately $2 \%$ of the sample achieved the $5 \%$ weight loss goal. Twentytwo percent of the sample achieved the weight loss goal of $5 \%$ or more by the end of the maintenance period. At the end of both the core (10 weeks) and maintenance (12-months) periods, $\sim 66 \%$ of the sample met or exceeded 150 minutes of physical activity per week (self-reported by the participants) (Table 4-2).

\section{Organizational Readiness Scores}

Each FBO was assigned a numerical OR score, which was subsequently used to statistically estimate the associations of organizational readiness. OR scores were computed from the qualitative interview data utilizing anchored rating scales and were a response to research question 1 (What was the level of organizational readiness amongst MPower's participating FBOs?). Scores varied between churches, ranging from four to seven. One congregation had an OR score of $4(\sim 12.4 \%)$. Three congregations had an OR score of $5(\sim 69.7 \%)$, while one had an OR score of $7(\sim 17.9 \%)$. (Table 4-3).

Faith-based organizations with an OR score of four were in the "pre-planning" stage of readiness (Plested, Edwards, Jumper-Thurman, 2006). According to the CRM, a score of four means "there is clear recognition that something must be done, and there may even be a group addressing it; however, efforts are not focused or detailed" (Plested, Edwards, Jumper-Thurman, 2006, p. 9). An OR score of 5 suggested that they were in the "preparation" stage (Plested, Edwards, Jumper-Thurman, 2006). This stage suggests that there are "active leaders" who have initiated "planning in earnest," with "modest support" from the community they intend to serve (Plested, Edwards, Jumper-Thurman, 2006, p. 9). The organization with the highest OR score of 7 was in the "stabilization" stage, which indicated that their initiatives were more coordinated and were fully supported by key individuals, including "administrators or community decision makers" (Plested, Edwards, Jumper-Thurman, 2006, p. 9). In order to evaluate the association 
Table 4-1. Sample characteristics $(\mathrm{N}=55)$

\begin{tabular}{lc}
\hline Variables & N (\%) \\
\hline Gender & \\
Female & $50(90.9)$ \\
Male & $5(9.1)$ \\
Age & \\
$<40$ & $5(9.1)$ \\
$40-49$ & $16(29.1)$ \\
$50-59$ & $17(30.1)$ \\
$>60$ & $17(30.1)$ \\
HGD (yes vs. no) & $4(7.2)$ \\
Physically active (yes vs. no) & $26(47.3)$ \\
High blood pressure (yes vs. no) & $29(52.7)$ \\
FHD (yes vs. no) & $38(69.1)$ \\
Risk test score & \\
Less than 5 & $9(16.4)$ \\
$>5$ & $46(83.6)$ \\
Baseline weight (mean/SD) & $204.8(51.8)$ \\
Baseline PA (mean/SD) & $105(65.6)$ \\
\hline
\end{tabular}

Fifty-six people were initially enrolled in the study.

Baseline data was missing for 1 participant.

Baseline Characteristics were obtained from the ADA Risk Test Assessment.

Risk test scores ranged from 1 to 9.

$\mathrm{FHD}=$ Family history of diabetes.

$\mathrm{HGD}=$ History of gestational diabetes

$\mathrm{PA}=$ Physical activity minutes 
Table 4-2. Comparison of weight and physical activity measures

\begin{tabular}{lcc}
\hline Outcomes & Core & Maintenance \\
\hline Weight loss (\%) & $(\mathrm{n}=43)$ & $(\mathrm{n}=36)$ \\
$2-3 \%$ & 11.6 & 13.9 \\
$4 \%$ & 11.6 & 11.1 \\
$>5 \%$ & 2.3 & 22.2 \\
Physical activity $(\%)$ & $(\mathrm{n}=29)$ & $(\mathrm{n}=24)$ \\
$<150$ minutes & 34.4 & 34.4 \\
$>150$ minutes & 65.6 & 65.6 \\
\hline
\end{tabular}

Weight loss results represent the percent change in weight from baseline to the final core (week 10) and maintenance (month 6) measurements.

Table 4-3. Organizational readiness by congregation

\begin{tabular}{lcccc}
\hline Congregations & $\begin{array}{c}\text { Sample size } \\
(\mathbf{n} \%)\end{array}$ & $\begin{array}{c}\text { Organizational } \\
\text { readiness } \\
\text { scores }\end{array}$ & $\begin{array}{c}\text { Baseline } \\
\text { weight M(SD) }\end{array}$ & $\begin{array}{c}\text { Baseline PA } \\
\text { M(SD) }\end{array}$ \\
\hline 1 & $15(26.8)$ & 5 & $194.2(30.7)$ & $91.7(42.7)$ \\
2 & $16(28.6)$ & 5 & $227.9(60.4)$ & $\ldots \ldots \ldots$. \\
3 & $8(14.3)$ & 5 & $149.7(24.3)$ & $\ldots \ldots \ldots .$. \\
4 & $10(17.9)$ & 7 & $176.7(16.6)$ & $\ldots \ldots \ldots$. \\
5 & $7(12.4)$ & 4 & $230.1(55.6)$ & $126(102.1)$ \\
\hline
\end{tabular}

Congregations 2 and 3 did not report any baseline PA measurements. In congregation 4, only one person reported a baseline PA measurement (120). The abbreviation PA refers to physical activity, which was reported in minutes. Weight was reported in pounds. 
between OR score and weight and physical activity, the analysis was completed using separate statistical models. Model 1 evaluated the association between OR score and core (weekly) weight measurements. Model 2 evaluated the association between OR score and maintenance (monthly) weight measurements. Model 3 evaluated the association between OR score and core physical activity measurements. Model 4 evaluated the association between OR score and maintenance weight measurements.

\section{Mixed Model Analysis Outcomes}

\section{Weight Loss Measurements}

Model 1 depicted the association between core weights (weekly) and OR score, including covariates $(n=42)$. The mean effect of time was negative and significant and demonstrated the general direction of weight across all people. As time progressed, weight decreased by 0.787 ( $\mathrm{p}=0.0006)$. An interaction term was tested to evaluate how congregations changed over time. Congregation $1(0.670, p=0.011)$ and $2(0.970$, $\mathrm{p}=0.0002$ ) had higher rates of change when compared with congregation 5. Baseline weight was highly correlated with trends in weight over the core period $(0.996, p<.0001)$. There was also a positive relationship between weight and physical activity. For every unit increase in self-reported physical activity, weight increased by $0.005(\mathrm{p}=0.044)$. The average weight for congregations with an OR score of 5 was higher than the weight for those with an OR score of $7(2.532, \mathrm{p}=0.048)$. There were no statistically significant changes in weight across any of the other covariates (Table 4-4). Post hoc analysis revealed significant mean differences in weight between congregations. The mean weight for congregation 1 was higher than the mean weight for congregations 4 $($ difference $=3.452, p=0.016)$ and $5($ difference $=4.646, p=0.0005)$. Congregation 2 had a significantly higher mean weight compared to both congregations 4 (difference $=5.264$, $\mathrm{p}<0.0006)$ and $5($ difference $=6.457, \mathrm{p}<0.0001)($ Table 4-5).

Model 2 depicted the relationship between maintenance weight (monthly) and OR score, including covariates $(n=40)$. There were statistically significant increases in weight among those who had a history of gestational diabetes $(7.982, \mathrm{p}<0.0001)$ and a family history of diabetes $(3.485, \mathrm{p}=0.036)$. Baseline weight was highly correlated with the trends in weight over the maintenance period $(1.018, \mathrm{p}<.0001)$. Those who selfmonitored their diet had a significant reduction in weight compared with those who did not self-monitor $(-0.911, \mathrm{p}=0.001)$. An interaction term, testing the change in physical activity between congregations over time, was significantly lower among those in congregation 3 when compared with congregation $5(-553.08, \mathrm{p}=0.014)$. Group(s) with an OR score of $5(6.093, \mathrm{p}=0.0018)$ gained weight compared to those with an OR score of 7. There were no statistically significant changes in weight across any other covariates (Table 4-6). Post hoc analyses revealed significant mean differences between congregation 1 and congregations 4 (difference $=7.896, p=0.001)$ and 5 (difference $=$ 10.708, $\mathrm{p}=0.003)($ Table 4-7). 
Table 4-4. Mixed model estimates for core weight measurements $(\mathrm{N}=42)$

\begin{tabular}{lccc}
\hline Variables & Estimate & Standard error & P-value \\
\hline $\begin{array}{l}\text { Time } \\
\text { Gender } \\
\text { (male vs. female) }\end{array}$ & -0.787 & 0.209 & 0.0006 \\
$\begin{array}{l}\text { Age } \\
\text { Active lifestyle }\end{array}$ & -0.809 & 1.438 & 0.575 \\
HGD (yes vs. no) & -0.696 & 0.904 & 0.443 \\
PA & -1.571 & 1.057 & 0.140 \\
$\begin{array}{l}\text { Hypertension } \\
\text { (yes vs. no) }\end{array}$ & 2.308 & 1.863 & 0.218 \\
$\begin{array}{l}\text { FHD (yes vs. no) } \\
\text { Risk test score }\end{array}$ & 0.006 & 0.003 & 0.044 \\
$\begin{array}{l}\text { Baseline weight } \\
\text { (pounds) }\end{array}$ & -0.771 & 0.807 & 0.341 \\
$\begin{array}{l}\text { Self-monitored } \\
\text { (yes vs. no) }\end{array}$ & -0.1706 & 1.017 & 0.620 \\
$\begin{array}{l}\text { Intervention } \\
\text { (yes vs. no) }\end{array}$ & 0.996 & 0.678 & 0.794 \\
$\begin{array}{l}\text { OR score } \\
\text { 4 vs. 7 }\end{array}$ & -0.025 & 0.011 & $<0.0001$ \\
$\begin{array}{l}\text { 5 vs. 7 } \\
\text { Baseline weight } \\
\text { (pounds) }\end{array}$ & 0.099 & 0.236 & 0.915 \\
$\begin{array}{l}\text { Time by congregation } \\
\text { Slope change in time } \\
\text { comparing 1 vs. 5 }\end{array}$ & 0.671 & 0.191 & 0.606 \\
$\begin{array}{l}\text { Slope change in time } \\
\text { comparing 2 vs. 5 }\end{array}$ & 0.970 & 1.393 & 0.232 \\
$\begin{array}{l}\text { Slope change in time } \\
\text { comparing 3 vs. 5 }\end{array}$ & 0.540 & 1.270 & 0.048 \\
$\begin{array}{l}\text { Slope change in time } \\
\text { comparing 4 vs. 5 }\end{array}$ & 0.564 & 0.011 & $<0.0001$ \\
\hline
\end{tabular}

Parameters were tested at the alpha level of 0.05 . PA=physical activity minutes. FHD $=$ family history of diabetes. Variance component $=0.143(\mathrm{p}=0.0004)$. It shows the random effects of weight with time. 
Table 4-5. Comparison of core weight between congregations

\begin{tabular}{lccc}
\hline Congregations & Mean differences & Standard error & P-value \\
\hline 1 vs. 2 & -1.811 & 1.224 & 0.141 \\
1 vs. 4 & 3.452 & 1.418 & 0.016 \\
1 vs. 5 & 4.646 & 1.293 & 0.0005 \\
2 vs. 4 & 5.264 & 1.487 & 0.0006 \\
2 vs. 5 & 6.457 & 1.325 & $<0.0001$ \\
4 vs. 5 & 1.194 & 1.543 & 0.441 \\
\hline
\end{tabular}

This table reflects the results of the post-hoc analysis from the mixed model. Mean differences were tested at the alpha level of 0.05 .

Table 4-6. Mixed model estimates for maintenance weight measurements $(\mathrm{N}=40)$

\begin{tabular}{lccc}
\hline Variables & Estimate & Standard error & P-value \\
\hline Time & -0.052 & 0.263 & 0.844 \\
$\begin{array}{l}\text { Gender } \\
\text { (male vs. female) }\end{array}$ & -2.295 & 2.750 & 0.405 \\
$\begin{array}{l}\text { Age } \\
\text { Active Lifestyle }\end{array}$ & 1.414 & 1.201 & 0.241 \\
(yes vs. no) & -1.049 & 1.570 & 0.505 \\
HDG (yes vs. no) & 7.981 & 1.821 & $<0.0001$ \\
PA & 0.001 & 0.001 & 0.099 \\
Hypertension & -0.840 & 1.418 & 0.555 \\
$\begin{array}{l}\text { (yes vs. no) } \\
\text { FHD (yes vs. no) }\end{array}$ & 3.484 & 1.645 & 0.036 \\
$\begin{array}{l}\text { Risk test score } \\
\text { Baseline weight }\end{array}$ & -2.607 & 1.020 & 0.012 \\
(pounds) & 1.018 & 0.015 & $<0.0001$ \\
$\begin{array}{l}\text { Self-monitored } \\
\text { (yes vs. no) }\end{array}$ & -0.911 & 0.273 & 0.001 \\
$\begin{array}{l}\text { Intervention } \\
\text { (yes vs. no) }\end{array}$ & 0.140 & 0.409 & 0.733 \\
$\begin{array}{l}\text { OR score } \\
\text { 4 vs. 7 }\end{array}$ & & & \\
5 vs. 7 & -2.399 & 2.396 & 0.318 \\
\hline
\end{tabular}

Parameters were tested at the alpha level of 0.05 . PA=Physical activity minutes. FHD $=$ Family history of diabetes. HGD $=$ History of gestational diabetes. Variance component $=1.902(\mathrm{p}=0.0001)$. It shows the random effects of weight with time. 
Table 4-7. Comparison of maintenance weight between congregations

\begin{tabular}{lccc}
\hline Congregations & Mean differences & Standard error & P-value \\
\hline 1 vs. 2 & 9.054 & 6.278 & 0.152 \\
1 vs. 3 & 6.466 & 6.879 & 0.349 \\
1 vs. 4 & 7.896 & 2.342 & 0.001 \\
1 vs. 5 & 10.708 & 2.888 & 0.0003 \\
2 vs. 3 & -2.588 & 7.073 & 0.715 \\
2 vs. 4 & -1.157 & 5.659 & 0.838 \\
2 vs. 5 & 1.654 & 5.918 & 0.780 \\
3 vs. 4 & 1.431 & 6.001 & 0.812 \\
3 vs. 5 & 4.243 & 4.808 & 0.379 \\
4 vs. 5 & 2.812 & 2.709 & 0.301 \\
\hline
\end{tabular}

The mean differences are a result of the post hoc analysis from the mixed model. Mean differences were tested at the alpha level of 0.05 . 
In response to research question 2, organizational readiness was associated with weight loss in this population, but only for certain groups. Hypothesis 2 , which stated that FBOs would have divergent weight loss patterns over time, depending on their organizational readiness level, was not fully supported.

\section{Physical Activity Measurements}

Model 3 depicted activity minutes measured from baseline to the final core measurement, including covariates $(n=47)$. Those with a family history of diabetes reported more physical activity minutes $(57.528, \mathrm{p}=0.052)$. The mean activity level of group(s) with an OR score of 4 and 5 were 166.02 minutes $(\mathrm{p}<0.0001)$ and 177.33 minutes $(\mathrm{p}<0.001)$ lower, respectively, than the group with an OR score of 7 (Table 4-8). Post hoc analysis revealed significant mean differences in physical activity minutes for congregation 1 compared with congregations 2 (difference $=-91.698, p=0.011)$, and $4($ difference $=-203.90, \mathrm{p}<0.0001)$. There were also significant mean differences between congregations 2 versus 4 (difference $=-112.20, p=0.010$ ) and 4 versus 5 (difference $=$ 155.18, $\mathrm{p}<.0006)$ (Table 4-9).

Model 4 depicted physical activity levels during the maintenance period, including all covariates $(n=44)$. There were significant differences in physical activity minutes with age $(305.11, \mathrm{p}=0.028)$. Also, there was a positive relationship between physical activity and a self-reported active lifestyle (358.83, $\mathrm{p}=0.005)$. Hypertension (468.91, $\mathrm{p}<0.0001)$, family history of diabetes $(255.97, \mathrm{p}=0.044)$, risk level $(-162.93$, $\mathrm{p}=0.054)$ and self-monitoring $(-163.65, \mathrm{p}<0.0001)$ were also significant in the model. There were also statistically significant differences in physical activity by OR category. Physical activity minutes among group(s) with an OR score of $4(-1284.21, \mathrm{p}<0.0001)$ and $5(-933.21, \mathrm{p}<0.0001)$ were lower than those with a score of 7 (Table4-10). The post hoc analysis revealed significant mean differences between congregations 2 (difference= $-2191.82, \mathrm{p}<0.0001$ ), and 4 (difference $=-1631.77, \mathrm{p}<0.0001$ ) when compared with congregation 1 . There were also significant mean differences in physical activity between congregations 2 versus 3 (difference $=2557.60, \mathrm{p}=0.0009)$ and $5($ difference $=1602.11$, $\mathrm{p}<0.001), 3$ versus 4 (difference $=-1997.55, \mathrm{p}=0.007$ ) and 4 versus 5 (difference $=1042.06, \mathrm{p}<0.001)($ Table 4-11).

In response to research question 3, organizational readiness score was associated with physical activity. Hypothesis 2, which stated that FBOs would have divergent physical activity patterns over time, depending on their organizational readiness level, was supported. Therefore, researchers must reject the null hypothesis in favor of the alternative, which assumes an effect of OR score on physical activity.

\section{Qualitative Evaluation}

Key informant interviews were used to assess attributes that would potentially be associated with success in the MPower Program. CHLs were selected to provide key 
Table 4-8. Mixed model estimates for core physical activity measurements $(\mathrm{N}=47)$

\begin{tabular}{lccc}
\hline Variables & Estimate & Standard error & P-value \\
\hline Time & 4.097 & 2.677 & 0.134 \\
$\begin{array}{l}\text { Gender } \\
\text { (male vs. female) }\end{array}$ & 29.411 & 42.791 & 0.493 \\
Age & & & \\
Active lifestyle & 35.169 & 26.731 & 0.191 \\
(yes vs. no) & 57.018 & 31.419 & 0.072 \\
HGD (yes vs. no) & 32.821 & 56.078 & 0.559 \\
Weight & 0.298 & 0.327 & 0.363 \\
Hypertension & 7.290 & 23.489 & 0.757 \\
(yes vs. no) & & & \\
FHD (yes vs. no)) & 57.528 & 29.349 & 0.052 \\
Risk test score & 4.527 & 19.958 & 0.821 \\
Self-monitored & -5.270 & 5.962 & 0.378 \\
(yes vs. no) & & & \\
Intervention & -1.465 & 5.347 & 0.785 \\
(yes vs. no) & & & \\
$\begin{array}{l}\text { OR Score } \\
\text { 4 vs. 7 }\end{array}$ & & 32.679 & $<0.0001$ \\
5 vs. 7 & -166.02 & 28.726 & $<0.0001$ \\
\hline
\end{tabular}

Parameters were tested at the alpha level of 0.05 . FHD $=$ Family history of diabetes. $\mathrm{HGD}=$ History of gestational diabetes. Intervention $=$ attended the educational group session. Variance component $=153.97(\mathrm{p}=0.0008)$. It shows the random effects of weight with time. 
Table 4-9. Comparison of core physical activity between congregations

\begin{tabular}{lccc}
\hline Congregations & Mean differences & Standard error & P-value \\
\hline 1 vs. 2 & -91.698 & 35.726 & 0.011 \\
1 vs. 4 & -203.90 & 38.822 & $<.0001$ \\
1 vs. 5 & -48.720 & 38.239 & 0.205 \\
2 vs. 4 & -112.20 & 43.140 & 0.010 \\
2 vs. 5 & 42.978 & 39.310 & 0.276 \\
4 vs. 5 & 155.18 & 44.194 & 0.0006 \\
\hline
\end{tabular}

This table reflects the results of the post hoc analysis from the mixed model. Mean differences were tested at the alpha level of 0.05 .

Table 4-10. Mixed model estimates for maintenance physical activity $(\mathrm{N}=44)$

\begin{tabular}{lccc}
\hline Variables & Estimate & Standard error & P-value \\
\hline Time & 5.408 & 76.018 & 0.944 \\
$\begin{array}{l}\text { Gender } \\
\text { (male vs. female) }\end{array}$ & 117.93 & 247.17 & 0.634 \\
$\begin{array}{l}\text { Age } \\
\text { Active lifestyle }\end{array}$ & 305.11 & 100.35 & 0.0028 \\
(yes vs. no) & 358.83 & 124.73 & 0.005 \\
HGD (yes vs. no) & 98.220 & 153.92 & 0.524 \\
Weight & -1.322 & 1.338 & 0.325 \\
Hypertension & 468.91 & 114.64 & $<0.0001$ \\
$\begin{array}{l}\text { (yes vs. no) } \\
\text { FHD (yes vs. no) }\end{array}$ & 255.97 & 126.52 & 0.045 \\
Risk test score & -162.93 & 83.727 & 0.054 \\
$\begin{array}{l}\text { Self-monitored } \\
\text { (yes vs. no) }\end{array}$ & -163.65 & 22.112 & $<0.0001$ \\
Intervention & & & \\
(yes vs. no) & 3.755 & 47.767 & 0.938 \\
$\begin{array}{l}\text { OR Score } \\
\text { 4 vs. 7 }\end{array}$ & & & \\
5 vs. 7 & -1284.21 & 219.07 & $<0.0001$ \\
\hline
\end{tabular}

Parameters were tested at the alpha level of 0.05 . FHD $=$ Family history of diabetes. $\mathrm{HGD}=$ History of gestational diabetes. Intervention $=$ attended the educational group session. Variance component $=1468(\mathrm{p}<.0001)$. It shows the random effects of weight with time. 
Table 4-11. Comparison of maintenance physical activity between congregations

\begin{tabular}{lccc}
\hline Congregations & Mean Differences & Standard Error & P-value \\
\hline 1 vs. 2 & -2191.82 & 508.80 & $<0.0001$ \\
1 vs. 3 & 365.78 & 771.21 & 0.636 \\
1 vs. 4 & -1631.77 & 244.79 & $<0.0001$ \\
1 vs. 5 & -589.72 & 333.48 & 0.079 \\
2 vs. 3 & 2557.60 & 751.88 & 0.0009 \\
2 vs. 4 & 560.05 & 481.29 & 0.246 \\
2 vs. 5 & 1602.11 & 484.67 & 0.0012 \\
3 vs. 4 & -1997.55 & 723.35 & 0.007 \\
3 vs. 5 & -955.49 & 670.41 & 0.156 \\
4 vs. 5 & 1042.06 & 309.33 & 0.001 \\
\hline
\end{tabular}

This table reflects the results of the post hoc analysis from the mixed model. Mean differences were tested at the alpha level of 0.05 . 
information about their FBO. All CHLs, who completed the MPower training, were selected for participation. Although seven CHLs completed the MPower training, only six CHLs responded to interview requests. Only five of the CHLs were able to implement the MPower intervention. Data obtained from the sixth CHL will be discussed in the negative case section of this chapter. The interviews addressed six dimensions of readiness: community efforts, community knowledge of the efforts, leadership, community climate, community knowledge about the issue, and resources related to the issue. All of these dimensions were evaluated independently before determining final OR scores. The following explanation answers research question 1a (How were congregations similar or dissimilar regarding dimensions of readiness?)

\section{Community Efforts}

To initiate conversation, CHLs were asked to rate the importance of health related issues in their respective organizations using the following question: using a scale from 1 to 10 , how important are health related issues in your church, with 1 being not at all and 10 being a very great concern. The following themes emerged:

Theme 1: There was a high level of concern regarding public health issues. Most of the CHLs believed there was a pretty high sense of awareness regarding their organization's concern for health initiatives, with ratings ranging from 8-10:

"10 is my answer and obesity and health goes together and we do believe in prevention. If you practice prevention in any kind of health related issue whether it's obesity or disease --- obesity is a disease, I think you'll be healthier in the long run and because it takes a while for things to develop. Prevention is the key. That's what we believe." [CHL 4]

Theme 2: Translating knowledge into action was challenging. Only one CHL provided a modest rating of 6 , and provided the following explanation:

"I guess I said 6 because I think the overall awareness and the message is getting out regarding disease prevention, obesity, and diabetes. So many of that plagues the black community but when it comes to, I guess, following the principles, we still want to indulge in our cultural foods, if you will; they know better but to put into action is another challenge." [CHL 1]

Theme 3: FBOs were engaged in health promotion initiatives prior to MPower. In house community efforts identified by the interviewees primarily included: church sponsored health fairs, information displays, raising awareness, blood pressure screenings, and run/walk events (Table 4-12). Organizations also engaged in health promotion activities sponsored by MHC. Most of the initiatives had been ongoing for several years and were initiated in-house. CHLs were asked to specifically identify health initiatives that occurred prior to, during, and after MPower. Prior to MPower, all church's had an established health ministry, raised awareness, and/or participated with MHC. 
Table 4-12. Health promotion efforts reported by key informants $(\mathrm{N}=5)$

\begin{tabular}{|c|c|c|c|}
\hline Initiatives & Type & $\begin{array}{l}\text { Participating } \\
\text { churches }\end{array}$ & Description \\
\hline Raised awareness & Church based & $1,2,3,4,5$ & $\begin{array}{l}\text { Offers pamphlets, } \\
\text { brochures, and other health } \\
\text { information via the church } \\
\text { bulletin, announcements, } \\
\text { and/or information tables } \\
\text { displayed in the church } \\
\text { lobby. }\end{array}$ \\
\hline Education/training & Community based & 3,5 & $\begin{array}{l}\text { Health leaders attended } \\
\text { health education training } \\
\text { courses through Memphis } \\
\text { Healthy Churches (MHC). } \\
\text { The information was used to } \\
\text { inform the congregation. }\end{array}$ \\
\hline $\begin{array}{l}\text { Weight loss } \\
\text { challenge }\end{array}$ & Community based & $1,3,4,5$ & $\begin{array}{l}\text { This was a 100-day } \\
\text { challenge sponsored by } \\
\text { MHC, which targeted } \\
\text { weight loss, diabetes } \\
\text { education, and healthy } \\
\text { eating. }\end{array}$ \\
\hline Health fair & Church based & $1,2,3,4,5$ & $\begin{array}{l}\text { This includes health fairs } \\
\text { which took place annually } \\
\text { or semi- annually. }\end{array}$ \\
\hline $\begin{array}{l}\text { Blood pressure } \\
\text { screenings }\end{array}$ & Church based & $1,2,4,5$ & $\begin{array}{l}\text { They were conducted at the } \\
\text { health fairs and/or on a } \\
\text { monthly basis. Also, upon } \\
\text { request, congregants could } \\
\text { receive a blood pressure } \\
\text { screening from the health } \\
\text { ministry team. }\end{array}$ \\
\hline Run/walk events & Community based & $1,2,4,5$ & $\begin{array}{l}\text { These included events } \\
\text { coordinated through various } \\
\text { organizations such as: breast } \\
\text { cancer society, American } \\
\text { Heart Association etc. }\end{array}$ \\
\hline Fitness classes & Church based & 1,4 & $\begin{array}{l}\text { These include } \\
\text { classes/workouts that are } \\
\text { coordinated and performed } \\
\text { through an on- site fitness } \\
\text { center. }\end{array}$ \\
\hline
\end{tabular}


Table 4-12. (Continued)

\begin{tabular}{|c|c|c|c|}
\hline Initiatives & Type & $\begin{array}{c}\text { Participating } \\
\text { churches }\end{array}$ & Description \\
\hline $\begin{array}{l}\text { Food } \\
\text { demonstrations }\end{array}$ & Church based & 1,4 & $\begin{array}{l}\text { Live cooking } \\
\text { demonstrations used to } \\
\text { inform people regarding } \\
\text { healthier cooking options. } \\
\text { Individuals review the } \\
\text { cooking process and sample } \\
\text { the finished product. }\end{array}$ \\
\hline Community garden & Church based & 4 & $\begin{array}{l}\text { Initiative that encourages } \\
\text { people to consume more } \\
\text { organic produce by growing } \\
\text { their own food. }\end{array}$ \\
\hline Junk food policy & Church based & 4 & $\begin{array}{l}\text { A pastoral approved policy } \\
\text { that limits unhealthy eating } \\
\text { patterns and has been } \\
\text { implemented and accepted } \\
\text { by congregants. }\end{array}$ \\
\hline
\end{tabular}


Some of them had ongoing fitness classes coordinated through the church's gym while others had no specific plan for fitness activities. Aside from participating in MHC events, there were no concurrent health promotion projects. Only one organization implemented a summer weight loss challenge following the MPower Program, which was based on an outside initiative that expired.

"Also, prior to M challenge, we participated in the Blue Cross/Blue Shield. We just try to increase our exercise, eat healthier, learn healthier eating, cooking techniques, and weigh in. We had to go there to weigh in at a different site. They would tell us which site to weigh in monthly. We had to go in and weigh in every month. Prior to us meeting them for weigh-ins, we would weigh in at our church once a week. Just get us ready for the big weigh-in." [CHL 1]

"The past few years, we were involved in a weight loss challenge which was really sponsored by Blue Cross/Blue Shield. They didn't do it this year. Since they did not sponsor it, we, as a church, did a weight loss challenge. We sent an e-mail to the people in other churches we knew who possibly would participate also and asked for people outside church to participate with us." [CHL 4]

Theme 4: Novel initiatives have been developed by FBOs as part of their inhouse health promotion efforts. The garden ministry concept was a novel initiative that was implemented to motivate congregants to make healthier food choices:

"The garden started when I started thinking about all the chemicals in the food that you buy in the grocery store, and we are trying to find a way to encourage people to be involved actively in their own health and be healthy at the same time and we are pushing organic food and for people to grow their own food and to point out all the things that go into the vegetables like the pesticides, all the chemicals that we don't need in our body. From that, a garden started. It's a lot of work but we are going to push it and encourage people to do their own." [CHL 4]

\section{Community Awareness of Efforts}

Most CHLs reported a high level of awareness regarding health promotion efforts. Using a scale from 1 to 10, CHLs were asked to rate their congregation's awareness about health initiatives occurring in their church, with 1 being no awareness and 10 being very aware. The following themes emerged:

Theme 1: There was a high sense of awareness. The majority of CHLs rated awareness at 8 or 10 . The CHLs generally felt that information regarding initiatives was disseminated well.

"I guess about an 8. They're aware --- whether or not they are compliant remains to be seen, but a lot of them have gotten better. They've shown some 
improvement, they have gone from not participating to participating, and being conscious---- whatever they're eating and their activity levels, and try to maintain the weight that they lost on the program." [CHL 2]

Theme 2: Awareness was motivated by health concerns. One CHL gave a modest rating of 5and suggested that awareness was based upon personal need of the congregant or a family member.

"When they have questions about something, I get phone calls but, like I said, the interest is not there a lot of time unless it's personally --- my family or somebody I'm close to." [CHL 5]

Theme 3: Program execution limitations were present. Primary obstacles to implementation of health initiatives, including MPower, varied. Reported barriers included the: age of the congregation, competing activities, time frame of the initiative, recognizing the issue and appropriate problem solving, motivation and cost of healthy food options.

"Lack of participation from the congregation, either it's not a priority health or they may have an attitude that I have a doctor and I don't need to hear anything else from you." [CHL 1]

"There were other events going on, church events. Some churches like our church, our pastor require us to be in certain events. He requires our attendance. That's why I think it's really important for alternate people, so other people are able to fill in. So, I'm going to say time, church events, and holidays." [CHL 3]

"The people who might be interested a lot of them are ... my older congregants are interested but for them a lot of times is a matter of getting out especially if you're talking about at night. The younger people ... the kids' activities tend to be their priority." [CHL 5]

Theme 4: Health promotion initiatives were beneficial. CHLs believed that initiatives improved the health of congregants. Specifically, they discussed the benefits of blood pressure screenings.

"It has helped a lot of people who had blood pressure issues, getting it little bit more controlled, helped some of them come off some medications." [CHL 2]

"Some people are doing better, health-wise. One member had a bad habit of not taking their blood pressure medicine and now they'll tell me "I took my blood pressure medicine."[CHL 5] 


\section{Leadership}

All of the CHLs were the health ministry directors in their respective organizations, which meant they were the leaders who specifically addressed health related issues within the congregation. However, all coordinated initiatives were based on pastoral approval. The following themes emerged:

Theme 1: Perceptions regarding pastoral support were positive. All of the CHLs believed that their pastor was very supportive of health promotion. Using a scale from 1 to 10 , CHLs were asked to rate the importance of obesity/health related issues to the leadership in their church and to explain their answer. All of them gave a fairly high rating, ranging from 8 to 10 . CHLs explained that pastoral support was high because: it was in line with the church's mission, the pastor was motivated by personal health concerns, or certain health issues could be a catalyst for other issues.

"I think he's aware and supports preventive health, and it would just go hand-inhand with his mission and our mission is a healthier congregation to spread the good news." [CHL 1]

"He stresses healthy habits, healthy eating and he tries to incorporate that in his lifestyle. You know, leads by an example. Usually, if he mentions it behind the pulpit, people will buy into." [CHL 2]

"It's very important because obesity brings on other diseases and we do believe some things we read. For instance, obesity could cause some cancer or heart disease. Those diseases are fatal. It's very important that we live and not die." [CHL 4]

Theme 2: Pastoral support for future initiatives was promising. Additionally, they all believed that the pastoral leader of their organization would be supportive of additional health initiatives similar to MPower.

"Sure. My pastor likes anything dealing with health that's going to help the church spiritually and physically." [CHL 3]

"Yeah, the pastor would be very pleased with new initiatives because we all about people living and not dying. A lot of times we are in control of our own health. We just have to encourage people to do that --- to be in control actually. Take that initiative. So, if we come up with an initiative that's reasonable, I think they would be very appreciative." [CHL 4]

Theme 3: Pastoral participation in health initiatives varied by organization. Despite their belief in their pastor's support, they reported varying degrees of pastoral backing during MPower. While some elected to encourage the congregation through participation in the MPower Program, others mentioned it from the pulpit directly or approved announcement(s) during Sunday worship. 
"He was one of the participants so when it was time for them to weigh in or listen to the teaching, he was part of it. He and his wife." [CHL 2]

'No, he didn't but someone talked about it from the pulpit. The person making the announcements talked about it and I think I may have mentioned it a few times from the pulpit." [CHL 4]

Theme 4: Initiation of health initiatives required support from organizational members. Aside from leadership, support from members of the body could have been improved. Although the size of each FBO varied, the health ministry was comprised of a small team. The smaller congregations, with membership ranging from 60 to 100 , had no more than three health ministry members. The larger churches, with 250-3,500 members, had an average of 7 members. One CHL noted that their organization lacked the additional support needed from the congregation to implement health promotion objectives.

"It seems like we always need more people to help, more volunteers. We do quite a bit at church but we do need to get more people to volunteer for our health related events because it is a lot involved and we do have a small number of people when you look at the whole church. We only have a small number of people who participate, or actively consistent. If we have more people pushing health and pushing eating right and exercise, I think more people would actually do it. The biggest issue is getting more people to be involved and how do you do that consistently." [CHL 4]

\section{Community Climate}

This dimension focused on the attitude of congregants and their support for health promotion efforts. The CHLs were somewhat divided in their perceptions. The following themes emerged:

Theme 1: Congregants had a positive outlook regarding health initiatives.

"They know every time I get up there they know it was going to be a walk and they're eager. Some are really eager and try to get in it and do it or they pull me to the side and say can I .... Yeah. Sure." [CHL 3]

"Our church's attitude is great. We believe in being healthy. Our attitude is we're going to do all we can. Most of us in our church want to be healthy." [CHL 4]

Theme 2: Support for health promotion efforts was modest. When asked how supportive congregants were regarding health initiatives, some CHLs decided to rate it 
based on a scale from 1 to 10. The average rating was five. The CHLs generally agreed that some improvement was needed.

"They're supportive--- but like they should. I'm still going to put a 6 on it." [ CHL 1]

"I think more people participate in the moving activities, such as exercise, walks, fitness class more so than the eating part. If people could get on board with the eating more, I think we would be right on target." [CHL 4]

"Five. There's a lot of work that still needs to be done." [CHL 5]

Theme 3: Despite support for health initiatives, personal application was challenging. In general, the CHLs believed that congregants were supportive of the FBO's health initiatives and had a positive disposition. However, consistency and utilization were reported concerns.

"Sometimes, we put off or delay what we should be doing today when we know better but it's just priority on different things. Sometimes, health may not always be the number one priority." [CHL 1]

"It depends on people. Some people think it's a challenge to eat right consistently. So, I don't think people are as consistent as they need to be." [CHL4]

"I think they pick the information up. I'm not sure if they are actually reading it and using it." [CHL 5]

\section{Community Knowledge about the Issue}

The FBOs consistently raised awareness. The perception, amongst CHLs, was that the congregants were knowledgeable regarding various health issues. The following themes emerged:

Theme 1: Information was received but may not have been fully processed. Congregants have consistent access to health information. However, they may not always utilize the information.

"They are very knowledgeable. We published information for them to know. So, I would consider them to be very knowledgeable. When they're not tuning things out, how do you really engage that?" [CHL 4]

"So, they're knowledgeable. The question is "what are you going to do about it?" [CHL 2] 
“I think they're knowledgeable. They're pretty intelligent but they're just not proactive. I guess, with some of the consequences, they just don't think it could happen to them maybe." [CHL 1]

Theme 2: There were several vehicles for information dissemination. Typically, health information was presented consistently via announcements, health bulletins, and/or information tables.

"We have a bulletin board that we can put it up on. That's one way of getting information out. I did a scrapbook on events that we attended all year. We did a PowerPoint on it just to show them and encourage them on what all we did that year." [CHL 1]

"That calorie thing that I had. There were people who asked about that. I ran copies off so they can get that and use that. The exercise, the chair exercise, the band itself. Someone needed that information. We printed out forms, printed out that information. We gave that to them too. We set-up tables with all information where people can get that information." [CHL 3]

"Health bulletin, professional medical person that we have come out to our church to talk to them about issues, the bulletin board in a hallway, that's designated as health ministry bulletin board. Those are things we do.” [CHL 4]

Theme 3: Multiple public health topics were addressed. Various health issues were addressed by congregations. Topics included issues such as: obesity, hypertension, infant mortality, diabetes, cancer, and sickle cell.

"We participate in walks, the MS walk, the Infant Mortality of Sisters-In-Motion, breast cancer, ongoing diabetes teaching, and hypertension. There's always a displayed table with information that's updated in regards to these issues and blood pressure checks." [CHL 2]

"We talked about sickle cell anemia this Sunday. We talk about how it is important to give blood for those patients. And the other patients who also deal with blood issues." [CHL 3]

Theme 4: Health information was based on national estimates.

CHLs were asked about the type of health information presented. They were asked about the availability of local data regarding health issues in their community.

"The health department probably is the closest thing I can think of, and the doctor's offices have all these pamphlets now about blood pressures, blood sugars, GI issues and all that." [CHL 2] 
"We don't really but we know they're always things like we're the fattest city in the state of Tennessee or maybe Tennessee is the fattest state. No, we don't have anything specific to Whitehaven but we consider that specific." [CHL 4]

\section{Resources Related to the Issue}

Resources were generally available in the form of funding, time, and space to support health promotion initiatives. The following themes emerged:

Theme 1: Time and facility usage was based on competing activities. One CHL explained the depth of her pastor's support related to time and space. In general, her explanation mirrored the consensus amongst other CHLs.

"He definitely provides time and space as long as there's no conflict with whatever else is going on. Even when we were doing the Mpower project, one of our associate ministers died and we did the Mpower project first and then left there and went to the funeral. Very supportive." [CHL 5]

Theme 2: Some organizations did not have an established budget for health promotion activities. Funding varied amongst organizations. The majority of the FBOs had no budget for enacting in-house health initiatives. One community health leader noted that in addition to not having a budget, there were stages of approval for health promotion ideas. Some solicited donations or attempted to earn the money to support initiatives such as health fairs.

"Basically, when I do health fairs, I'll go out and start real early and try to get outside vendors to donate food items for the event --- monetary or food. It works but the economy is getting bad. Things we use to get, we can't get anymore but, for the most part, it works out pretty good with people donating." [CHL 1]

"I usually had my own budget as far as financing whatever needs to be financed, so I wouldn't have to ask the church for anything." [CHL 2]

"Usually my first thing is I take it to the pastor. If he says yes, let's try this. Then, we take it to the board and see if it's something that we can do or we can afford to do." [CHL 5]

Theme 3: Some organizations had a budget for coordinated health efforts. Only two of the organizations had an established annual budget. One CHL reported a small budget that did not always cover pertinent expenses.

"Our budget is like $\$ 200$ as far as health ministry. Then, we get donations but we are encouraged to come up with activities of some sort to provide for our ministry. I did the videos, tapes. I took pictures, then downloaded them and put it 
on DVD. We sold those for like a $\$ 1$ and we made pretty good off it. That helped us to get supplies." [CHL 3]

"We have a budget. Our church has a budget in each category. It has a certain budget for the year." [CHL 4]

Theme 4: The FBOs' budget was reflective of their congregation's size. Those with no budget had a smaller congregation, ranging from 60 to 250 members. The size of the congregations with a budget in place, $\$ 200$ and $\$ 5,000$, had approximately 500 and 3,500 members respectively.

"Yes. The budget varies each year. Based on what we have planned, the budget for this year is $\$ 5,000 . "$ [CHL 4]

Theme 5: Most FBOs did not seek external funding. Although some FBOs solicited outside donations, only one sought grant funding for health objective(s).

"We had submitted a proposal or grant request. We submitted an application for garden ministry to an organization where we could use the money to cover the soil, if we need additional soil, and gardening tools." [CHL 4]

Theme 6: The leadership encouraged volunteerism. When asked if the pastor urged members to volunteer to help the health ministry team with specific objectives, some believed that the pastor was very supportive.

"Very proactive. He encourages and he also participates himself. So, his usual comment is just let me know what you need, what do you need us to do." [CHL 2]

"He would encourage people to dedicate time. He does participate as well. As much as he can. His own time." [CHL 4]

Theme 7: The leadership advocated support for health objectives. Other CHL believed that the pastor encouraged the members to support health initiatives through attendance.

"Activities, he encourage them whatever you are doing, like the community health fair, to come out and support." [CHL 3]

One CHL noted that her pastor is very supportive and seemingly has a high degree of confidence in her ability to initiate and carry out objectives; but, he does not necessarily encourage the congregation to volunteer.

"Not really. I guess, he just thinks old sister has it." [CHL 5]

Theme 8: There were no sophisticated evaluations of health initiatives. The CHLs were asked if their FBO evaluated the strengths or weaknesses of health/obesity related 
initiatives. Evaluations were primarily indirect. Reported evaluation techniques included testimonials, leadership meetings, and surveys.

"No, not per se. Usually, the members will do their testimony to say how it has helped them, what they've done, changes they've made, how it impacted their health and offered encouragement to others." [CHL 2]

"We had a survey but it was just from the community health fair. I don't think they ever did one that I know of." [CHL 1]

Theme 9: Policy was developed to reinforce health goals. One CHL petitioned the pastor to modify church-sponsored food options. As a result, the pastor implemented a ban on soda at church-sponsored events.

"Formal policies, no sodas. That's been in place for maybe five years or so. We've got that down pretty good. Only water." [CHL 4]

\section{Negative Case Analysis}

During the enrollment phase of MPower, one CHL who will be referenced as congregation 6 , experienced some difficulty and did not recruit any participants for the project. At the time, she served as the health ministry leader at a satellite location, which was in the process of closing. As a result, she began worshipping at her FBO's main location. Due to this, she was asked about both the satellite location and the main location. Overall, differences in leadership styles may have hampered the introduction of MPower following her move to the main location. She believed that the satellite location was more focused on health initiatives and that success was primarily a result of pastoral support. She believed that her efforts, as the health ministry leader, were well supported by the associate pastor, who presided over the satellite location. The following themes emerged:

Theme 1: Pastoral support was integral to success.

"Actually, my pastor was the overseer of ministry. She was over all ministries. That was one of the reasons I think we were so successful at the location because I had the pastor's ear. Let's put it that way and we had regular conversations about what I thought would be good for the health ministry. Really, really being able to talk with and finding where the pastor has time to listen to your plans. To make it a priority on the church calendar of events what they're planning to do." [CHL 6]

Theme 2: The level of concern for health initiatives varied by location. When asked about the importance of health issues to the leadership, using a scale of 1 to 10 , she provided a rating of 8 and 1 for the satellite and main locations respectively. It seems the main location did not have as much emphasis on health promotion activities. 
"Being that I really have not seen any efforts presented to make it a priority, I'm going to say not important enough. From 1 to 10. I'm sorry, I'm going to have to put down 1." [CHL 6]

Theme 3: Pastoral involvement was more evident in the smaller church setting. In addition to support at the satellite location, she also talked about the leadership's involvement in health initiatives.

"They were very involved because I know one time the men had a --- I don't know if you want to call it the Men's Summit, but one of the ministers took some information on prostate cancer and maybe HIV as well to that and set it up for me and got a list of the people who came to that. That was very helpful. Like I said, we were closer knit people. They knew me well and supported it." [CHL 6]

Theme 4: Pastoral interest in novel initiatives was influenced by competing activities. Although the CHL noted that the main location was not as health oriented as the satellite location, she believed they would potentially be supportive if new health initiatives were introduced. However, she noted that competing priorities could have an impact on success.

"I think they would and the thing about it --- although nothing is really going on. I'm not saying that they are not interested, it just hasn't come forth as being a priority for the church. I know a lot of things are going on and I recognize that you can only focus on so many things. What's my priority may not be your priority but you're still considered as important. I believe with time that we will get back to that. I don't see how at this day and time health insurance and disparities with African-American people being what they are that we can ignore not having health ministry in a church. This is where people congregate on a regular basis. It would be so easy to make it a part of the ministry from my point of view. You have a captive audience. If you, being the leader, say this and people believe you, they will follow you. They are there and they will come to this particular location for services on a regular basis. There is something about this church, the pastor or whatever that people believe in. So, I believe it will be very effective if the leader would say something -- to say that I am in full support of health ministry, y'all get on board. There's plenty work to be done. I think people would buy into it. Nobody is buying into everything but I believe a great would buy into it that it could be effective for the congregation, as well as the community." [CHL 6]

Theme 5: Spiritual objectives superseded heath objectives. Although, she thought the main location might at least take interest in an initiative, her doubt about prioritizing could have been a result of her personal experience. The CHL's noted that she tried to implement a disaster preparedness program that was sponsored by an outside funding agency. Her perception is that the FBO primarily focused on religious principles. 
"Spiritual programs. Things that were already on the calendar. With me coming from the other location, it was even harder to put things into place. Like I said, I was already competing with programs that were already in place. You can only do so many things, spread so many people in so many places. It really didn't go over as well as it could have gone over. Even with the announcement, I sent the announcement to the church and they only announced it one Sunday. So, it was just kind of lost." [CHL 6]

Theme 6: Health promotion activities varied by location. At the satellite location, the CHL seemingly had no problem incorporating various health promotion activities. Some of the health promotion activities included monthly blood pressure screenings, raising awareness, information table displays, and health fairs. However, the aforementioned activities were lacking at the main location. The only health related activity identified for the main location was fitness classes.

"When it comes to health ministry, the church is still just one-sided as far as what it's really focused on and it is $99.9 \%$ spiritual." [CHL 6]

Theme 7: There were varying degrees of knowledge about health issues. When addressing knowledge about health issues, she believed that some people, at the main location, were knowledgeable as a result of their profession while others were not as aware. However, she could not pinpoint any awareness efforts that were in place at the main location.

"Say 5-10\% percent are very knowledgeable. I would say probably the next 50\% are probably fairly knowledgeable, and $40 \%$ who are probably not so knowledgeable." [CHL 6]

Theme 8: The organization's size possibly impacted effectiveness. The size of both churches and their respective health ministries may confirm the CHL's views about their interest in health promotion. The satellite location had approximately 350 members with a health ministry team of five people. The main location had approximately 4,500 members with a team of two working in the health ministry. It appears that the satellite location was more centered on coordinating various efforts and networking with various organizations to provide health information. Contrarily, the main location was seemingly focused on immediate concerns that may have occurred during services.

"I don't even know if they call it the health room or what they call it, but it's a little room. I don't think it's anything that people would go in or even if it's set up for people to go in to get health materials. I think you have to be sick to go in there." [CHL 6] 


\section{CHAPTER 5. DISCUSSION}

The outcomes, in this project, demonstrated that behavior change can be impacted in these types of studies. There was an increase in self-reported physical activity from baseline. There was a significant relationship between physical activity minutes and OR score in both the core and maintenance periods. This was possibly due to the structure of the participating FBOs, as some had on-site exercise facilities that were available for congregant use. Some also had coordinated fitness classes, which may have diminished physical activity barriers. During the maintenance period, MPower implemented a team challenge between FBOs, which may have motivated congregants to maintain physical activity levels. The challenge required congregants to increase physical activity minutes and urged them to incorporate strength training exercises using MPower provided therabands and exercise guides. The physical activity results are supported by findings in the literature, which have demonstrated that faith-based interventions can impact physical activity levels (Wilcox et al., 2013; Peterson \& Cheng, 2011; Duru, Sarkisian, Leng, \& Mangione, 2010; Kim, Linnan, Campbell, Brooks, Koenig, \& Wiesen, 2006; Resnicow, Jackson, Blissett, et al., 2005).

The weight loss results suggest that OR alone may not be sufficient to promote and sustain behavior change. Overall, less than one fourth of the population achieved weight loss goals and final changes in weight from baseline were minimal. Some groups actually gained weight during the study. However, this phenomenon is common in the maintenance phase of weight loss studies (Voorhees, Stillman, Swank, et al., 1996). Organizational readiness score was associated with weight outcomes. However, groups within the same OR category had significantly different weight averages. The differences, by congregation, were revealed in the post hoc analyses, which demonstrated significant intra-group variations irrespective of organizational readiness score. This finding suggests that weight variations may be better explained by congregational affiliation. In addition to significant congregational variations noted in the statistical analysis, the qualitative observation revealed characteristic differences. Those in categories four and five had similar characteristics, which included: an affiliation with smaller FBOs, miniscule budgets for health promotion, and a lack of long-term health strategies. However, those in OR category 7 had the following: a larger organization (3500 members), a yearly budget, formal health policy, long-term health promotion goals. They also sought grant funding to further support health promotion initiatives. All OR categories were more similar on issues such as: participation barriers and pastoral support. Thus, researchers may need to invest more time and resources when targeting organizational members.

\section{CRM Stage Recommendations}

Despite the lack of a significant relationship between weight loss and OR scores, trends in participation and outcomes suggest that organizations could have possibly benefited from pre-intervention strategies. Organizational groups in this study varied in 
readiness from preplanning to stabilization. The CRM provides strategies to assist organizations and/or evaluators for each stage of readiness. For those in the preplanning stage, the CRM suggests that organizers initiate coordinated efforts to raise awareness. Strategies include: the presentation of information via public forums, inciting the interest of front-runners, evaluating the success of current initiatives, elucidating the audience of interest, and gathering participant feedback to highlight concerns and pertinent resolutions (Plested, Edwards, Jumper-Thurman, 2006). Suggestions for those in the preparation stage are geared towards effective planning. This includes but is not limited to: the use of questionnaires to better understand the population, engaging the population through scheduled events, organizing municipal meetings for strategizing purposes, allowing keynote officials and/or speakers to address participating groups (Plested, Edwards, Jumper-Thurman, 2006). Additionally, leaders should have a solid method for measuring achievement (Plested, Edwards, Jumper-Thurman, 2006). The stabilization stage rests on maintenance of momentum. At this juncture, organizers should continue to host events to sustain interest (Plested, Edwards, Jumper-Thurman, 2006). Additionally, they should make sure that key individuals are adequately trained and participating members thoroughly understand procedures (Plested, Edwards, Jumper-Thurman, 2006). Organizers should also hold regularly scheduled summits to measure progress and revise methods as needed (Plested, Edwards, Jumper-Thurman, 2006).

Possibly, readiness tools could have been used to build capacity prior to the implementation of the intervention. This is because the CRM provides tools to progress organizations to the next stage of readiness, which can be done prior to program execution. However, funding and time constraints prevented such measures. Many of the churches were receptive to the idea of MPower and welcomed the opportunity to help congregants make healthier decisions. Although the health leaders were confident that congregants were aware of health promotion efforts, they were less confident in the congregation's ability to actually adopt certain behaviors. Primary concerns included participation and getting congregants to engage in preventative behaviors. Some of the churches had a relatively large congregation; however, each CHL was only able to recruit a small percentage of congregants for MPower. This suggests that the strength of the organization alone is not sufficient to implement and sustain an intervention. Moving into an organization that is well structured is seemingly a great foundation for successful implementation; but, it must be met with good reception from individual units. According to Rafferty et al. (2013), the steps that are integral to readiness to change diverge at the "individual, group, and organizational" segments. Thus, researchers must invest more time and resources in order to reach organizational members. This study supported findings in the literature, that despite an organization's position on the readiness continuum, several barriers may exist, including: program execution, long-term maintenance of behavioral elements, and sustainability (Langley, Nadeem, Kataoka et al., 2010; Weiner, 2009; Glasgow, Lichtenstein, \& Marcus, 2003; Shediac-Rizkallah \& Bone, 1998). 


\section{Program Execution Limitations}

\section{Implementation Barriers}

A primary challenge to successful lifestyle modification programs is motivating individuals to embrace new concepts (National Institutes of Health, 2014; Deci, Ryan, 2012). Although readiness assessments highlight the collective ability of a group to incorporate a new innovation, individual characteristics are simultaneously at work (Weiner, 2009; Plested, Edwards, Jumper-Thurman, 2006). As demonstrated by this study, readiness measurements do not ensure behavior change. According to Weiner (2009), within group differences in readiness could potentially impede program execution. In this study, there were significant congregational variations noted in the statistical analysis. This was also noted in the qualitative observation as congregations varied on characteristics such as: participation, structure of the health ministry, pastoral involvement, and in-house health promotion initiatives.

Therefore, researchers should consider the peripheral factors that impact program enactment. Specifically, the level of participant "buy-in" is an important consideration for program success (Langley, Nadeem, Kataoka et al., 2010). Even if an organizational entity is prepared, structurally speaking, to engage in health promotion initiatives, as demonstrated, many factors could impede progress. In this study, participant buy-in was minimal with respect to the size of the participating FBO. For example, the largest congregation had only ten enrollees. No congregation had over sixteen members enrolled in MPower and the largest groups were members of smaller FBOs. Drawing from The Heath Belief Model, individuals must value the need to integrate healthy principles into their daily routine (Glanz, Rimer, \& Lewis, 2002). When risk is not apparent, individuals are less likely to take action; additionally, they must realize that the proposed lifestyle change is beneficial (Glanz, Rimer, \& Lewis, 2002). In addition to the aforementioned notion, confidence may also impact personal application because individuals must believe they possess the ability to conquer the intended objectives (Langley, Nadeem, Kataoka et al., 2010; Glanz, Rimer, \& Lewis, 2002). Weiner (2009) suggests that organizational readiness to change may be greatest when individuals are motivated and self-assured. Findings from the qualitative analysis suggested that empowerment, lack of confidence, and prioritization were obstacles to efforts addressing health related issues. Specifically, health and fitness is a personal journey that requires dedication and consistency; and, one's desire to embark on that journey may be directly related to their enthusiasm.

The literature suggests that lay leaders are essential to program implementation, as they are trusted community entities (Ali et al., 2012; Calman, 2005; Gary et al., 2003; Lorig and González, 2000) Hence, it may have been beneficial for organizers to work more closely with CHLs during recruitment efforts. This approach could have illuminated potential participation and communication barriers. Specifically, the project team could have potentially provided a more thorough explanation of intervention details. Despite the pastor's influence, organizers could have more effectively communicated the study 
intent, significance, and potential impact on the community. In addition to participation, pastoral buy-in is just as important. Though all of the community leaders believed that pastoral approval was high, very few of the pastors actually participated in the MPower Program themselves. Some of them mentioned it directly from the pulpit; but, the CHLs were primarily responsible for making the congregation aware of MPower and encouraging them to maintain enrollment. The literature highlights the importance of pastoral involvement and how it is integral to the success of objectives (Harmon, Blake, Armstead, Hébert, 2013; Hippolyte et al, 2013; Williams et al., 2013; Newlin et al., 2012; De Marco et al., 2011; Austin \& Claiborne, 2011; Williams, Glanz, Kegler \& Davis, 2009; Ammerman et al., 2003; Markens et al., 2002; Taylor et al., 2000). The experiences of the negative case analysis were directly in line with the literature that suggests pastoral support is integral to successful programming in ecclesiastical establishments.

Also, pastoral endorsement is not limited to participation, but is also linked with available resources. While some FBOs had a specific budget, even if small, to accomplish annual health objectives, others were reliant on fund raising, donations and/or outside resources. Although all of the FBOs provided resources such as time and space, a miniscule budget limited them to raising awareness. With the elimination of outside resources such as $\mathrm{MHC}$, there may be a greater need to explore partnerships with FBOs. Due to a lack of funding, MHC no longer provides disease education to FBOs. MHC's involvement could have been a primary source for addressing health issues in FBOs, especially considering that some congregations have no budget for health promotion. Despite potential funding issues, FBOs possess vital resources such as: time, space, and captive audiences. Therefore, future partnering organizations should find ways to establish trust, provide funding, and motivate the pastor's direct involvement. Collectively, they should establish strategies to motivate congregants to action. This underscores the basis of CBPR, which incorporates input from organizational leaders, the target community, and researchers in all aspects of an intervention process (Israel, Schulz, Parker, \& Becker, 1998). This includes: determining the issue of interest, raising awareness, and determining strategies for implementation in the target community. CBPR recognizes the participants as partners with an active role in planning the details of the intervention (Israel, Schulz, Parker, \& Becker, 1998). Wilcox et al. (2007), similar to this study, used health facilitators to disseminate the intervention to their respective FBO. However, they used focus groups to capture feedback from the target audience and subsequently establish intervention guidelines. For example, as a result of the focus groups, intervention materials were laced with saintly principles; and, fitness communications were integrated into normal activities, such as pastoral messages, oral reports, and weekly publications (Wilcox et al., 2007).

In addition to generating mass appeal, some health promotion efforts focus on the wide dissemination of health information, which may be counterintuitive, especially among individuals with diminished reading capabilities (Nutbeam, 2006). Information may be dispensed without concern for how the information is being processed. This can be problematic, especially if program success depends on the individual's ability to incorporate the pertinent information into their daily routine. Particularly, the literature indicates that most educational efforts, targeting lifestyle factors, have either been 
unsuccessful or incurred marginal influence as a result of health literacy (Nutbeam, 2006).

According to Nutbeam (2006): health Literacy represents the cognitive and social skills that determine the motivation and ability of individuals to gain access to, understand and use information in ways that promote and maintain good health. Therefore, it is crucial to confidence-building, autonomy, and enthusiasm (Nutbeam, 2006). The health literacy of the participants was a cited concern in the qualitative evaluation. Although people have access to information, literacy levels may impede benefits. The qualitative analysis revealed concerns about literacy and comprehension, as one CHL believed that literacy could potentially present a problem with the elderly. Also, she acknowledged that comprehension of health promotion materials could even be problematic for educated individuals. According to Parker et al. (1995), operational "health literacy" is the ability to read and understand "health" information. Therefore, ineptitude could have impeded the success of MPower, which was largely based on the dissemination of chronic disease information. Although intervention sessions were orally presented by the CHLs, participants were also provided with a hard copy of materials to apply to everyday life. However, their ability to correctly interpret and apply the materials could have been hindered. According to Nutbeam (2006), persons with limited reading and writing capability may be less exposed to basic health education materials, thus rendering them incapable of applying the information to daily routines. Even educated individuals may not be exempt, as their ability to navigate the healthcare system and apply healthy principles may be limited. This is because health literacy transcends ethnicity, finances, and age (Speros, 2005).

Also noted are circumstantial issues which should be considered in the program execution phase (Langley, Nadeem, Kataoka et al., 2010; Weiner, 2009). An evaluation of a group-based psychological well-being initiative explicitly outlined barriers to successful program execution, which included: conflicting obligations and beliefs about the program (Langley, Nadeem, Kataoka et al., 2010). This may especially be applicable to faith-based settings, which host a variety of services and/or activities throughout the week. For example, individuals who are committed to weekly activities, such as bible study, choir practice, and/or weekly meetings, may find it cumbersome to add another activity to their schedules. Therefore, certain preliminary strategies should be incorporated to accommodate competing interests, including summits and feedback sessions (Langley, Nadeem, Kataoka et al., 2010). Overall, successful program execution hinges on the: application of a group specific action plan, knowledge of which assets are fundamental, period for completion, and the ordering of events (Weiner, 2009). It is possible that some individuals did not enroll or fully participate in MPower due to the timing of the intervention and/or competing activities. Since the CHLs were responsible for establishing the intervention time in their respective organization, it's quite possible that dates and times were based on personal schedules, availability of space, and allotted time slots. The qualitative data revealed competing interests that varied by age category for one FBO. For the elderly, nightly activities were seemingly less desirable, while weekend activities were more likely to be embraced. The younger participants seemingly experienced time conflicts due to work, children, and extracurricular activities. 
Another issue that may have been problematic was the number of activities present on the church calendar. While the CHLs reported no concurrent projects, similar to MPower, there were other church activities that could have interfered with participation. Many of the CHLs actually mentioned the FBOs' yearly calendar with respect to how it could have been a source of competition. When the intervention started, the FBOs' yearly event calendars were already in effect. Therefore, this could have potentially impacted participation levels. This sentiment was also expressed in the negative case analysis, as the CHL believed that competing initiatives obstructed implementation efforts. Also noted is that organizations participated in a weight loss challenge that ended prior to recruitment for the MPower Program. This initiative was also diabetes related and was sponsored through MHC. The reported activities were very similar to the MPower intervention and ended just before MPower commenced. Thus, intervention timing could have deterred enrollment, especially amongst members who engaged in the previous intervention. The qualitative analysis revealed that individuals were potentially deterred by the similarities to the MHC initiative and the 12-month time commitment associated with MPower.

\section{Maintenance Barriers}

Another commonly cited drawback of health promotion efforts is sustained success. (Ory, Smith, Mier, \& Wernicke, 2010) In this study, there were mean differences in weight between congregations in the core phase, which were not evident in the maintenance phase. Several studies have reported that achievement of intervention goals are often met with relapse in benefits over time. (National Institutes of Health, 2014; Ory, Smith, Mier, \& Wernicke, 2010; Fitzgibbon, Stolley, \& Schiffer, et al., 2010; ShediacRizkallah \& Bone, 1998). Oftentimes, the impact of lifestyle modification efforts is resilient post-intervention; nevertheless, benefits typically dwindle as time progresses when long-term reinforcement is lacking (Ory, Smith, Mier, \& Wernicke, 2010).

According to the National Institutes of Health (2014), the most rigorous interventions, targeting behavior, are imperfect in their attempt to achieve long-standing success; oftentimes, complete transformation is reserved for the ambitious and is restricted to a singular objective (National Institutes of Health, 2014). For instance, the Obesity Reduction Black Intervention Trial (ORBIT), a "randomized controlled" experiment, evaluated changes in weight and sustainability in African-American females (Fitzgibbon, Stolley, \& Schiffer, et al., 2010). Outcomes were assessed at "6 and 18months" post-intervention (Fitzgibbon, Stolley, \& Schiffer, et al., 2010). The two groups differed substantially "6 months" post-intervention (Fitzgibbon, Stolley, \& Schiffer, et al., 2010). Despite this initial achievement, outcomes were not retained 12months after the previous assessment (Fitzgibbon, Stolley, \& Schiffer, et al., 2010). In fact, increases in weight were documented communally, decreasing the initial gap noted at the "6-month follow-up" (Fitzgibbon, Stolley, \& Schiffer, et al., 2010). They concluded much work is essential to determine how to achieve lasting benefits (Fitzgibbon, Stolley, \& Schiffer, et al., 2010). 
In order to maintain momentum, researchers should possibly redefine their views on performance management. One suggestion entails evaluating lifestyle programs under the same microscope as long-term disease remedies, which require extended cycles of effective therapy (Ory, Smith, Mier, \& Wernicke, 2010). Longstanding performance tactics are just as vital as preliminary behavior modification approaches (ShediacRizkallah \& Bone, 1998). This is due to the notion that lifestyle transformation occurs incrementally and is influenced by both "education and social change;" moreover, lasting effects are contingent on continuous exposure and the trickle down impact on prospective "generations" (Shediac-Rizkallah \& Bone, 1998, p. 93). However, the notion of a farreaching approach is often encumbered by funding and intervention length (ShediacRizkallah \& Bone, 1998). One concern was that inconsistency may have impacted longterm benefits during this 1 year study period. One CHL believed that people typically want immediate results. However, they don't always recognize that results materialize with time and require consistent exercise along with dietary restrictions.

\section{Program Endurance}

Lack of support is another reason for overall intervention ineffectiveness (Shediac-Rizkallah \& Bone, 1998). Even when substantial funding is available initially, efforts may be extinguished long before the intended goals are reached, or at least before the group is truly acclimated to the process. This study was supported by a small grant that permitted a modified adaptation of the original DPP. During the qualitative analysis, some CHLs expressed interest in a continued partnership with MPower. However, this was not possible under the existing funding conditions. Consequently, interventions that succumb to funding issues may also witness deterioration of achievements (Calhoun, Mainor, Moreland-Russell, et al., 2014). In an assessment across 9 districts, autonomy and intervention assimilation, following the endowment period, were issues of primary concern for the majority (Shediac-Rizkallah \& Bone, 1998). In a literature review of thirty-seven AIDS prevention programs, initially financed by the Robert Wood Johnson Foundation, ongoing financial support was also a stated problem (Janz, Zimmerman, Wren, et al., 1996). Remarkably, identification of the aforementioned problem superseded issues regarding participation, despite the social stigma associated with the disease problem (Shediac-Rizkallah, \& Bone, 1998; Janz, Zimmerman, \& Wren, et al., 1996). Since "program termination is counterproductive when the disease that a program was established to address remains or recurs," decision-makers must ponder methods to successfully utilize limited capital (Shediac-Rizkallah, \& Bone, 1998, p. 88). Generally, this is an insignificant issue for several projects; however, timely and detailed preparation is required to preserve the infrastructure (Shediac-Rizkallah, \& Bone, 1998). Following the qualitative evaluation, CHLs suggested that the MPower education materials would be used to promote continued awareness. However, there was no indication that FBOs would implement in-house obesity prevention activities.

According to Calhoun, Mainor, Moreland-Russell, et al. (2014), "Building capacity involves developing processes that allow programs to leverage resources to 
effectively implement evidence-based policies and activities" (p. 1). One suggestion encourages leaders to observe what is necessary in light of capital (Calhoun, Mainor, Moreland-Russell, et al., 2014). A study dealing with financial insecurities, employed strategies to pinpoint issues that hindered progress overall (Calhoun, Mainor, MorelandRussell, et al., 2014). By working through issues, they isolated the program components which were necessary to long-reaching endurance (Calhoun, Mainor, Moreland-Russell, et al., 2014). They discovered that communication endeavors were not conducive to attracting sponsors. Hence, they devised a strategy to not only highlight their achievements, via readily available technology, but to foster relationships that would impact future endeavors (Calhoun, Mainor, Moreland-Russell, et al., 2014). Considering that financial backing is fundamental, irrespective of program maturity and proficiency, managers should initiate efforts by developing a continuous "logic model" (Calhoun, Mainor, Moreland-Russell, et al., 2014). This process requires various input at all organizational levels (Fitzgibbon, Stolley, \& Schiffer, et al., 2010). By incorporating diverse perspectives, leaders can more accurately gauge programmatic advantages and limitations (Calhoun, Mainor, Moreland-Russell, et al., 2014). Furthermore, this permits decision-makers to conceptualize the "ideal future" and determine strategies to mend discrepancies (Fitzgibbon, Stolley, \& Schiffer, et al., 2010). During the qualitative evaluation, one FBO sought external grant funding to continue ongoing health initiatives.

\section{Policy Implications}

Chronic diseases present the greatest challenge for the public health system, particularly diseases associated with modifiable risk factors such as overeating, physical inactivity, alcohol and tobacco use. Additionally, the majority of the United States' health care and economic costs are due to chronic diseases and associated health risk behaviors. Consequently, policy makers have shifted priorities, from the spread of communicable disease to behavior modification, as they recognize that amendments in the medical sector alone are not adequate strategies for public health improvement. Behavior modification is difficult as lifestyle choices are influenced by many factors, such as cultural setting, moral compass, education, and/or economics. Public health officials and legislative bodies have sought policies that apply both traditional and more innovative public health tools to combat chronic health conditions/risk factors. In doing so, they must confront critical questions about how to set priorities and evaluate the wisdom of policy approaches, specifically including the importance of the problem, the effectiveness and cost-effectiveness of various interventions, and the likelihood that the chosen interventions will be well received. However, the challenge is to respond to the need in ways that provide a comfortable platform for individuals to respond. Thus, collaborations between health promotion agencies and community-based organizations can help communities leverage their strengths. Faith-based organizations, specifically, have the benefit of reaching untapped populations.

Prior research suggests that trust is a key factor that must be considered in health promotion efforts, especially in underserved populations. If individuals believe that ecclesiastical organizations possess the authority to confront health related issues, it may 
drive support and compliance. Historically, FBOs have been the backbone of the AfricanAmerican community. Modern day FBOs are not solely concerned with spiritual wellbeing, but have evolved to incorporate "civic and political activity, health promotion, and disease prevention" (Torrence, Phillips, \& Guidry, 2005, p. 161). Considering their reach within the African-American community, healthcare workers and policy-makers alike recognize the potential to connect with high risk populations. According to Torrence, Phillips, \& Guidry (2005), "there is growing evidence that religious involvement, in addition to providing increased access to health promotion interventions, exerts positive and diverse health benefits for the African-American community; thus, the church is often viewed as the bridge between community and public institutions" (p. 161) For example, access to the safety-net population or even wealthy African-Americans, could be fortified through partnerships.

Additionally, faith-based events are typically open to the surrounding community, meaning that any potential health gains would be extended to the community at large, regardless of membership. In this particular study, CHLs indicated their effort to invite other FBOs and the surrounding community to both spiritual and health promotion activities. Also, as the number of uninsured remains at approximately 30 million, post ACA, the influence of FBOs could possibly be more critical (Nardin et al., 2013). Although the vitality of FBOs are apparent, partnerships alone are not sufficient for successful execution of health promotion programs. Therefore, public health officials must work closely with FBOs to pinpoint effective recruitment, implementation, and maintenance strategies to reach the community at various sectors. This includes but is not limited to: targeted training and development which equips FBOs to act as change agents, and subsidies to support the costs of health promotion activities.

\section{Limitations}

The sample size was small. However, this analysis was based on a feasibility study with limited funding. Despite the small number of enrollees, a benefit of longitudinal designs is that it is not necessarily impacted by low participation, but the strength lies in the repeated measures on individuals. The MPower study was scheduled to last for 1 year with continuous participant action, which raised concern regarding attrition. Also, men were underrepresented in this population. However, Black men are considerably less apt to be associated with any religion when compared with Black women (16\% vs. 9\%) (Sahgal \& Smith, 2009). Since feedback was solely collected from the study population, the results may not reflect the perceptions and attitudes of the general population. Furthermore, OR scores were based solely on CHL responses. Organizational readiness scores could have been strengthened by multiple interviews within the same FBO. Nevertheless, funding and time constraints inhibited such assessments. Moreover, data may be subjected to self-selection bias. Initial feedback from the CHLs revealed that individuals were interested in receiving copies of intervention materials but chose not to officially enroll in MPower. During the key informant interviews, CHLs were asked to recollect details that occurred before, after, and/or during MPower. Therefore, the data may also be subjected to recall bias. The 
MPower data contains limited demographic variables (i.e., age, gender), which may have impacted statistical outcomes.

\section{Trustworthiness}

Credibility was achieved through triangulation, which incorporated various forms of data collection, such as interview recordings with CHLs, clarification of participant feedback, and documentation of participant feelings and expressions. Additionally, data were analyzed by an additional reviewer for inter-rater reliability. To enhance trustworthiness, an audit trail of decisions was documented.

\section{Ethical Concerns}

Every participant was notified of the researcher's intent and the purposes for which the data were used. All were treated in accordance with the ethical guidelines of the University of Tennessee's Institutional Review Board (IRB). The interviews were audio taped to capture immediate responses. However, all participants were assigned a unique client ID; therefore, no personally identifiable data were collected.

\section{Future Considerations}

Health promotion efforts among ecclesiastical organizations have been successful in improving various disease states. However, more funding opportunities may be available if organizers are able to demonstrate a program's effectiveness and the return on investment (ROI). A "program" represents a systematized "response" instituted to combat or eradicate issues (Deniston, Rosenstock, \& Getting, 1968). It entails the: description of goals, adoption and execution of multiple events and the procurement and delineation of funding (Deniston, Rosenstock, \& Getting, 1968). Given this, allencompassing measurements of performance and success are necessary (Deniston, Rosenstock, \& Getting, 1968). Most intervention action plans are centered on at least three expectations:

(a) the expenditure of resources as planned will result in the performance of planned activity, (b) each activity, if properly performed, will result in the attainment of the sub-objective with which it is linked, and (c) each sub-objective must necessarily be accomplished before the next one can be achieved and, if all sub-objectives are attained, the program objective will be attained (Deniston, Rosenstock, \& Getting, 1968, p. 604).

An assessment of intervention success requires that particular markers for achievement are established and information regarding progress is methodically amassed (Deniston, Rosenstock, \& Getting, 1968). This includes careful documentation of both program and cost efficiency (Deniston, Rosenstock, \& Getting, 1968). 
Effectiveness refers to the degree to which predetermined goals are reached as it relates to organizational undertakings (Deniston, Rosenstock, \& Getting, 1968). Measuring program effectiveness should, at minimum, incorporate techniques to assess stipulations outlined in the program objective, as well as measurement of all possible "sub objectives" (Deniston, Rosenstock, \& Getting, 1968). Therefore, it must go beyond querying if the goals were merely attained, but should also consider if goal accomplishment can be credited to the program (Deniston, Rosenstock, \& Getting, 1968). This includes contrasting the program's actual achievement to the intended achievement (Deniston, Rosenstock, \& Getting, 1968). A program is deemed ineffective for various reasons. Sometimes, funding has not been properly applied to the previously specified objectives (Deniston, Rosenstock, \& Getting, 1968). Also, the suppositions connecting program performance to resources or intended goals are unfounded, thus, impeding the fulfillment of pre-planned initiatives (Deniston, Rosenstock, \& Getting, 1968). Therefore, as researchers continue to make strides in the faith-based setting, they should consider more rigorous program evaluation efforts, especially in the area of "costeffectiveness" (World Health Organization, 2014). A sophisticated cost-effectiveness analysis was not performed for this study. However, the lack of literature on costeffectiveness of faith-based programs reveals an important gap that should be explored in ongoing efforts (World Health Organization, 2014).

On another note, various approaches may be useful in the identification of potential barriers; however, a common pitfall hinges on the assumption that input from the general community of leaders is sufficient to develop a one size fits all approach. Interventions that utilize lay leaders to disseminate intervention materials to a larger population should have methods in place to guarantee that information is user friendly and well received by the population. Sometimes, it may even be necessary to incorporate age specific intervention strategies, as recruitment and attrition may be an issue amongst younger age groups. The CBPR approach can be useful in this regard. It could help researchers identify and diminish initial barriers based on participant feedback. Wilcox et al. (2007) found that younger people were less likely to remain in their study, which reinforced the notion that targeted messages could have been beneficial.

Considering participation patterns in this study, it may be best to target smaller FBOs for similar interventions. One of the benefits of a small FBO is intimacy. In the smaller settings, individuals and/or families may be more connected and may motivate each other. Furthermore, members may have more personal contact with organizational leaders, which could strengthen recruitment efforts. The experiences of the negative case analysis, in this study, reinforced the need for trusted representatives who are connected to the members.

Finally, a common pitfall in weight loss studies is that there are no strategies to address long-term goals, especially considering that individuals who reach the maintenance stage in this type of study often regress. Therefore, in an effort to address and achieve long-term health goals, researchers should develop enduring strategies to assist individuals in various stages of the intervention. For example, individuals may 
benefit from some form of motivational interviewing to keep them on track during the maintenance period. Strategists should also seek economical methods that last beyond the intervention cycle.

\section{Conclusion}

In summation, multiple influences may impact the breadth of lifestyle modification programs in the faith-based setting. This includes but is not limited to: program execution, extended maintenance, and program sustainability. Although strategists can draw from the literature to avoid commonly cited pitfalls, sound methods, for wide-reaching success, should be sought continuously. Researchers should also recognize that change at the organizational level encompasses multi-stage procedures. Though often used interchangeably, organizational and individual differences must be addressed as two entirely different concepts. Taking this into consideration during the intervention planning stage may diminish organizational snags and yield more substantial results overall. 


\section{LIST OF REFERENCES}

Abramson, J.H. (1979). The four basic types of evaluation: clinical reviews, clinical trials, program reviews, and program trials. Public Health Reports, 94(3), 210215.

Ackermann, R. T., Finch, E. A., Brizendine, E., Zhou, H., \& Marrero, D. G. (2008). Translating the Diabetes Prevention Program into the Community The DEPLOY Pilot Study. American Journal of Preventive Medicine, 35(4), 357-363.

Ahmad, L. A., \& Crandall, J. P. (2010). Type 2 Diabetes Prevention: A Review. Clinical Diabetes, 28(2), 53-59.

Albright, A. L., \& Gregg, E. W. (2013). Preventing Type 2 Diabetes in Communities Across the U.S. The National Diabetes Prevention. American Journal of Preventive Medicine, 44(4S4), S346-S351.

Ali, M. K., Echouffo-Tcheugui, J. B., \& Williamson, D. F. (2012). How Effective Were Lifestyle Interventions In Real-World Settings That Were Modeled On The Diabetes Prevention Program? Health Affairs, 31(1), 67-75.

Allicock, M., Campbell, M. K., Valle, C. G., Carr, C., Resnicow, K., \& Gizlice, Z. (2012). Evaluating the dissemination of Body \& Soul, an evidence-based fruit and vegetable intake intervention: challenges for dissemination and implementation research. Journal of Nutrition Education and Behavior, 44(6), 530-538.

American Diabetes Association (2008). Economic Costs of Diabetes in the U.S. in 2007. Diabetes Care, 31(3), 596-615.

American Diabetes Association (2013). Complications - American Diabetes Association. Retrieved August 19, 2013, from http://www.diabetes.org/living-with/complications/

Ammerman, A., Corbie-Smith, G., George, D. M., Weathers, B., \& Jackson-Christian, B. (2003). Research Expectations Among African American Church Leaders in the PRAISE! Project: A Randomized Trial Guided by Community-Based Participatory Research. American Journal of Public Health, 93(10), 1720-1727.

Anderson, R. M. (2007). Thematic Content Analysis (TCA) Descriptive Presentation of Qualitative Data. Retrieved November 12, 2012, from http://www.wellknowingconsulting.org/publications/pdfs/ThematicContentAnalys is.pdf

Asomugha, C. N., Derose, K. P., \& Lurie, N. (2011). Faith-Based Organizations, Science, and the Pursuit of Health. Journal of Health Care for the Poor and Underserved, 22(1), 50-55.

Baruth, M., Wilcox, S., \& Condrasky, M. D. (2011). Perceived Environmental Church Support Is Associated with Dietary Practices among African-American Adults. Journal of the American Dietetic Association, 111, 889-893.

Baruth, M., \& Wilcox, S. (2013). Multiple Behavior Change among Church Members Taking Part in the Faith, Activity, and Nutrition Program. Journal of Nutrition Education and Behavior, 45(5), 428-434.

Boltri, J.M., Davis-Smith, M., Okosun, I.S., Seale, J.P., \& Foster, B. (2011). Translation of theNational Institutes of Health Diabetes Prevention Program in African American churches. Journal of National Medical Association, 103(3), 194-202. 
Brody, G., Stoneman, Z., Flor, D., \& McCrary, C. (1994). Religion's role in organizing family relationships: Family process in rural, two-parent African American families. Journal of Marriage and Family, 56, 878-888.

Calhoun, A., Mainor, A., Moreland-Russell, S., Maier, RC., Brossart, L., Luke, D.A. (2014). Using the Program Sustainability Assessment Tool to Assess and Plan for Sustainability. Preventing Chronic Disorders, 11,130-185.

Calman, N. (2005). Making Health Equality A Reality: The Bronx Takes Action. Health Affairs, 24(2), 491-498.

Centers for Disease Control and Prevention (2011). National diabetes fact sheet: national estimates and general information on diabetes and prediabetes in the United States. Retrieved August 19, 2013, from http://www.cdc.gov/diabetes/pubs/pdf/ndfs_2011.pdf

Centers for Disease Control and Prevention (2012, October 5). CDC - About the Program - National Diabetes Prevention Program - Diabetes DDT. Retrieved August 7, 2013, from http://www.cdc.gov/diabetes/prevention/about.htm

Chapman-Novakofski, K., \& Karduck, J. (2005). Improvement in Knowledge, Social Cognitive Theory Variables, and Movement through Stages of Change after a Community-Based Diabetes Education Program. Journal of the American Dietetic Association, 105, 1613-1616.

Chilenski, S. M., Greenberg, M. T., \& Feinberg, M. E. (2007). COMMUNITY READINESS AS A MULTIDIMENSIONAL CONSTRUCT. Journal of Community Psychology, 35(3), 347-365.

Clark, C. M., Fradkin, J. E., Hiss, R. G., Lorenz, R. A., Vinicor, F., \& WarrenBoulton, E. (2001). The National Diabetes Education Program, Changing the Way Diabetes Is Treated: Comprehensive diabetes care. Diabetes Care, 24, 617-8.

Creswell, J.W. (2013). Qualitative inquiry \& research design: Choosing among five approaches. Los Angeles, CA: SAGE.

Deci, E. L., \& Ryan, R. M. (2012). Self-determination theory in health care and its relations to motivational interviewing: a few comments. The International Journal of Behavioral Nutrition and Physical Activity, 9, 24.

Deeg, D.J. (2002). Attrition in longitudinal population studies: Does it affect the generalizability of the findings? An introduction to the series. Journal of Clinical Epidemiology, 55, 213-215.

DeHaven, M. J., Hunter, I. B., Wilder, L., Walton, J. W., \& Berry, J. (2004). Health Programs in Faith-Based Organizations: Are They Effective? American Journal of Public Health, 94(6), 1030-1036.

De Marco, M., Weiner, B., Meade, S.-A., Hadley, M., Boyd, C., Goldmon, M., ... Corbie-Smith, G. (2011). Assessing the Readiness of Black Churches to Engage in Health Disparities Research. Journal of the National Medical Association, 103(9-10), 960-967.

Deniston, O. L., Rosenstock, I. M., Welch, W., \& Getting, V. A. (1968). Evaluation of program efficiency. Public Health Reports, 83(7), 603-610.

Denzin, N. K., \& Lincoln, Y. S. (1998). The landscape of qualitative research: Theories and issues. Thousand Oaks, CA: Sage Publications.

Denzin, N. K., \& Lincoln, Y. S. (2011). The sage handbook of qualitative research $\left(4^{\text {th }}\right.$ ed.). Thousand Oaks, CA: Sage Publications. 
Donnermeyer, J. F., Plested, B. A., Edwards, R. W., Oetting, G., \& Littlethunder, L. (1997).Community readiness and prevention programs. Journal of the Community Development Society, 28(1), 65-83.

Diabetes Prevention Program Research Group. (2002). REDUCTION IN THE INCIDENCE OF TYPE 2 DIABETES WITH LIFESTYLE INTERVENTION OR METFORMIN. The New England Journal of Medicine, 346(6), 393-403.

Diabetes Prevention Program Research Group. (2009). 10-year follow-up of diabetes incidence and weight loss in the Diabetes Prevention Program Outcomes Study. The Lancet, 374(9702), 1677-1686.

Duan, N., Fox, S. A., Derose, K. P., \& Carson, S. (2000). Maintaining mammography adherence through telephone counseling in a church-based trial. American Journal of Public Health, 90(9), 1468-1471.

Duru, O. K., Sarkisian, C. A., Leng, M., \& Mangione, C. M. (2010). Sisters in Motion: A Randomized Controlled Trial of a Faith-Based Physical Activity Intervention. Journal of the American Geriatrics Society, 58(10), 1863-1869.

Ehlers , D. K., Huberty, J. L., \& Beseler , C. L. (2013). Is school community readiness related to physical activity before and after the Ready for Recess intervention? Health Education Research, 28(2), 192-204.

Findholt, N. (2007). Application of the community readiness model for childhood obesity prevention. Public Health Nursing, 24(6), 565-570.

Fitzgibbon, M. L., Stolley, M. R., Schiffer, L., Sharp, L. K., Singh, V., \& Dyer, A. (2010). Obesity Reduction Black Intervention Trial (ORBIT): 18-Month Results. Obesity (Silver Spring, Md.), 18(12), 2317-2325.

Gagnon, M. P., Labarthe, J., Légaré, F., Ouimet, M., Estabrooks, C. A., Roch, G., ... Ghandour, E. K. (2011). Measuring organizational readiness for knowledge translation in chronic care. Implementation Science, 6(72).

Gary, T. L., Batts-Turner, M., Bone, L. R., Yeh, H., Wang, N., Hill-Briggs, F., ... Brancati, F. L. (2004). A randomized controlled trial of the effects of nurse case manager and community health worker team interventions in urban AfricanAmericans with type 2 diabetes. Controlled Clinical Trials, 25(1), 53-66.

Gillies, C. L., Abrams, K. R., Lambert, P. C., Cooper, N. J., Sutton, A. J., Hsu, R. T., \& Khunti, K. (2007). Pharmacological and lifestyle interventions to prevent or delay type 2 diabetes in people with impaired glucose tolerance: systematic review and meta-analysis. British Medical Journal, 334, 299.

Glanz, K., Rimer, B. K., \& Lewis, F. M. (2002). Health behavior and health education: Theory, research, and practice (3rd ed.). San Francisco, CA: Jossey-Bass.

Glasgow, R.E., Lichtenstein, E., \& Marcus, A.C. (2003). Why Don't We See More Translation of Health Promotion Research to Practice? Rethinking the Efficacyto-Effectiveness Transition. American Journal of Public Health, 93, 1261-1267.

Gong, Q., Gregg, E. W., Wang, J., An, Y., Zhang, P., Yang, W., ... Bennett, P. H. (2011). Long-term effects of a randomised trial of a 6-year lifestyle intervention in impaired glucose tolerance on diabetes-related microvascular complications: the China Da Qing Diabetes Prevention Outcome Study. Diabetologia, 54(2), 300 -7.

Green, J., \& Thorogood, N. (2009). Qualitative methods for health research (2nd ed.). Thousand Oaks, CA: SAGE. 
Harmon , B. E., Blake, C. E., Armstead , C. A., \& Hébert , J. R. (2013). Intersection of identities. Food, role, and the African-American pastor. Appetite, 67, 44-52.

Harris, M. I., Flegal, K. M., Cowie, C. C., Eberhardt, M. S., Goldstein, D. E., Little, R. R., ... Byrd-Holt, D. D. (1998). Prevalence of diabetes, impaired fasting glucose, and impaired glucose tolerance in U.S. adults. The Third National Health and Nutrition Examination Survey, 1988-1994. Diabetes Care, 21, 518 -24.

Hippolyte, J. M., Phillips-Caesar, E. G., Winston, G. J., Charlson, M. E., \& Peterson, J. C. (2013). Recruitment and Retention Techniques for Developing Faith-Based Research Partnerships, New York City, 2009-2012. Preventing Chronic Disease, 10, E30.

Holt, D. T., Armenakis, A. A., Feild, H. S., \& Harris, S. G. (2007). Readiness for Organizational Change The Systematic Development of a Scale. Journal of Applied Behavioral Science, 43(2), 232-255.

Holt, D. T., Helfrich, C. D., Hall, C. G., \& Weiner, B. J. (2010). Are You Ready? How Health Professionals Can Comprehensively Conceptualize Readiness for Change. Journal of General Internal Medicine, 25(Suppl 1), 50-55.

Holstein, J.A., \& Gubrium, J.F. (2002). Qualitative Research. Retrieved from http://www.encyclopedia.com

Israel, B.A., Schulz, A.J., Parker, E.A., \& Becker, A.B. (1998). Review of communitybased research: assessing partnership approaches to improve public health. Annual Review of Public Health, 19, 173-202.

Janz, N.K., Zimmerman, M.A., Wren, P.A., Israel, B.A., Freudenberg, N., \& Carter, R. J. (1996). Evaluation of 37AIDS prevention projects: successful approaches and barriers to program effectiveness. Health Education Quarterly, 23, 80-97.

Joubish, M.F., \& Khurram, M.A., (2011). Ahmed A. Paradigms and Characteristics of a Good Qualitative Research. World Applied Sciences, 12(11), 2082-2087.

Katula, J.A., Vitolins, M.Z., Rosenberger, E.L., Blackwell, C.S., Morgan, T.M., Lawlor, M.S., \& Goff, D.C. (2011). One-year results of a community-based translation of the Diabetes Prevention Program: Healthy-Living Partnerships to Prevent Diabetes (HELP PD) Project. Diabetes Care, 34, 1451-1457.

Kim, K.H., Linnan, L., Campbell, M.K., Brooks, C., Koenig, H.G., \& Wiesen, C. (2006). The WORD (Wholeness, Oneness, Righteousness, Deliverance): a faith-based weight-loss program utilizing a community-based participatory research approach. Health Education \& Behavior, 35(5), 634-50.

Kramer, M. K., Kriska, A. M., Venditti, E. M., Miller, R. G., Brooks, M. M., Burke, L. E., ... Orchard, T. J. (2009). Translating the Diabetes Prevention Program A Comprehensive Model for Prevention Training and Program Delivery. American Journal of Preventive Medicine, 37(6), 505-511.

Krueger, C., \& Tian, L.A. (2004). Comparison of the General Linear Mixed Model and Repeated Measures ANOVA Using a Dataset with Multiple Missing Data Points. Biological Research for Nursing, 6(2), 151-157.

Lane, D. (2012). Online Statistics Education: A Multimedia Course of Study. Retrieved from http://onlinestatbook.com/

Langley, A.K., Nadeem, E., Kataoka, S.H., Stein, B. D., \& Jaycox, L. H. (2010).

Evidence-Based Mental Health Programs in Schools: Barriers and Facilitators of Successful Implementation. School Mental Health, 2, 105-113. 
Lasater, T. M., Becker, D. M., Hill, M. N., \& Gans, K. M. (1997). Synthesis of findings and issues from religious-based cardiovascular disease prevention trials. Annals of Epidemiology, 7, 46-53.

Lawsin, C. R., Barrayo, E. A., Edwards, R., \& Belloso, C. (2007). Community readiness to promote Latinas' participation in breast cancer prevention clinical trials. Health $\&$ Social Care in the Community, 15(4), 369-78.

Li, G., Zhang, P., Wang, J., Gregg, E.W., Yang, W., Gong, Q., Li, H., Jiang, Y., ... Bennett, P.H. (2008). The long-term effect of lifestyle interventions to prevent diabetes in the China Da Qing Diabetes Prevention Study: a 20-year follow-up study. The Lancet, 371, 1783-1789.

Lindström, J., Ilanne-Parikka, P., Peltonen, M., Aunola S., Eriksson, J.G., Hemiö, K., ...Tuomilehto, J. (2006). Sustained reduction in the incidence of type 2 diabetes by lifestyle intervention: follow up of the Finnish Diabetes Prevention Study. The Lancet, 368, 1673-1679.

Lorig, K., \& González, V.M. (2000). Community-Based Diabetes Self-Management Education: Definition and Case Study. Diabetes Spectrum, 13(4), 234.

Markens, S., Fox, S. A., Taub, B., \& Gilbert, M. L. (2002). Role of Black Churches in Health Promotion Programs: Lessons From the Los Angeles Mammography Promotion in Churches Program. American Journal of Public Health, 92(5), 805810.

McNabb, W., Quinn, M., Kerver, J., Cook, S., \& Karrison, T. (1997). The PATHWAYS church-based weight loss program for urban African-American women at risk for diabetes. Diabetes Care, 20(10), 1518-23.

Memphis Healthy Churches: Christ Community Health Services (CCHS) (2013)

Retrieved October 2, 2013, from

http://www.christcommunityhealth.org/memphis-healthy-churches

Millar, L., Robertson , N., Allender, S., Nichols , M., Bennett , C., \& Swinburn , B. (2013). Increasing community capacity and decreasing prevalence of overweight and obesity in a community based intervention among Australian adolescents. Preventive Medicine, 56(6), 379-384.

Moser, B.E. (2004, May). Repeated measures modeling with proc mixed. Abstract presented at SUGI 29 Meeting. Montreal, CA.

Nardin, R., Zallman, L., McCormick, D., Woolhandler, S., \& Himmelstein, D. (2013, June 6). The Uninsured After Implementation Of The Affordable Care Act: A Demographic And Geographic Analysis. Retrieved from http:/healthaffairs.org/blog/2013/06/06/the-uninsured-after-implementation-ofthe-affordable-care-act-a-demographic-and-geographic-analysis/

Nathan, D. M. (2002). Small steps, large problems: advances in the management of diabetes mellitus. American Journal of Medicine, 113, 339-340.

National Institutes of Health. Behavior Change and Maintenance. Retrieved September 22, 2014, from http://obssr.od.nih.gov/scientific_areas/health_behaviour/behaviour_changes/inde x.aspx. 
Newlin, K., Dyess, S. M., Allard, E., Chase, S., \& Melkus, G. D. (2012). A Methodological Review of Faith-Based Health Promotion Literature: Advancing the Science to Expand Delivery of Diabetes Education to Black Americans. Journal of Religion \& Health, 51(4), 1075-1097.

Newman, I., \& Benz, C. R. (1998). Qualitative-quantitative research methodology: Exploring the interactive continuum. Carbondale, IL: Southern Illinois University Press.

Norris, S., Chowdhury, F., Van Le, K., Horsley, T., Brownstein, J., Zhang, X.,... Satterfield, D.W. (2006) Effectiveness of community health workers in the care of persons with diabetes. Diabetic Medicine, 23(5), 544-556.

Nutbeam, D. (2006). Health literacy as a public health goal: a challenge for contemporary health education and communication strategies into the 21 st century. Health Promotion International, 15(3), 259-267.

Oetting, E. R., Donnermeyer, J. F., Plested, B. A., Edwards, R. W., Kelly, K., \& Beauvais, F. (1995). Assessing community readiness for prevention. The International Journal of the Addictions, 30(6), 659-683.

Ory, M.G., Smith, M.L., Mier, N., \& Wernicke, M.M. (2010). The science of sustaining health behavior change: the health maintenance consortium. American Journal of Health Behavior, 34(6), 647-59.

Parker, R. M., Baker, D. W., Williams, M. V., \& Nurss, J. R. (1995). The test of functional health literacy in adults. Journal of General Internal Medicine, 10(10), $537-41$.

Peterson, J.A., \& Cheng, A.L. (2011). Heart and soul physical activity program for African American women. Western Journal of Nursing Research, 33, 652-670.

Plested, B., Smitham, D. M., Jumper-Thurman, P., Oetting, E. R., \& Edwards, R. W. (1999). Readiness for drug use prevention in rural minority communities. Substance Use and Misuse, 34(4\&5), 521-544.

Plested, B. A., Edwards, R. W., \& Jumper-Thurman, P. (2006). Community readiness: A handbook for successful change. Fort Collins, CO: Tri-Ethnic Center for Prevention Research.

Plested, B. A., Edwards, R. W., \& Thurman, P. J. (2007). Disparities in Community Readiness for HIV/AIDS Prevention. Substance Use \& Misuse, 42(4), 729-39.

Rafferty, A. E., Jimmieson, N. L., \& Armenakis, A. A. (2013). Change Readiness: A Multilevel Review. Journal of Management, 39(1), 110-135.

Resnicow, K., Jackson, A., Braithwaite, R., DiIorio, C., Blisset, D., Rahotep, S., \& Periasamy, S. (2002). Healthy Body/Healthy Spirit: a church-based nutrition and physical activity intervention. Health Education Research, 17(5), 562-573.

Resnicow, K., Jackson, A., Blissett, D., Wang, T., McCarty, F., Rahotep, S., \& Periasamy, S. (2005). Results of the Healthy Body Healthy Spirit Trial. Health Psychology, 24(4), 339-348.

Sahgal, N., \& Smith, G. (2009, January 30). A Religious Portrait of African-Americans | Pew Research Center. Retrieved from http://www.pewforum.org/2009/01/30/areligious-portrait-of-african-americans/

SAS Institute Inc. (2002-2008). SAS software 9.2. Cary, NC, USA: SAS Institute.

Saunders, R.P., Wilcox, S., Baruth, M., \& Dowda, M. (2014). Process evaluation methods, implementation fidelity results and relationship to physical activity and 
healthy eating in the Faith, Activity, and Nutrition (FAN) study. Evaluation and Program Planning, 43, 93-102.

Sawyer, M. T., \& Deines, C. K. (2013). Missing the Mark With Latina Women With Type 2 Diabetes: Implications for Educators. The Diabetes Educator, 39(5), 6718.

Scherer, J. A., Ferreira-Pinto, J. B., Ramos, R. L., \& Homedes, N. (2001). Measuring readiness for change in two northern border Mexican communities. Journal of Border Health, 6(1), 22-30.

Shediac-Rizkallah, M.C., \& Bone, L.R. (1998). Planning for the sustainability of community-based health programs: conceptual frameworks and future directions for research, practice and policy. Health Education Research, 13(1), 87-108.

Silverman, D. (2011). Interpreting qualitative data (4th ed.). Thousand Oaks, CA: SAGE.

Silwa, S., Goldberg, J. P., Clark, V., Collins, J., Edwards , R., Hyatt, R. R., ... Nahar, E. (2011). Using the community readiness model to select communities for a community-wide obesity prevention intervention. Preventing Chronic Disease, 8(6), A150.

Skup, M. (2010). Longitudinal fMRI analysis: A review of methods. Statistics and Its Interface, 3(2), 235-252.

Slater, M. D., Edwards, R. W., Plested, B. A., Thurman, P. J., Kelly, K. J., Comello, M. L. G., \& Keefe, T. J. (2005). Using Community Readiness key informant assessments in a randomized group prevention trial: Impact of a participatory community-media intervention. Journal of Community Health, 30(1), 39-53.

Speros, C. (2005). Health Literacy: Concept Analysis. Journal of Advanced Nursing, 50, 633-640.

Tabák , A. G., Herder, C., Rathmann, W., Brunner, E. J., \& Kivimäki, M. (2012). Prediabetes: a high-risk state for diabetes development. The Lancet, 379(9833), 2279-2290.

Taylor, R. J., Ellison, C. G., Chatters, L. M., Levin, J. S., \& Lincoln, K. D. (2000). Mental health services in faith communities: The role of clergy in black churches. Social Work, 45(1), 73-87.

The Diabetes Prevention Program Research Group (2012). The 10-year cost-effectiveness of lifestyle intervention or metformin for diabetes prevention. Diabetes Care, 35(4), 723-30.

Thurman, P. J., Vernon, I. S., \& Plested, B. (2007). Advancing HIV/AIDS Prevention Among American Indians Through Capacity Building and the Community Readiness Model. Journal of Public Health Management and Practice, S49-S54.

Torrence, W. A., Phillips, D. S., \& Guidry, J. J. (2005). The Assessment of Rural African-American Churches' Capacity to Promote Health Prevention Activities. American Journal of Health Education, 36(3).

Twisk, J., \& de Vente, W. (2002). Attrition in longitudinal studies. How to deal with missing data. Journal of Clinical Epidemiology, 55(4), 329-37.

Venditti, E. M., \& Kramer, M. K. (2013). Community Outreach Perspectives on Lifestyle Training and Translation. American Journal of Preventive Medicine, 44(4S4), S339-S345.

Vojta, D., Koehler, T. B., Longjohn, M., Lever, J. A., \& Caputo, N. F. (2013). A 
Coordinated National Model for Diabetes Prevention: Linking Health Systems to an Evidence-Based Community Program. American Journal of Preventive Medicine, 44(454), S301-S306.

Voorhees, C.C., Stillman, F.A., Swank, R.T., Heagerty, P.J., Levine, D.M., \& Becker, D.M. (1996). Heart, body, and soul: impact of church-based smoking cessation interventions on readiness to quit. Preventive Medicine, 25(3), 277-85.

Weiner, S. (2001). "I Can't Afford That!": Dilemmas in the Care of the Uninsured and Underinsured. Journal of General Internal Medicine, 16(6), 412-418.

Weiner, B. J., Amick, H., \& Lee, S. D. (2008). Review: Conceptualization and Measurement of Organizational Readiness for Change: A Review of the Literature in Health Services Research and Other Fields. Medical Care Research and Review, 65, 379-436.

Weiner, B. J. (2009). A theory of organizational readiness for change. Implementation Science, 4(67).

Wiist, W.H., \& Flack, J.M. (1990). A church-based cholesterol education program. Public Health Reports, 105(4), 381-889.

Wilcox, S., Laken, M., Bopp, M., Gethers, O., Huang, P., McClorin, L., ...Yancey, A. (2007). Increasing physical activity among church members: community-based participatory research. American Journal of Preventive Medicine, 32(2), 131-138.

Wilcox , S., Parrott, A., Baruth, M., Laken, M., Condrasky , M., Saunders, R., ... Zimmerman, L. (2013). The Faith, Activity, and Nutrition Program A Randomized Controlled Trial in African-American Churches. American Journal of Preventive Medicine, 44(2), 122-131.

Williams, R. M., Glanz, K., Kegler, M. C., \& Davis, E. (2009). A Study of Rural Church Health Promotion Environments: Leaders' and Members' Perspectives. Journal of Religion \& Health, 51(1), 148-60.

Williams , L. B., Sattin , R. W., Dias, J., Garvin, J. T., Marion , L., Joshua, T., ... Narayan, V. (2013). Design of a cluster-randomized controlled trial of a diabetes prevention program within African-American churches: The Fit Body and Soul study. Contemporary Clinical Trials, 34, 336-347.

Winett, S. G., Anderson, E., Whiteley, J., Wojcik, J., Rovniak, L., Graves, K., \& Galper, D. (1999). Church-based health behavior programs: Using social cognitive theory to formulate interventions for at-risk populations. Applied \& Preventive Psychology, 8, 129-142.

World Health Organization. (2008). Qualitative and Quantitative. http://www.gfmer.ch/Medical_education_En/Afghanistan_2008/pdf/Qualitative_q uantitative_research_Abawi_Afghanistan_2008.pdf

World Health Organization. Track 2: Health literacy and health behavior. Retrieved from http://www.who.int/healthpromotion/conferences/7gchp/track2/en/ (accessed 2014 Sep 23).

Zhang, Y., Dall , T. M., Mann, S. E., Chen, Y., Martin, J., Moore, V., ... Quick, W.W. (2009). The economic costs of undiagnosed diabetes. Population Health Management, 12(2), 95-101. 


\section{APPENDIX A. INTERVIEW GUIDE}

\section{$\underline{\text { A. Community Efforts(programs, activities, policies, etc.) AND B. Community }}$ Knowledge of the Issue}

1. Using a scale from 1-10, how important are health /obesity issues in your church (with 1 being "not at all" and 10 being "a very great concern")? Please explain.

2. Please describe the efforts that are available in your church to address health/obesity related issues.

3. How long have these efforts been going on in your church?

4. What efforts were fully implemented before, during, and/or after MPower?

5. Using a scale from 1-10, how aware are people in your church of health/obesity related initiatives/activities (with 1 being "no awareness" and 10 being "very aware")? Please explain.

6. What does the community know about these initiatives or activities?

7. What are the strengths of these initiatives/activities?

8. What are the weaknesses of these initiatives/activities?

9. What age group is typically served by these initiatives/activities?

10. Is there a need to expand health/obesity related initiatives/activities in your church? If not, why not?

11. Is there any planning for health/obesity initiatives/activities going on in your church at this time? If yes, please explain.

12. What formal/ informal policies or practices related to health/obesity are in place in your church, and for how long?

13. How are the policies or practices viewed by your church?

\section{Leadership}

14. Who are the "leaders" specific to addressing health/obesity in your community?

15. Using a scale from 1 to 10 , how important are health/obesity issues to the leadership in your church 
16. How are the leaders involved in health/obesity related efforts? Please explain? Please explain. (For example: Are they involved in a committee, task force, etc.? How often do they meet?)

17. Would the leadership be supportive of additional efforts? Please explain.

\section{Community Climate}

18. How would you describe your church's attitude toward health?

19. How supportive are church members of the efforts to address health/obesity?

20. What are the primary obstacles to efforts addressing health/obesity in your church?

21. Based on the answers that you have provided so far, what do you think is the overall feeling among church members regarding health/obesity issues?

E. Knowledge About the Issue

22. How knowledgeable are church members about health/obesity issues? Please explain.

23. What type of information is available in your church regarding health/obesity issues?

24. What local data are available on this issue in your community?

25. How do people obtain this information in church?

\section{F. Resources For Prevention}

26. To whom would an individual affected by health/obesity issues turn to first for help in your church? Why?

27. On a scale from 1 to 10 , what is the level of expertise and training among those working in your churches health ministry?

28. How many volunteers are involved in your church health ministry?

29. What is your church's membership count?

30. What is your organization/pastor's attitude about supporting efforts to address this health/obesity issues, including encouraging knowledgeable 
members to volunteer time, contributing financial donations, and/or providing space?

31. How are current efforts funded? Please explain.

32. Are you aware of any proposals or action plans that have been submitted for funding that address health/obesity in your church? If yes, please explain.

33. Has your organization evaluated the strengths or weaknesses of the health/obesity related initiatives/activities?

34. If yes, on a scale of 1 to 10 , how sophisticated is the evaluation effort?

35. Are the evaluation results being used to make changes in programs, activities, or policies or to start new ones?

36. Is there anything else you would like to tell me?

Notes: All bold font questions were required for the interview scoring process. Normal font questions were optional; therefore, they were only used for dialogue and/or clarification purposes when necessary.

Modified with permission. Plested, B. A., Edwards, R. W., \& Jumper-Thurman, P.

(2006). Community readiness: A handbook for successful change. Fort Collins, CO: TriEthnic Center for Prevention Research. 


\section{APPENDIX B. ANCHORED RATING SCALES (DIMENSIONS A-F) \\ Dimension A. Existing Community Efforts}

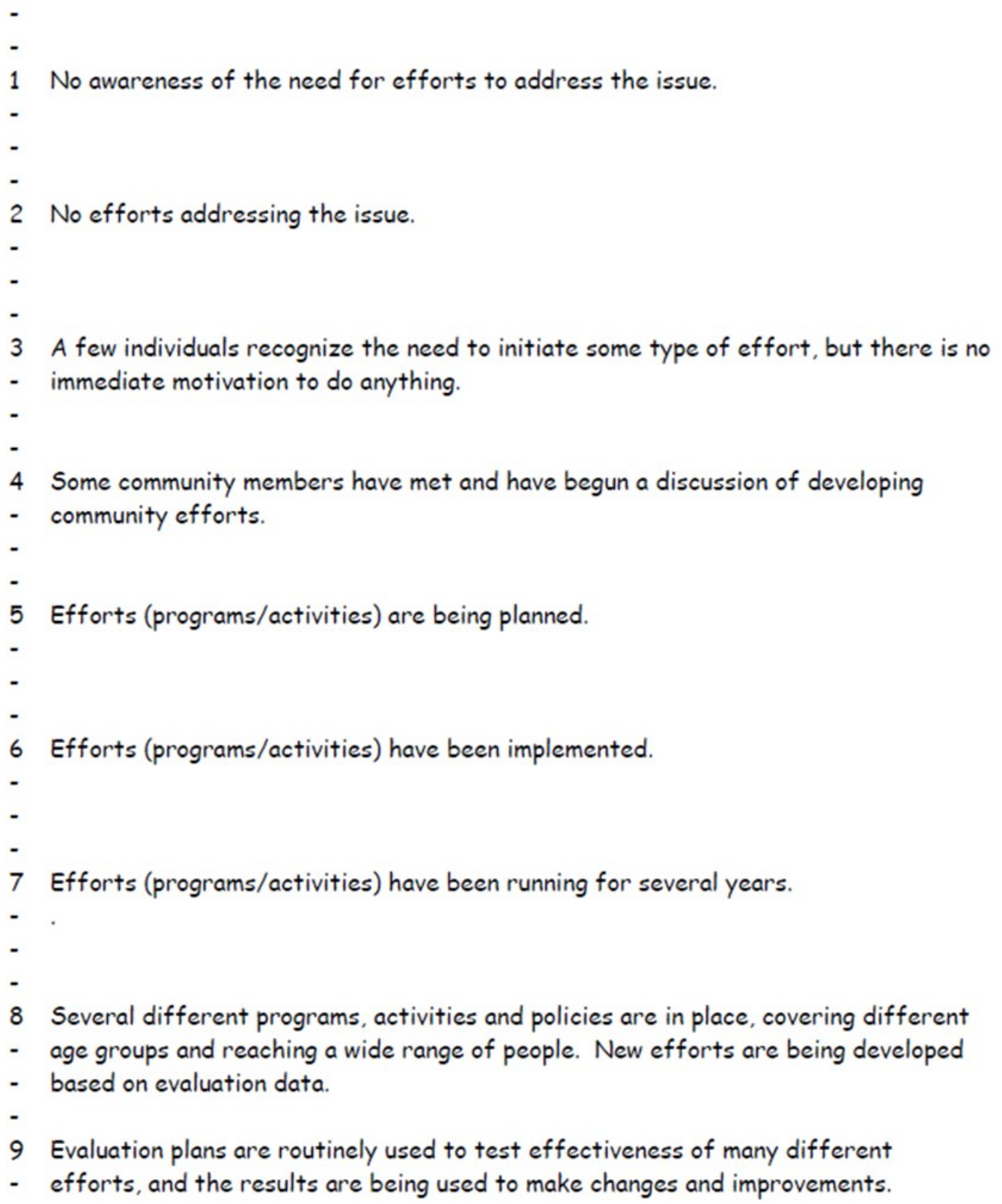




\section{Dimension B. Community Knowledge Of The Efforts}

1 Community has no knowledge of the need for efforts addressing the issue.

$-$

2 Community has no knowledge about efforts addressing the issue.

$-$

$-$

3 A few members of the community have heard about efforts, but the extent of their

- knowledge is limited.

$-$

4 Some members of the community know about local efforts.

5 Members of the community have basic knowledge about local efforts (e.g., purpose).

$-$

$-$

6 An increasing number of community members have knowledge of local efforts

- and are trying to increase the knowledge of the general community about these

- efforts.

$-$

7 There is evidence that the community has specific knowledge of local efforts

- including contact persons, training of staff, clients involved, etc.

$-$

8 There is considerable community knowledge about different community efforts,

- as well as the level of program effectiveness.

9 Community has knowledge of program evaluation data on how well the different

- local efforts are working and their benefits and limitations. 


\section{Dimension C. Leadership (includes appointed leaders \& influential community members)}

$-$

1 Leadership has no recognition of the issue.

$-$

2 Leadership believes that this is not an issue in their community.

$-$

3 Leader(s) recognize(s) the need to do something regarding the issue.

$-$

4 Leader(s) is/are trying to get something started.

$-$

5 Leaders are part of a committee or group that addresses this issue.

$-$

6 Leaders are active and supportive of the implementation of efforts.

$-$

7 Leaders are supportive of continuing basic efforts and are considering resources

- available for self-sufficiency.

$-$

8 Leaders are supportive of expanding/improving efforts through active participation

- in the expansion/improvement.

$-$

9 Leaders are continually reviewing evaluation results of the efforts and are modifying

- support accordingly. 


\section{Dimension D. Community Climate}

1 The prevailing attitude is that it's not considered, unnoticed or overlooked within the

- community.

- "It's just not our concern."

2 The prevailing attitude is "There's nothing we can do," or "Only 'those' people do that,"

- or "We don't think it should change."

3 Community climate is neutral, disinterested, or believes that the issue does not affect

- the community as a whole.

4 The attitude in the community is now beginning to reflect interest in the issue.

- "We have to do something, but we don't know what to do."

5 The attitude in the community is "we are concerned about this," and community members are

- beginning to reflect modest support for efforts.

6 The attitude in the community is "This is our responsibility" and is now beginning

- to reflect modest involvement in efforts.

7 The majority of the community generally supports programs, activities, or policies.

- "We have taken responsibility."

8 Some community members or groups may challenge specific programs, but the

- community in general is strongly supportive of the need for efforts. Participation level

- is high. "We need to keep up on this issue and make sure what we are doing is

- effective."

9 All major segments of the community are highly supportive, and community members

- are actively involved in evaluating and improving efforts and demand accountability. 


\section{Dimension E. Community Knowledge About The Issue}

1 Not viewed as an issue.

2 No knowledge about the issue.

3 A few in the community have some knowledge about the issue.

4 Some community members recognize the signs and symptoms of this issue,

- but information is lacking.

5 Community members know that the signs and symptoms of this issue occur locally,

- and general information is available.

6 A majority of community members know the signs and symptoms of the issue

- and that it occurs locally, and local data are available.

7 Community members have knowledge of, and access to, detailed information about

- local prevalence.

$-$

8 Community members have knowledge about prevalence, causes, risk factors, and

- consequences.

$-$

9 Community members have detailed information about the issue as well as information

- about the effectiveness of local programs. 


\section{Dimension F. Resources Related To The Issue (people, money, time, space, etc.)}

1 There is no awareness of the need for resources to deal with this issue.

$-$

$-$

2 There are no resources available for dealing with the issue.

$-$

$-$

$-$

3 The community is not sure what it would take, (or where the resources would come

- from) to initiate efforts.

$-$

$-$

4 The community has individuals, organizations, and/or space available that could be

- used as resources.

$-$

$-$

5 Some members of the community are looking into the available resources.

$-$

$-$

$-$

6 Resources have been obtained and/or allocated for this issue.

$-$

$-$

7 A considerable part of support of on-going efforts are from local sources that are

- expected to provide continuous support. Community members and leaders are

- beginning to look at continuing efforts by accessing additional resources.

8 Diversified resources and funds are secured and efforts are expected to be

- ongoing. There is additional support for further efforts.

$-$

9 There is continuous and secure support for programs and activities, evaluation is

- routinely expected and completed, and there are substantial resources for trying new

- efforts.

Reprinted with permission. Plested, B. A., Edwards, R. W., \& Jumper-Thurman, P. (2006). Community readiness: A handbook for successful change. Fort Collins, CO: TriEthnic Center for Prevention Research. 


\section{APPENDIX C. STAGES OF READINESS OUTLINE}

\begin{tabular}{|c|c|}
\hline STAGE & DESCRIPTION \\
\hline 1. No Awareness & $\begin{array}{l}\text { Issue is not generally recognized by the community or leaders } \\
\text { as a problem (or it may truly not be an issue). }\end{array}$ \\
\hline $\begin{array}{l}\text { 2. Denial / } \\
\text { Resistance }\end{array}$ & $\begin{array}{l}\text { At least some community members recognize that it is a } \\
\text { concern, but there is little recognition that it might be } \\
\text { occurring locally. }\end{array}$ \\
\hline $\begin{array}{l}\text { 3. Vague } \\
\text { Awareness }\end{array}$ & $\begin{array}{l}\text { Most feel that there is a local concern, but there is no } \\
\text { immediate motivation to do anything about it. }\end{array}$ \\
\hline 4. Preplanning & $\begin{array}{l}\text { There is clear recognition that something must be done, and } \\
\text { there may even be a group addressing it. However, efforts are } \\
\text { not focused or detailed. }\end{array}$ \\
\hline 5. Preparation & $\begin{array}{l}\text { Active leaders begin planning in earnest. Community offers } \\
\text { modest support of efforts. }\end{array}$ \\
\hline 6. Initiation & $\begin{array}{l}\text { Enough information is available to justify efforts. Activities } \\
\text { are underway. }\end{array}$ \\
\hline 7. Stabilization & $\begin{array}{l}\text { Activities are supported by administrators or community } \\
\text { decision makers. Staff are trained and experienced. }\end{array}$ \\
\hline $\begin{array}{l}\text { 8. Confirmation/ } \\
\text { Expansion }\end{array}$ & $\begin{array}{l}\text { Efforts are in place. Community members feel comfortable } \\
\text { using services, and they support expansions. } \\
\text { Local data are regularly obtained. }\end{array}$ \\
\hline $\begin{array}{l}\text { 9. High Level of } \\
\text { Community } \\
\text { Ownership }\end{array}$ & $\begin{array}{l}\text { Detailed and sophisticated knowledge exists about prevalence, } \\
\text { causes, and consequences. Effective evaluation guides new } \\
\text { directions. Model is applied to other issues. }\end{array}$ \\
\hline
\end{tabular}

Reprinted with permission. Plested, B. A., Edwards, R. W., \& Jumper-Thurman, P. (2006). Community readiness: A handbook for successful change. Fort Collins, CO: TriEthnic Center for Prevention Research. 


\section{VITA}

Troylyn Braud Francis was born in New Orleans, LA to Betty and Zachary Braud. She was reared in St. James, LA before her family relocated to Laplace, LA. She graduated from East Saint John High School in 1999. In 2002, she graduated from Xavier University with a degree in Biology. Following graduation, she worked with the University of Tennessee Health Science Center's Preventive Medicine Department. During this time she worked with an environmental epidemiologist and nurtured a passion for outcomes based research. In 2007, she enrolled in the University of Tennessee's Master of Epidemiology Program. During this time, she worked simultaneously with research studies that: explored neurocognitive development in children, and provided support and pregnancy education for high risk mothers in an attempt to combat infant mortality.

Following completion of her master's degree, she published her master's research project, which evaluated residential proximity to toxic release sites and the implications for unfavorable birth outcomes. In 2011, she decided to further her education and enrolled in the University of Tennessee's Health Outcomes and Policy Research Program. During this time, she worked with an obesity prevention program that targeted faith-based establishments. 